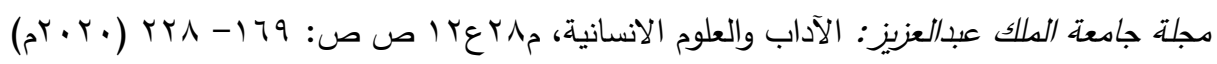
DOI:10.4197/Art.28-12.7

\title{
أثر تكنولوجيا المعلومات في تنمية الموارد البشرية: دراسة تطبيقية على كلية الآداب والعلوم الإنسانية
}

د. عثمان بن موسى عقيلي و أ. محمد بن عبدالله العمري و أ. عادل بن محمد الغامدي وزاة التعليم جامعة الملك عبدالعزيز

$$
\text { كلية الآداب والعلوم الإنسانية }
$$

مستخلص. هدفت الدراسة إلى التعرف على أثر تكنولوجيا المعلومات في تتمية الموارد البشرية من وجهة نظر منسوبي كلية الآداب والعلوم الانسانية. واتِّعتِ الدراسة المنهج الوصفي المسحي من خلال استخدام أسلوب دراسة

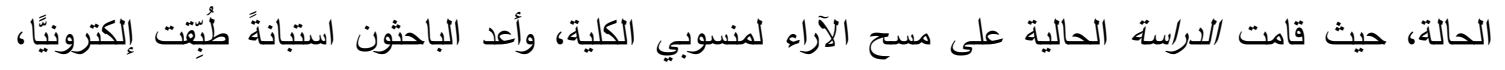
وتكونت عينة الدراسة من (ع V) فرداً من منسوبي كلية الآداب والعلوم الإنسانية في جامعة الملك عبد العزيز • وقد صمم الباحثون استبانة للدراسة تكونت من خمس مجالات رئيسية. وتوصلت الدراسة على العديد من النتائج والتي من أهمها: أن هناك وضوح لدى عينة الدراسة لأهمية استخدام تكنولوجيا المعلومات في اداره تتمية الموارد البشرية بكلية الآداب، وكذلك أدارك تام لفوائدها من قبلهم. كما بينت نتائج الدراسة بأن كلية الآداب والعلوم الانسانية تدعم عملية التحول الى استخدام تكنولوجيا المعلومات في تتمية الموارد البشرية مما يساعد تحويل جميع الأنظمة التقليدية الموجودة حاليا بكلية الآداب والعلوم الإنسانية إلى إلكترونية. وايضا اظهرت نتائج الدراسة أن استخدام تكنولوجيا

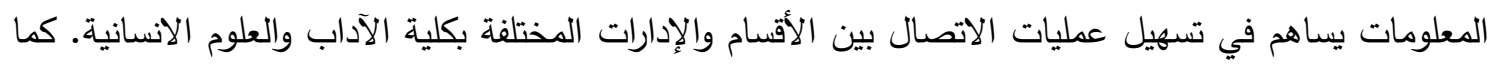

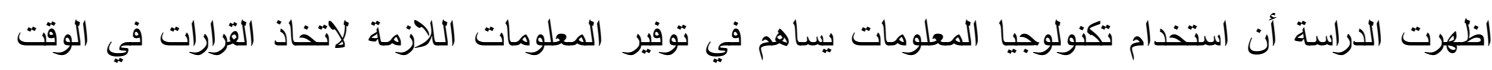
المناسب. وأظهرت الدراسة التوصيات والمقترحات الاتية: ضرورة قيام الادارة الالكترونية في المنظمات بالتوجه الرسمي والعملي نحو استخدام تكنولوجيا المعلومات في تتمية الموارد البشرية. ومواكبة التغيرات المتسارعة في مجال استخدام تكنولوجيا المعلومات في تتمية الموارد البشرية في المنظمات. الاستفادة من الخدمات الادارية والتعليمية والاكاديمية الاككترونية في انشطة ووظائف ادارة الموارد البشرية كالتدريب والتعليم والتعلم عن بعد. الكلمات المفتاحية: تكنولوجيا المعلومات، تتمية الموارد البشرية، كلية الآداب والعلوم الانسانية 
وتعد القوى البشرية أول ركائز البنية الأساسية

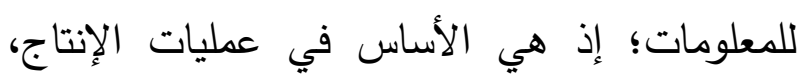

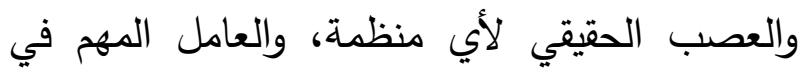
التميز والتقدم ، ولابد أن تكون قوى بشرية متعلمة

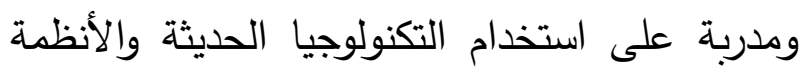

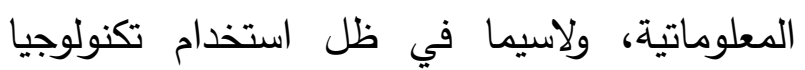
المعلومات لمواكبة التقدم؛ فهي المحرك الرئيسي في فئي لبعض التغييرات الحديثة والمستقبلية ، والداعمة

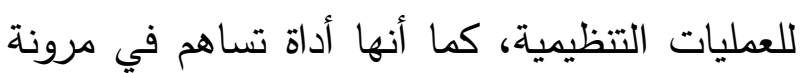
الإجراءات وتسهيلها، وتخلق مشاركة أكبر للعاملين

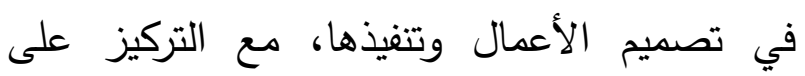
الإنتاج والجودة. لذا وجب على المنظمات تتمية مواردها البشرية من ون

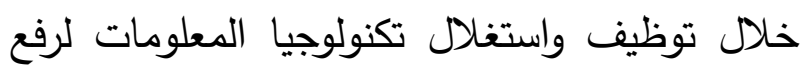
كفاءاتها وتعزيز قدراتها وتحقيق المميزات التنافسية

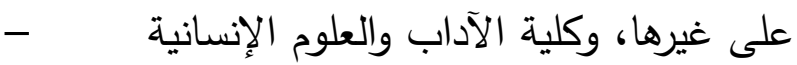

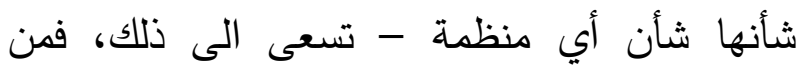
ضمن أهدافها "تأهيل وتطوير الكفاءات الأكاديمية والكوادر الإدارية والفنية". وانطلاقا من الأثر الذي تقدمه تكنولوجيا المعلومات

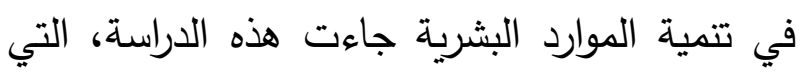
تتكون من ثلاث متغيرات، هي كالتالي: المتغير الأول: تكنولوجيا المعلومات كمتغير مستقل. هيتل المتغير الثاني: تتمية الموارد البشرية كمتغير تابع.

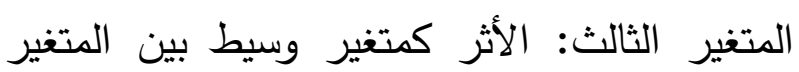
المستقل والتابع في مجتمع الدراسة.

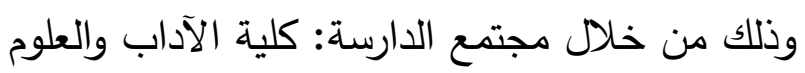

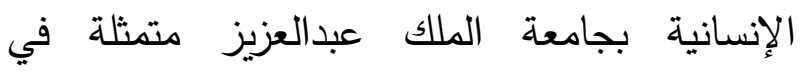

\section{تمهيد}

شهد العقدان الماضيان قوة متزايدة لتقنيات الحاسب وانخفاض كبير في تكلفة المعدات والبرمجيات،

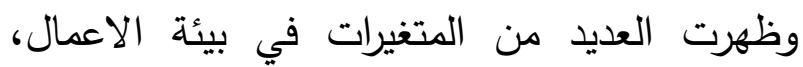
وكانت هذه التغيرات نتيجة للتطور المتسارع في لئني

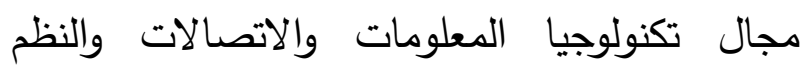
المحوسبة واتساع تأثير مفهوم العولمة، وعملت هذه التغيرات على تغيير البيئة الداخلية والخارجية

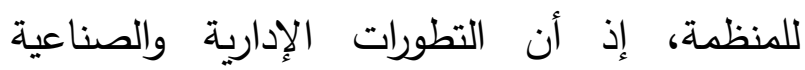
والاقتصادية والحضارية والعسكرية والسياسية ماهي الإني

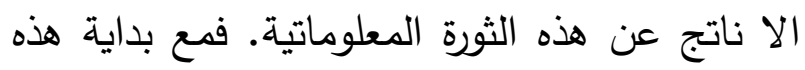
الثورة المعلوماتية والدخول في آفاق معلوماتية جديدة وبأنماط متعددة ومختلفة من أدب وفن واقتصاد

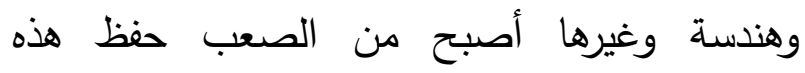
المعلومات وجمعها وترتيبها وتخزينها والرجوع اليها بالطرق البدائية. لذا لابد من استخدام أساليب حديثة وتئة وتهني

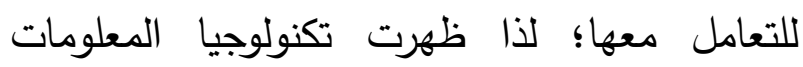

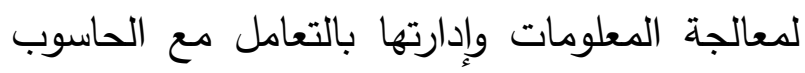

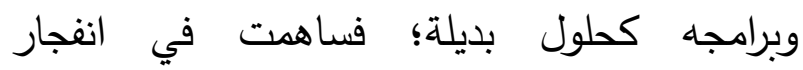
المعلومات الذي تمنَّل في إنتاجها ونموها الهائل، فيلهان وتنوع مصادرها وتعدد أشكالها. فأصبحت مقولة "المعلومات هي القوة" واقعية أكثر وتعدران من أي وقت مضى؛ وذلك نتيجة للتقدم السريع في

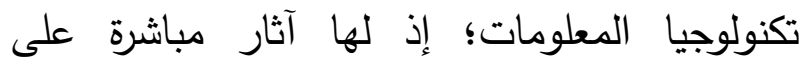
التتمية، ليس بالطرق المباشرة فقط، ولكن -أيضًا-

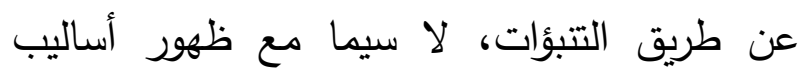
جديدة لجمع البيانات وتحليلها (مثل ذكاء الأعمال). 
المعلومات، وتخزينها واسترجاعها في الوقت المناسب وبطريقة فعالة. وبعبارة أخرى تكمن أهمية الدراسة فيما يلي: وفئل محاولة إبراز أهمية تكنولوجيا المعلومات. محاولة إبراز أهمية تتمية الموارد البشرية. الكثف عن مدى توظيف تكنولوجيا المعلومات وأثرها في تتمية الموارد البشرية في كلية الآداب لوطي

$$
\text { والعلوم الإنسانية. }
$$

تقديم تقييم واقعي لمدى تحقيق تكنولوجيا لتصنيا المعلومات لتنمية الموارد البشرية في كلية الآداب والعلوم الإنسانية. الإفادة العلمية والتطبيقية من نتائج هذه الإراسـة في توظيف تكنولوجيا المعلومات في تتمية

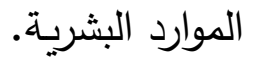

\section{أهداف الدراسة:}

تسعى هذه الدراسة لتحقيق الأهداف التالية:

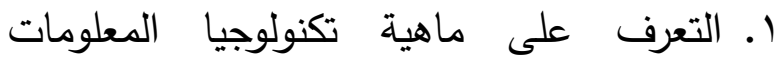
واستخداماتها.

r. التعرف على ماهية تتمية الموارد البشرية. r. التعرف على العلاقة بين تكنولوجيا المعلومات

$$
\text { وتتمية مواردها البشرية. }
$$

ـ. التعرف على واقع استخدام تكنولوجيا المعلومات

$$
\text { بكلية الآداب والعلوم الإنسانية. }
$$

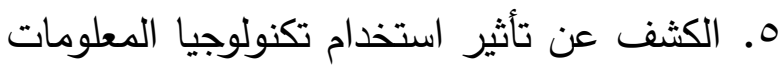

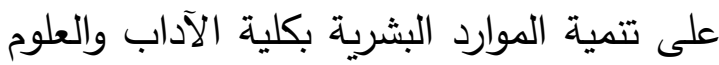

$$
\text { الإنسانية. }
$$

مواردها البشرية من أعضاء هيئة التدريس والإداريين والفنيين.

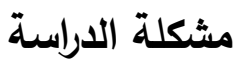

انطلاقا من أهمية الموارد البشرية في كلية الآداب والعلوم الإنسانية، التي تعتبر المحرك الأساس لبقية الفوانية الموارد -خاصة عند تضمئنها القدرات المعرفية والمهارات العالية- ومع استخدام تكنولوجيا المعلومات في أساليب الأعمال الاكاديمية والإدارية والفنية وإجراءاتها، لتحقيق مستوى عالٍ من الأداء

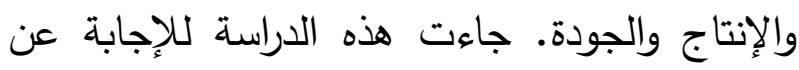

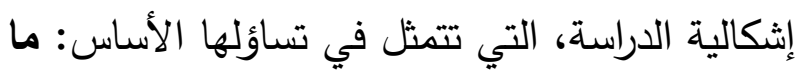
هو أثر تكنولوجيا المعلومات على تنمية الموارد

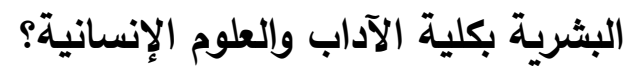
أهمية الدراسة:

تبرز أهمية هذه الدراسة من أهمية متغيرها المستقل وهو - تكنولوجيا المعلومات - وهي ما يميز عصرنا الحالي؛ إذ لها إسهامات عده في الإنتاج والإبداع والابتكار والتقدم، وتعد عاملاً أساسيًّا للتطوير الإنتاج والتتمية لمن يستثرها لبناء القدرات التتافسية، كما أنها القوة لمن يحتكرها ويمارس من خلالها الهيمنة تجاريًّا واقتصاديَّا وسياسيًّا. كما تبرز أهميتها من أهمية متغيرها التابع وهو - تصنيا. تتمية الموارد البشرية - التي تعتبر الدافعة إلى لفي تحقيق زيادة في الإنتاجية، والكفاءة، والفعالية، والقدرة التنافسية، والأهداف للمنظمة. فمع إضافة تكنولوجيا المعلومات إلى الموارد البشرية تحدث قوة في المنظمة؛ إذ تُكن الموارد البشرية -

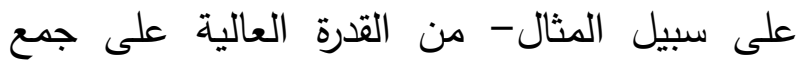


والنشر والبث للمعلومات، في جميع أشكالها (المرئية، والسمعية ...الخ).

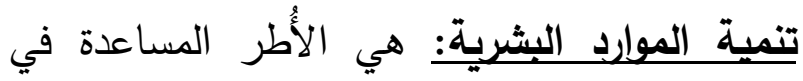
تطوير مهارات الموارد البشرية الشخصية والتنظيمية، وكذلك تطوير معارفهم وقدارته وإمكانياتهم المهنية، حيث تتضمن العديد من المهام الإنمائية مثل كالتدريب والتعليم والتثقيف والتوجيه...الخ. إما التعريف الإجرائي لتنمية الموارد البشرية فقد ولتئية

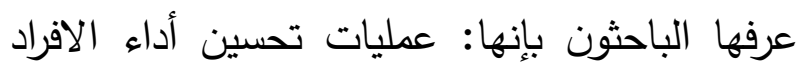
والجماعات بفعالية في المنظمات وتطوير كفاءاتهح

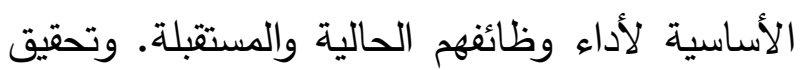
التطابق بين احتياجات العاملين الثخصية والتنظيمية والاستراتيجيات للمنظمات التابعين لها. الإطار النظري والدراسات السابقة أولاً: تكنولوجيا المطلومات النظات

\section{مفهوم التكنولوجيا (Technology):}

من خلال مراجعة الأدبيات المتعلقة فب هذا المجال، مغون

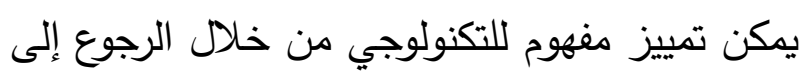
أصل الكلمة، وهي على النحو الاتي:

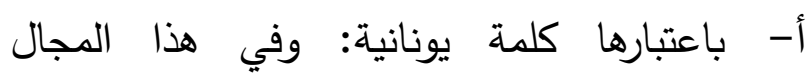
التكنولوجيا كلمة مركبة من مقطعين: المقطع الأول (Techno) بمعنى (حرفة أو معطين صنعة أو فن) المقطع الثاني (Logy) وتعني علم. والكلمة بمقطعيها (Technology) تشير إلى على علم ألم الحرفة أو علم الصنعة. ب- اعتبارها كلمة انجليزية: إن المقطع الأول من المنة

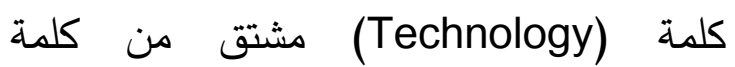

7. تقديم مقترحات وتوصيات لاستغلال تكنولوجيا المعلومات في تتمية الموارد البشرية بكلية الآداب والعلوم الإنسانية. حدود الاراسة:

1. الحدود الموضوعية: أثر تكنولوجيا المعلومـات في تتمية الموارد البشرية في كلية الآداب و العلم الانسانية.

r. الحدود اللغويـة: ما صدر باللغة العربية و الإنجليزية من كتب وأبحاث تتعلق بالدر اسة.

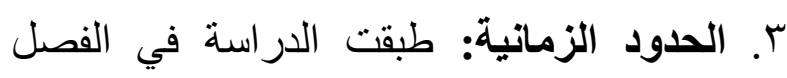
الدراسي الاول لعام إــ أهـ.

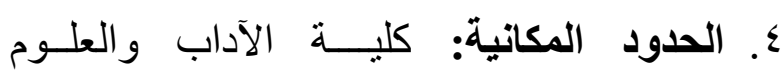
الإنسانيــة بجـامعـة المـلك عبــالعزيز. 0. الحدود البشرية: الموارد البشرية بكلية الآداب

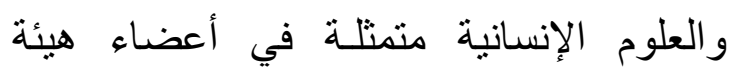
التدريس و الإداريين و الفنبين.

\section{مصطلحات الاراسة:}

تكنولوجيا المعلومات: هي مجموعة المعارف والخبرات والمهارات المتراكمة والمتاحة، والأدوات

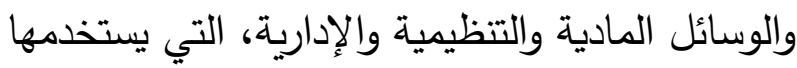

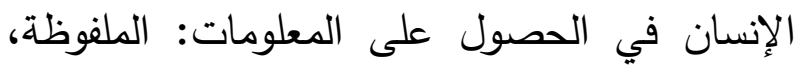
المصورة، والمتينة، والمرسومة والرقمية، وفي ولي

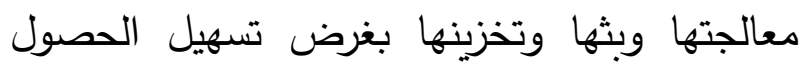
على المعلومات وتبادلها وجعلها متاحة للجميع. ل

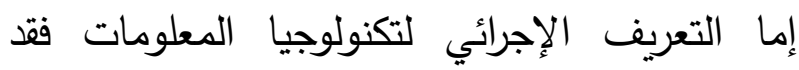

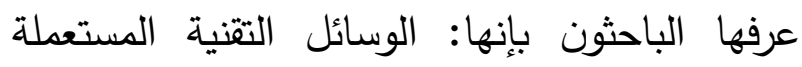

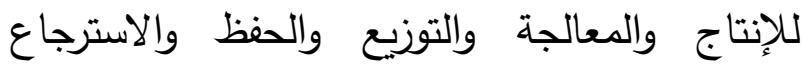


العملية المناسبة لها، وتطويرها، واستخدامها، وادارتها، وتقويمها، لتحقيق أهداف معينة. كما تعرف التكنولوجيا على أنها "الطرق والعمليات والأساليب والمعرفة والتسهيلات المتاحة لإتمام العمل

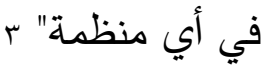

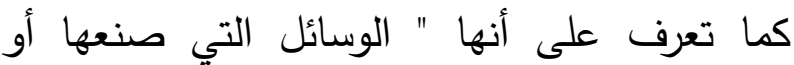

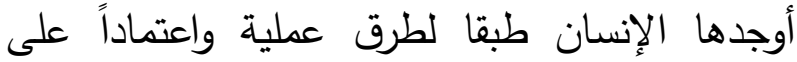
معارفه وخبراته ومهاراته وسخرها لخدته". ويرى

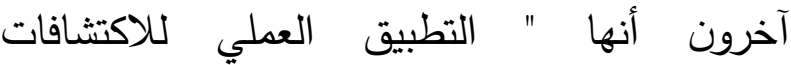

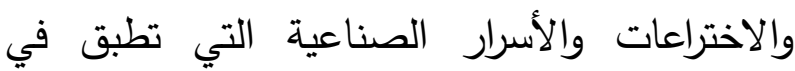
الصناعة " كما يرى آخرون أنها " التطبيق العملي التئي للاكتشافات والاختراعات المختلفة التي جاءت نتيجة

$$
\text { البحث العلمي" ؛ }
$$

ويمكن تلخيص ما يتضمنه مفهوم التكنولوجيا بالنقاط

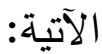

ا ـ وجود نظام عام شامل يحيط بجميع أبعاد عملية

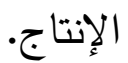

r. وجود أنظمة فرعية يتكون منها النظام. ץ. ضرورة وجود نوع من التجانس في العمل بين مكونات كل من هذه الأنظمة الفرعية الداخلية في عملية الإنتاج حتى يتم التجانس العام الذي يؤدي إلى حسن سير العمل وتحقيق أهداف

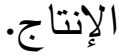

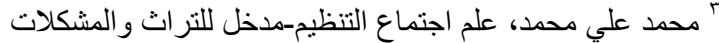

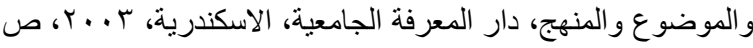

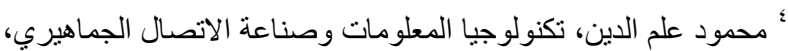

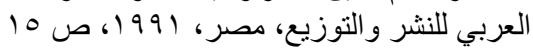

الإنجليزية الأصل بمعنى (Technique) التقنية أو الأداء التطبيقي.

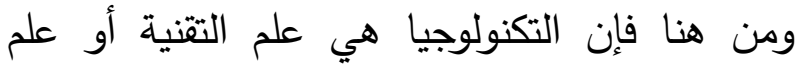

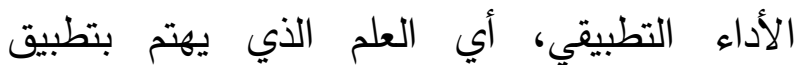
النظريات ونتائج البحوث التي توصل إليها العلوم

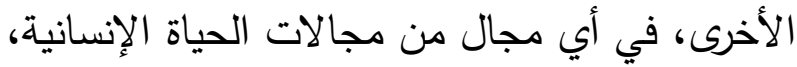

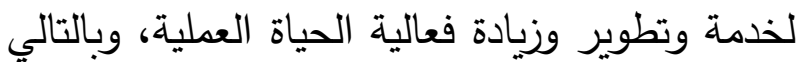
فإن هناك مجالات عديدة للتكنولوجيا في مناحي الحياة المختلفة: التكنولوجيا الطبية، التكنولوجيا الزراعية، تكنولوجيا التصنيع، تكنولوجيا المعلومات،

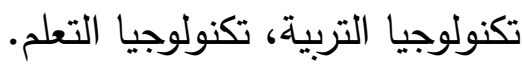
أما النظرة الى التكنولوجيا كعمليات (Processes) وهي النظرة الواسعة للتكنولوجيا فترى أنها التطبيق المنظم للمفاهيم والحقائق ونظريات العلوم المختلفة لأجل أغراض عملية، وبذلك لا يقتصر مفهوم

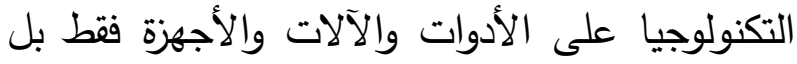

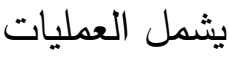
ويؤكد على ذلك جال بريث (Galbraith) في تعريفه

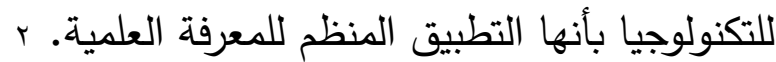
وقد عرف خميس التكنولوجيا بأنها: العملية المنهجية المنظمة التي يتم من خلالها تطبيق المعرفة العملية لحل مشكلات عملية. والتكنولوجيا العلم الذي يعني لتئي بعملية التطبيق المنهجي النظامي للبحوث

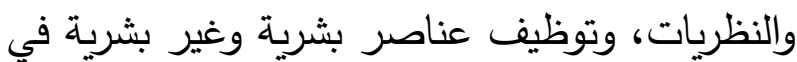
مجال معين، لمعالجة مشكلاته، وتصميم الحلول ؟ العياصرة، وليد رفيق، تكنولوجيا التعليم والتعليم الإلكتروني، صـ با ـ ـ 
الإنسان: الإنسان هو العنصر الأول والأهم في لياني التطبيق التكنلوجي باعتباره الدحرك الحقيقي لهذان التطبيق، والقائم بتصميمه وتنفيذه، والمتحكم في إخضاع عملية التطبيق لتحميق أهدافه، والإنسان هو

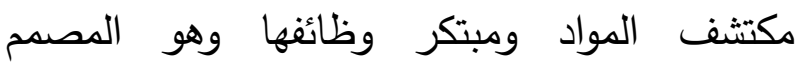
للأدوات والمنفذ لها. المواد: تمثل المواد الضلع الثاني في التطبيق التكنلوجي، وتأتي بعد الإنسان في الأهمية، فالإنسان حينما وجد على سطح الأرض فكر في المواد وكلما

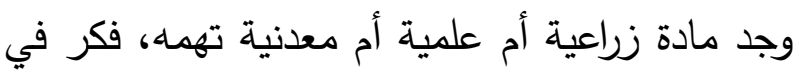

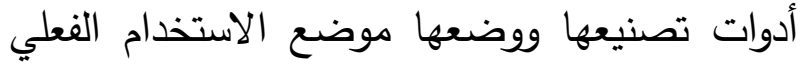
لتني بمتطلباته، فوجود مادة الحديد جعلت الإنسان

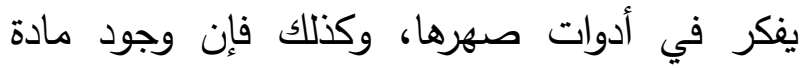
تعليمية جعلت الإنسان يفكر في أدوات توصيلها للأخرين، فوجود الأدوات مرهون بوجود المواد، هذان هو السبب في أن تكون المواد في المستوى الثاني بعد الإنسان مباشرة وقبل الأدوات.

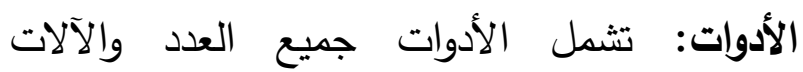
والأجهزة اللازمة لصياغة المادة وإخراجها بشكل صالح لتحقيق أهداف الإنسان. والأدوات وإن كانت تأتي في المرتبة الثالثة من حيث الأن التان الأهمية في العلاقة المثلثية للعملية التكنلوجية إلانية أنها جانب له أهيته القصوى في الدحصلة النهائية للتطبيق. وخلاصة القول إن التكنولوجيا هي محصلة التفاعل

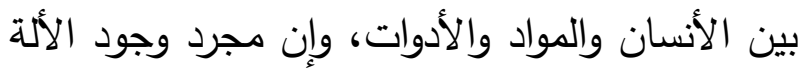
لا يعني وجود التكنولوجيا، ولكن عملية استخدام
ع. الديناميكية والتفاعل بين جميع عناصر هذه الأنظمة وفروعها. 0. وجود الضوابط التي تساعد على الاحكم في التيا هذه العمليات والقدرة على التقييم المستمر لكل منها. T. وخلاصة الأمر يمكن القول بأن التكنولوجيا

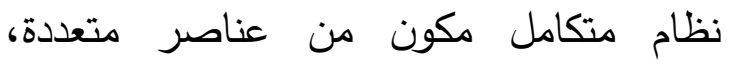

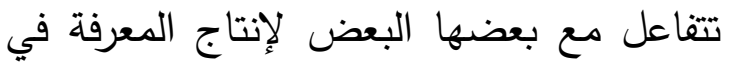

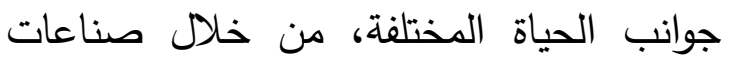
وادوات متطورة، فتؤهل الفرد وتمكنه من التغير لحياة التكنولوجيا وليكون قادر على أنتاج وتطوير التكنولوجيا في المجتمع. •

\section{مكونات العملية التكنولوجية:}

للعملية التكنولوجية ثلاث مكونات متفاعلة، تمثل ثلاثة اضلاع لدثلث واحد وهي الإنسان، والمواد، والأدوات.

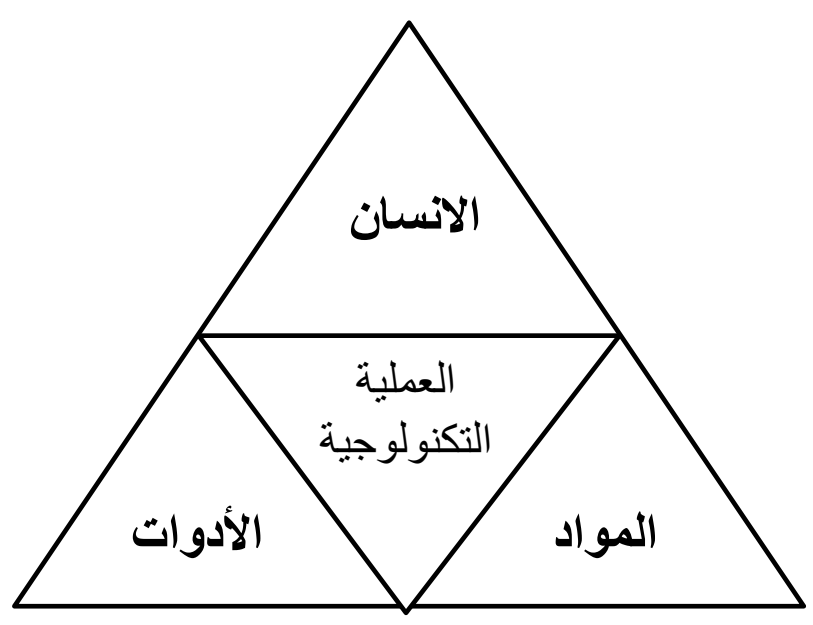

" العياصرة، وليد رفيق، تكولوجيا التعليم والتطليم الإكتروني، ص \& 
والتي يمكن تداولها وتسجيلها ونشرها وتوزيعها في

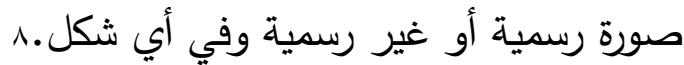

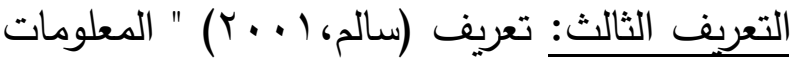
هي البيانات المصوغة بطريقة هادفه لتكون أساساً لاتخاذ القرار". تقسيمات المعلومات:

ا ـ المعلومات الإنمائية أو التطويرية: وهي تلك التي تساعد في التطوير والأنماء كالمعلومة

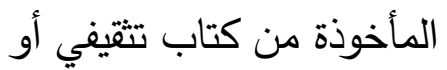
r. المعلومات التعليمية أو البيداغوجية: وهي تلك لكي التي تسهم في التعليم وتساعد عليه كالمعلومة المأخوذة من كتاب دراسي.

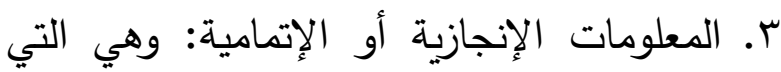

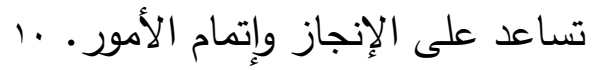
أهمية المعلومات:

لا جدال في أهمية المعلومات وقيمتها في حياتتا الحاضرة، وهي على أي حال من الأحوال أساس أي في فئ فئ قرار يتخذه كل مسئول في موقعه، ويقدر توافر

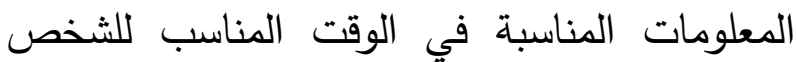
المسئول، تكون دقة القرار وصحته. إن للمعلومات دورها الذي لا يمكن إنكاره في كل نواحي النشاط، فهي أساسية للبحث العلمي، وهي لإن لإني

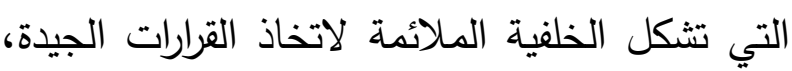
وهي عنصر لا غنى عنه في الحياة اليومية لأي
الألة أو تصنيع المواد من قبل الإنسان هي بداية

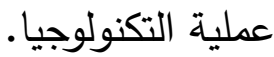
ويمكن تمثيل مكونات العملية التكنولوجية من خلال المعادلة التالية: "تثاعل الإنسان مع المواد ومع لتع

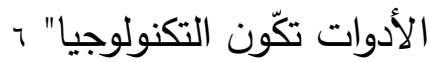
مفهوم المعلومات (Information): إن لفظ " معلومات " يحتمل مفاهيم ومعاني مختلفة للوهلة الاولى، لذلك يجب التثريق ما بين ما يتبادر الى اذهاننا وما الذي نقصده بهذه الكلمة. المقصود بالمعلومات: استخدام لفظ معلومات للدلالة على أشياء عديدة، وهو من "Information" الألفاظ التي يصعب تعريفها، نظرا لكثرة استخدامه من جانب فئات متعددة، وفي مجالات مختلفة، ونستعرض عدة تعريفات للمعلومات:

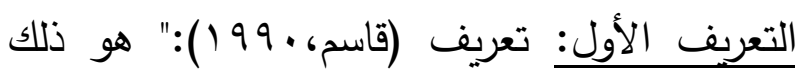
الثيء الذي يغير من الحالة المعرفية للمتلقي (القارئ أو المشاهد أو المستمع، أو أياً كانت الحاسة

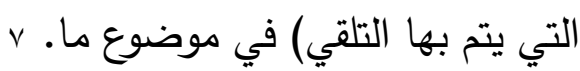

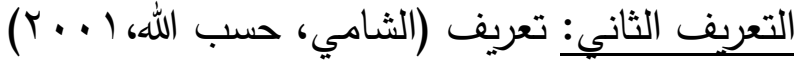
المعلومات هي البيانات التي تمت معالجتها لتحقيق

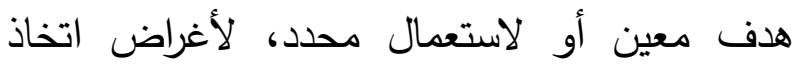

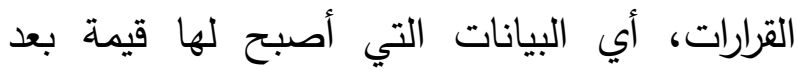

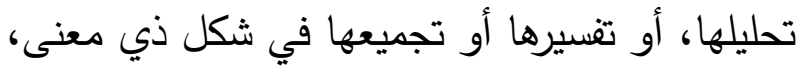

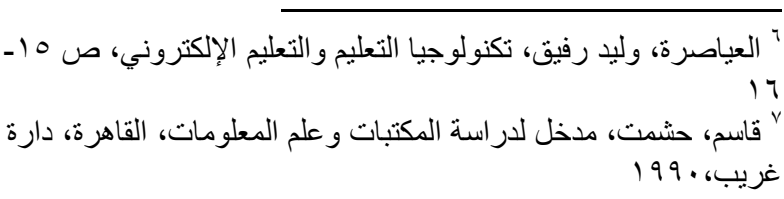




\section{تكنولوجيا المعلومات}

ان المعلومات الأولية أساسها الانسان وكان لابد من جمع المعلومات ونشر المعرفة، وسهولة التواصل فاستطاع البشر تطوير علم جديد فيفضل تكنولوجيا المعلومات التي تمكن الانسان من التواصل بسهولة

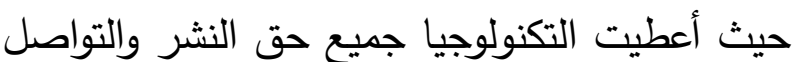
مما أثر على حياة الانسان بشكل كبير وأحدث تغييرا جذريا فيها، وتكنولوجيا المعلومات مصطلح يتكرر بشدة في كافة المستويات وهي مظهر من مظاهر الاستثمار العام والخاص في مجال العلوم والهندسة والتي تمكن الانسان من خلالها من اجراء تغييرات واسعة وهامة في المجتمع وتعتبر تطبيقا لحل المشكلات التي يواجها الانسان.ءء تعريف تكنولوجيا المعلومات تعد تكنولوجيا المعلومات نتاجاً مناسباً للتلاحم بين كل من تكنولوجيا الحاسبات الألية وتكنولوجيا

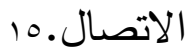

كما يمكن القول إنها دراسة وتصميم وتطوير أنظمة المعلومات خصوصا المرتبطة بعلوم الحاسوب بحيث تستخدم أحدث التقنيات في تحويل وتخزين وحماية ومعالجة ونقل واستعادة البيانات وتوفير مستوى جيد لأمان المعلومات والشبكات وأنشاء الحمول للشركات المرتبطة بكافة نواحي الحياة سواء كانت سياسية أو اقتصادية أو اجتماعية أو غير ذلك. 17

' ' فريال مريم، بن لحرش، تكنولوجيات الحديثة و أثرها على إدارة

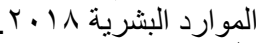
' العتيبي، عزيزة، أثر استخدام تكنولوجية البيا المعلومات على اداء الموارد

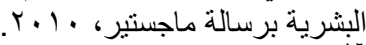

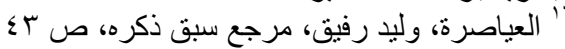

فرد، وهي بالإضافة إلى هذا كله مورد ضروري للصناعة والتنمية والشئون الاقتصادية والإدارية والعسكرية والسياسية. وتصل المعلومات إلى الأنسان في العادة عن طريق حواسه الخمسة المعروفة، وهنا لانقصد المعلومة المكتوبة أو المطبوعة أو المصورة فحسب ولكننا نقصد أي شكل حملت فيه المعلومة، فالمعلومات أحيان كثيرة تكون محملة على أفلام أو أقراص ممغنطة أو أقراص مضغوطة إضافية للأوعية

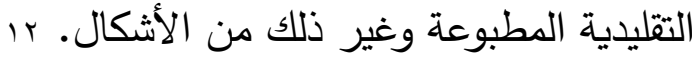
وهنا نورد العديد من الفوائد التي يمكن أن تتحقق وعن نتيجة لتوافر المعلومات: ا ـ تتمية القدرة على الإفادة من المعلومات المتاحة والخبرات التي تحققت من قبل. r. ترشيد وتتسيق ما يبذل من جها في البحث والتطوير على ضوء ما هو متاح من معلومات. r. كفالة قاعدة معرفية عريضة لحل المشكلات. ء. توفير بدائل وأساليب حديثة لحل المشكلات، واختيارات تكفل من الحد من هذه المشكلات بالمستقبل ه. رفع مستوى فعالية وكفاءة الأنشطة الفنية في قطاعات الخدمات والإنتاج. 7. ضمان القرارات السليمة في جميع القطاعات وعلى مختلف مستويات المسئولية. v. للمعلومات دور هام في إنجاح خطط التنمية.با

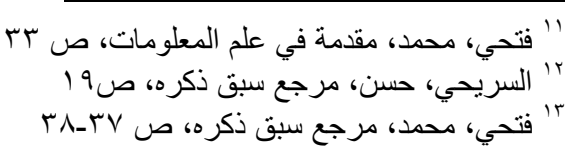


ع. مرحلة اختراع الحاسب الإلكتروني وتطويره عبر

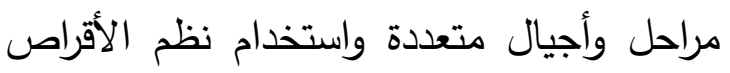

المدمجة.

مكونات تكنولوجيا المعلومات

تتكون تكنولوجيا المعلومات من خمسة عناصر

وهي:

ا ـ المكونات المادية: عبارة عن الأجهزة المادية

التي تستخدم في انشطة الادخال، والمعالجة، والاخراج والتي تحتوي على وحدة المعالجة الحاسوبية، واجهزة الادخال، والاخراج المتنوعة،

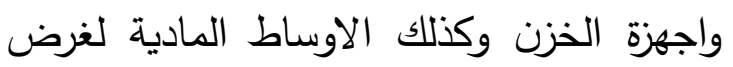
ربط الاجزاء معاً، وكما تعرف على انها جميع الاونياط المادية لرضئ الاجهزة والمواد المادية المستخدمة في معالجة المعلومات مثل الحاسبات واوساط البيانات والاشياء الملموسة الاخرى التي يمكن بواسطتها

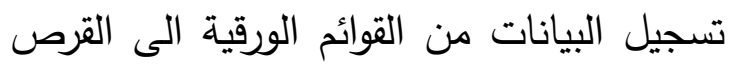
المغناطيسي. r. البرمجيات: وهي البرامج المسجلة او برامج المالكين او الحزم البرمجية، أي انها برامج

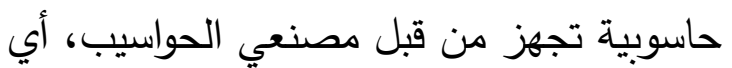
تعتمد على برمجيات الشركة المصنعة او مستخدمي الحاسوب الاخرين، وان البرمجيات نوعين برمجيات التطبيق وبرمجيات التشغيل. r. الموارد البشربة: وهم الكوادر المؤهلة والمدربة

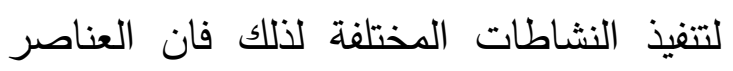
البشرية يجب ان تكون ذات مستويات وكفاءات
ويمكن أن نستخلص مما سبق من تعريفات لتكنولوجيا المعلومات ما يلي: أن تكنولوجيا المعلومات تتعامل مع المعلومات بأشكالها كافة، وبمراحل تداولها المختلفة، أي ما لمعات تصعات يتعلق بإنتاجها واختزانها ومعالجتها واسترجاعها

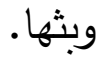
• أنها لا تقتصر على الأجهزة، وإنما تمتد إلى الوسائل المتعددة مثل البرامج والنظم وغيرها. أن التكنولوجيا الحديثة تتضمن: م الحاسبات الإلكترونية، التي تقوم بتجهيز المعلومات واختزان كميات ضخمة منها، واسترجاعها بسرعة ودقة.

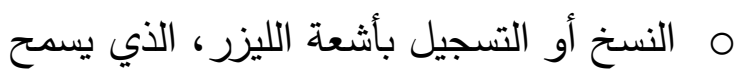
باختزان كميات ضخمة من المعلومات في

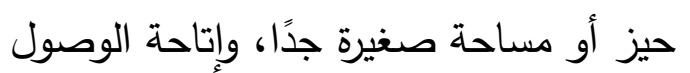
إليها بسرعه وسهولة. م الاتصالات عن بعد التي تستطيع توزيع

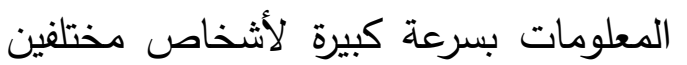

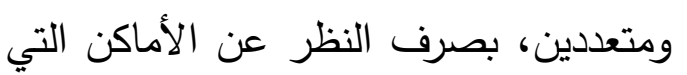
يقيمون فيها. وقد مرت تكنولوجيا المعلومات عبر الزمن بمراحل عدة يمكن تصورها على النحو التالي: ا ب أ. مرحلة اختراع الكتابة.

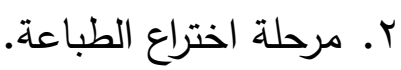
r. مرحلة التكنولوجيا المسموعة والمرئية والنسخ

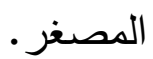


r. تقليص المكان: تتيح وسائل التخزين التي تستوعب حجما هائلا من المعلومات المخزنة والتي يمكن الوصول إليها بيسر وسهولة.

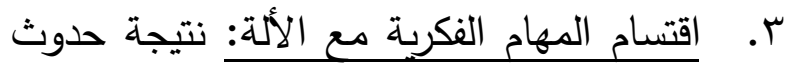
التفاعل والحوار بين الباحث والنظام.

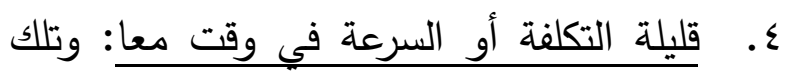
هي وتيرة تطور منتجات تكنولوجيا المعلومات. - المات

0. الذكاء الاصطناعي: أهم ما يميز تكنولوجيا

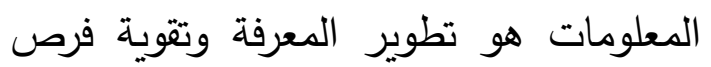
تدريب المستخدمين من أجل الثمولية والتحكم في عملية الإنتاج. 7. تدربب شبكات الاتصال: تتوحد مجموعة التجهيزات المستندة على تكنولوجيا المعلومات من أجل تشكيل شبكات الاتصال، وهذا ما لدات يزيد من تدفق المعلومات بين المستعملين والصناعيين، وكذلك منتجي الآلات، ويسمح لئن بتبادل المعلومات مع بقية النشاطات الأخرى. V. التفاعلية: أي أن المستعمل لهذه التكنولوجيا

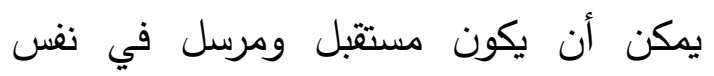
الوقت، فالمشاركين في عملية الاتصال يستطيعون تبادل الأدوار وهو ما يسمح بخلق نوع من التفاعل بين الأنشطة.

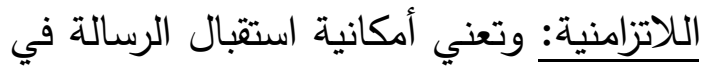

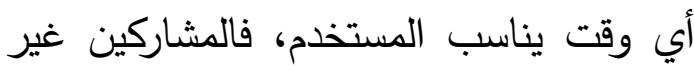
مطالبين باستخدام النظام في نفس الوقت. 9. اللامركزبة: وهي خاصية تسمح باستقلالية تكنولوجيا المعلومات والاتصالات، فالإنترنت
مختلفة حسب طبيعة النظام ووظائفه، حيث ان تدريب القوى العاملة في الشركات أصبح حاجة ملحة، وبالرغم من انه لا تتوفر التسهيلات الكبيرة والتي تتطلب دعم وظيفي كبير • إلا انه لابد من تدريب الموظف تدريباً جيداً. وهذا واحد

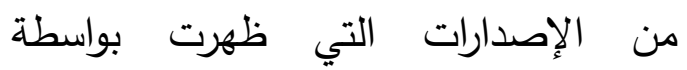

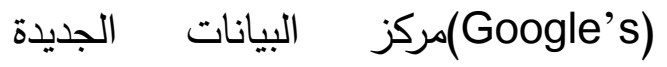
في(Dallas). ع. قواعد البيانات: هي مجموعة بيانات مرتبطة مع بعضها او المعلومات المخزونة على اجهزة

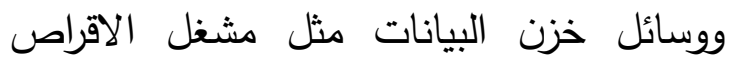
الصلبة للحاسبة والاقراص المرنة او الاشرطة.

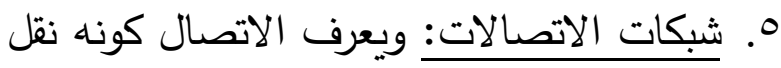

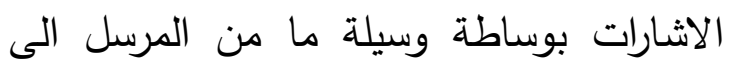
المستقبل والاشارة (signal) تتضمن رسالة تتألف من البيانات والمعلومات (Message) وتذهب الاشارة عبر وسيلة من وسائل الاتصال

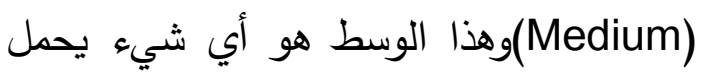

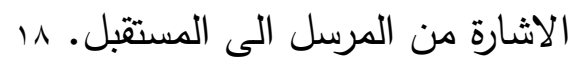
خصائص تكنولوجيا المعلومات لقد تميزت تكنولوجيا المعلومات عن غيرها من

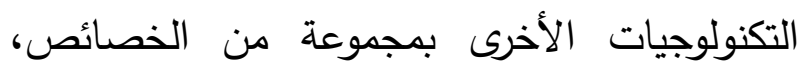
أهمها ما يلي: 1. تقليص الوقت: فالتكنولوجيا تجعل كل الأماكن - إلكترونيا متجاوزة.

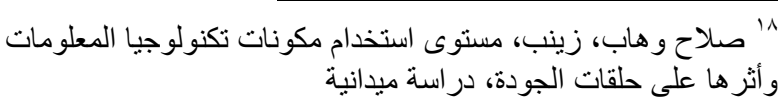


10. العالمية والكونية: وهو المحيط الذي تتشط فيه هذه التكنولوجيا، يث تأخذ المعلومات مسارات مختلفة ومعقدة تنتشر عبر مختلف هند مناطق العالم، وهي تسمح لرأس المال المعلوماتي فيسمح لها بتخطي عائق المكان

$$
\begin{aligned}
& \text { والانتقال عبر الحدود الدولية. } 19 \\
& \text { أثثار استخدام تكنولوجيا المعلومات }
\end{aligned}
$$

رغم ما تقدمه تكنولوجيا المعلومات من مزايا إلا أنه

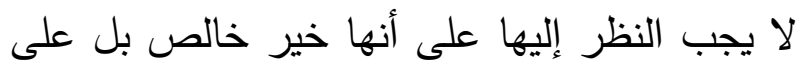

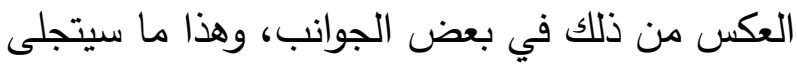

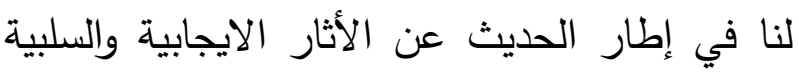

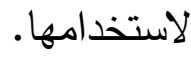

\section{اولاً: الاثار الإيجابية: الخابة}

1. الخدمات المقدمة من طرف شبكة الانترنت في

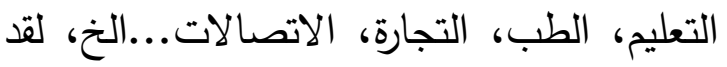
زادت من شعور الفرد بالحرية ونزعت عن كاهله

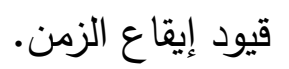

r. توفر تقدم تكنولوجيا المعلومات موارد غنية لئات ومهمة كما توفر المعلومات في شتى مجالات

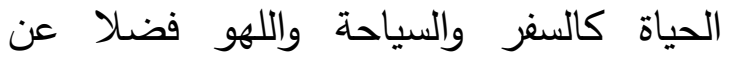
منتديات النقاش والحوار الإلكترونية التي تساهم ولهر

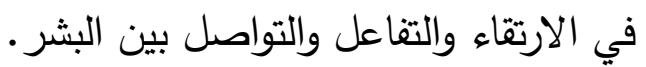
r. تساعد الانترنت القوى الانظمة والحكومات

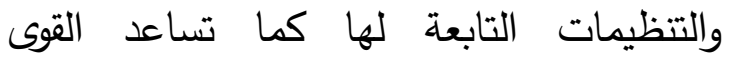
المعارضة في التواصل وتنظيم نفسها.
مثلا تتمتع باستمرارية عملها في كل الاحوال، فلا يمكن لأي جهة أن تعطل الانترنت على لئى مستوى العالم بأكمله.

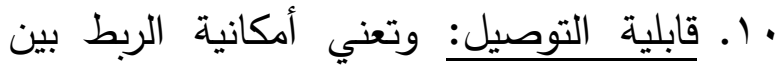

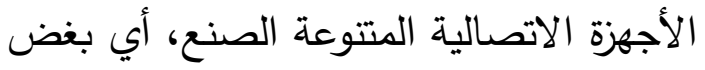

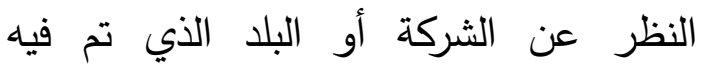

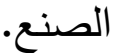
11. قابلية التحرك والحركية: أي أنه يمكن للمستخدم أن يستقيد من خدماتها أثناء تنقلاته، أي من أي مكان عن طريق وسائل

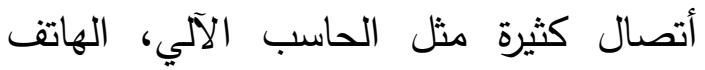
النقال .... الخ. rا قابلية التحويل: وهي إمكانية نقل المعلومات من وسيط إلى أخر، كتحويل الريل الرسالة المسموعة الى رسالة مطبوعة أو مقروءة. r ا. اللاجماهيرية: وتعني إمكانية توجيه الرسالة الصوتية إلى فرد أو جماعة معينة بدل توجيهها بالضرورة إلى جماهير ضخمة، وهذا يعني إمكانية التحكم فيها حيث تصل مباشرها من المنتج إلى المستهلك كما أنها تسمح بالجمع بين الأنواع المختلفة للاتصالات سواء

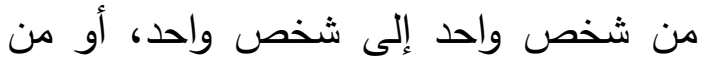

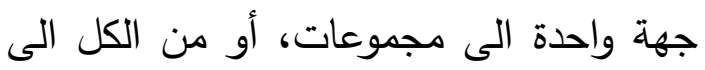
الكل أي من مجموعة الى مجموعة. ع ا. الثيوع والانتشار: وهي قابلية هذه الشبكة

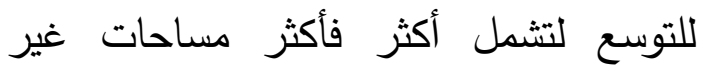

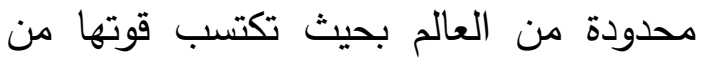
هذا الانتشار المنهجي لنمطها المرن. 
الهائل من المعلومات التي يحصلون عليها يفرز ضغوطا نفسية وعصبية عليهم. ع. خرق حرمة الأشخاص والتظظيمات، عن طريق عليق الاخول في ملفاتهم الخاصة بهم ومعرفة أدق ولتقات التفاصيل عن حياتهم الخاصة، وهذه الاختراقات قد تطال في بعض الأحيان حتى الرؤساء والثخصيات البارزة.

ه. شجعت على ظهور ما يعرف بالنشاطات السلبية والهدامة مثل تجارة الممنوعات والمخدرات وتجارة ما يعرف بالجنس واستدراج الأطفال الى عالم الجنس والجريمة. 7. يرى الكثير من المفكرين أنها تهدد المجتمعات الجنهات وحتى الأمن فضلا على أنها تشكل نوع وسلاح جديد يعد من الحروب المعلوماتية حيث ظهر الامن لي أنها تشكل نوع وسلاح جديد من الجرائم وهي الجرائم المعلوماتية. V. إن الموجات الكهرومغناطيسية التي تنشرها هذه التكنولوجيا لها أثار سلبية على صحة الأنسان كمرض الأعصاب والديسك والسرطان الناتج

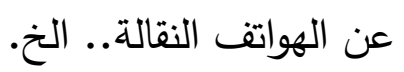
^. تفشي ظاهرة السرقات الجاهزة مما سهل عملية

$$
\text { الثبكات المعلوماتية }
$$

أحدث التطور التكنولوجي طفرةً في حياة الإنسان ونقله إلى مستوياتٍ متقدمةٍ بشكلٍ سريعِ جداً، ودخلت التكنولوجيا إلى جميع مجالات هياة الإنسان وساهت في تسهيل حياته وتيسيرها، كما أدى الجى الاتيان
ع. تساهم شبكة الأنترنت على الترويج وبيع

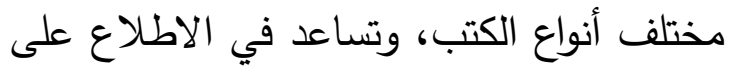
الأدبيات التي تحظرها بعض الحكومات.

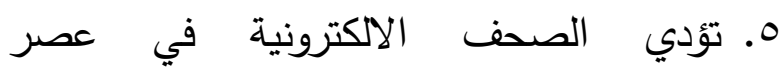
المعلوماتية دورا هاما في نشر المعلومات والتتوير والتواصل بين الثعوب.

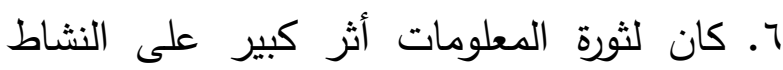
التجاري لمختلف الشركات والمؤسسات التجارية، فنمت التجارة الالكترونية، ووفرت إتاحة السلع والخدمات للجمهور الكبير • التهات

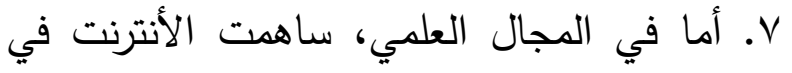
تعزيز العمل الأكاديمي الجامعي، وفتحت أفاقا

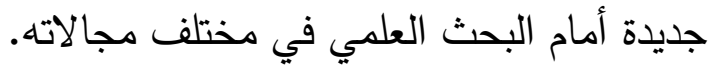
ثانياً: الأثار السلبية:

1. استمرار وجود التفاوت الاجتماعي والمعرفي بين الاتسار الين الناس سواء داخل الدولة الواحدة، أو بين الدول

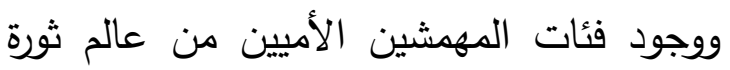

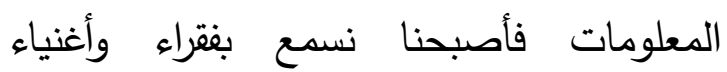
المعلومات في عصر المعلومات.

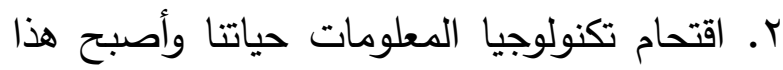
الواقع الافتراضي يسيطر على أفكارنا وذواتتا وفتح مجالا كبيرا لتلاعب في حقائق تاريخية عديدة r. تأثير شبكة الأنترنت على الأطفال، بل على الكبار أيضا، فالجلوس لساعات طويلة أمام

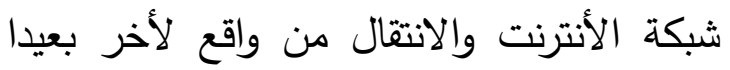
عن العالم الواقعي الذي يعيشون فيه، والكم 
البعض عقد تسويق الانترنت فإن معظم من يتحدث

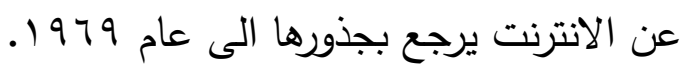

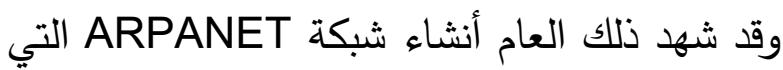
ربطت بين أربع مؤسسات بحث للقوات المسلحة

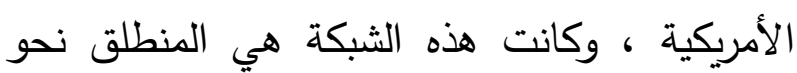

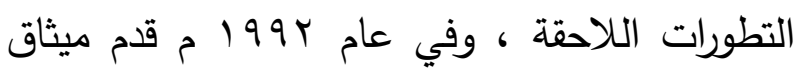

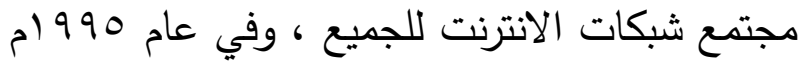
تمت خصخصة الخدمة حيث أعلنت المؤسسة الوطنية للعلوم في الولايات المتحدة في . أب أبريل

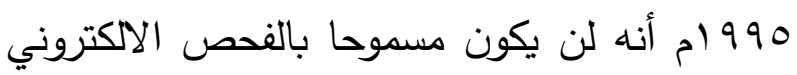

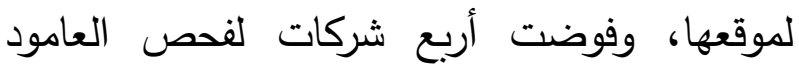

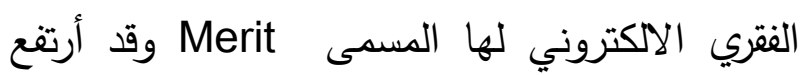

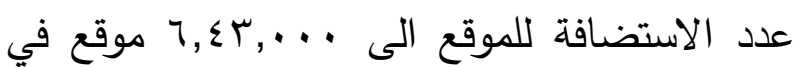
عام 1990 ثم الى ل .., 10, 10, موقع عام $r .199 \mathrm{~V}$ خصائص الأنترنت: للأنترنت خصائص تتميز بها عن باقي الشبكات

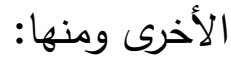

ا. الإنترنت مفتوحة مادياً ومعنوياً: فبإككان أية

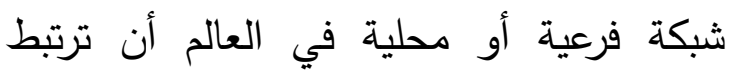
بشبكة الإنترنت، وتصبح جزءا منها دون قيود

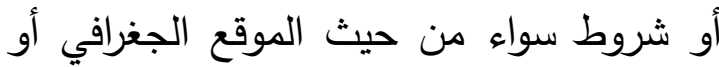
التوجه السياسي أو الاجتماعي.

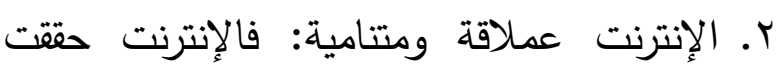
مالم تحققه أية تقنية سابقة في تاريخ الإنسان

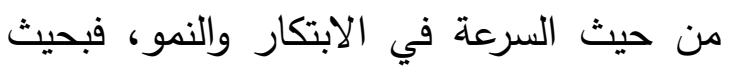

اكتشاف الثبكة العنكبوتية إلى ربط مواقع العالم معاً

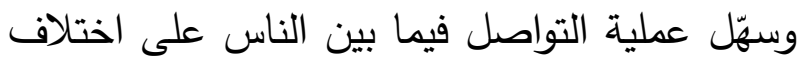

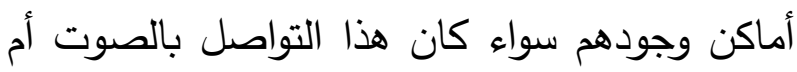
الصورة، كما أنّه سهل تناقل المعلومات والبيانات فيما بينهم، ويتم هذا التواصل من خلال ما يعرف بالثبكة المعلوماتية الي تربط جهازي حاسوب أو أون أكثر بإحدى طرق الاتصال المتوفرة، ويتم تبادل

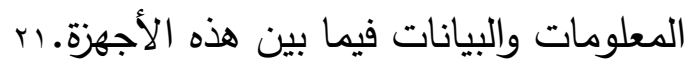
شبكة الأنترنت:

الإنترنت هي مجموعة من الحاسبات المنتشرة جغرافيًا عبر العالم والمرتبطة من خلال شبكات محلية وشبكات واسعة وموزعة في العالم بهدف نقل البيانات على الشبكة، ولذلك أطلق على الأنترنت شبكة الثبكات، والثبكات التي تربط هذه الحاسبات تستخدم عدة وسائط للاتصال فيما بينها، ويحكم

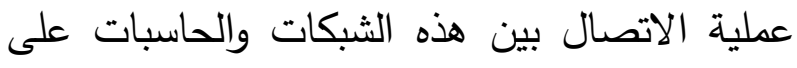
الإنترنت وبروتوكول الاتصال (TCP/IP) والذي لاتصبي يسمح للحاسبات المختلفة بن تتحادث وتفهر بعضها البعض. وتعتبر الإنترنت وعاء ضخما جدًا من المعلومات والتي يتم تحديثها بصفة مستمرة في مالِترني حاسبات منتشرة حول العالم.rr تاربخ شبكة الإنترنت: رغم أن ذيوع الانترنت وانتشاره على نطاق واسع بداء في أوائل التسعينات من القرن العشرين والذي يعتبره

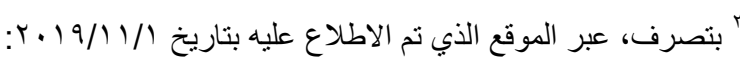
https://mawdoo3.com

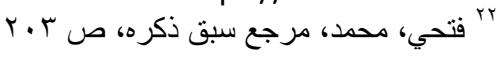


الأنترنت كل يوم يعدنا بالجديد والمفاجآت

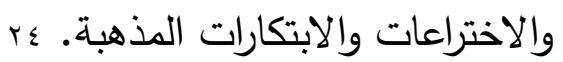

خدمات الإنترنت:

تقدم شبكة الإنترنت العديد من الخدمات لمستخدميها، هذه الخدمات يمكن ذكرها كم يلي: ا ـ خدمات البربد الالكتروني E-mail أهم الخدمات التي تقدمها الثبكة وأشهرها، فمن الترن

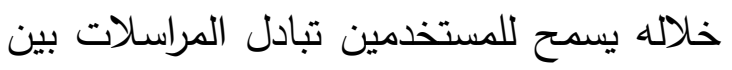

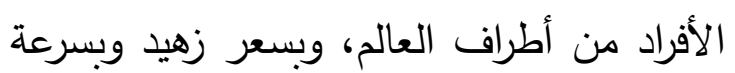
فائقة.

$$
\text { وللبريد الالكتروني عدة ميزات هي: }
$$
هرعة وصول الرسالة إلى المستثبل. عدم ضياع الرسائل الالكترونية. همكن إبقاء الرسائل الالكترونية على حالها أو الوكية طبعها، كما يمكن أعادة أرسالها ومعاينتها.

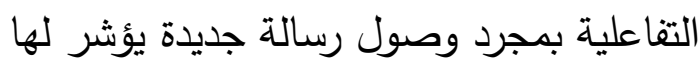

$$
\text { عند وقت الاستعمال. }
$$

هجهولية صاحب الرسالة حيث لا يظهر على الانعي

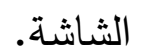

وعادة يتكون عنوان البريد الالكتروني من:

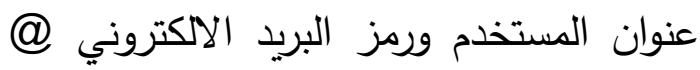

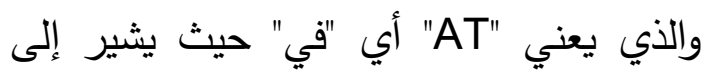

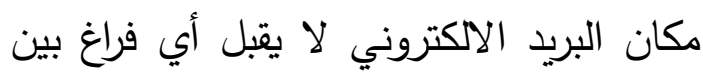

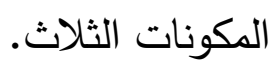
r. المجموعات الإخبارية Newsgroups: هي تلنيات منتديات تجمع بين الأفراد مهتمين بنفس لهريه
احتاج المذيع رب سنه ليصبح لديه ـ0 مليون

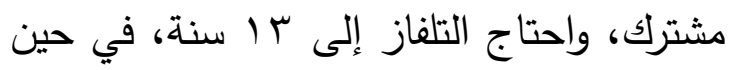
أحتاج الحاسوب 7 اسنة، أما الإنترنت فأنها أحتاجه ؛ سنوات فقط بالإضافة إلى أن عدد الإنقات المستخدمين لها في تزايد مستمر . r. العشوائية: فالمعلومات المتواجدة في الإنترنت هي بشكل عشوائي ومتناثرة، ولذلك قامت عدة فئات جهات، غير ربحية وأخرى تجارية بإنشاء

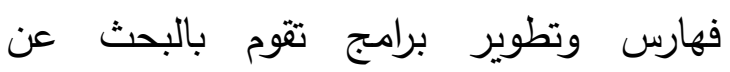
المعلومة لبتي يطلبها المستخدم، ومن القضايا

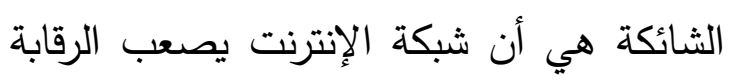
أو المحاسبة على ما ينشر فيها.

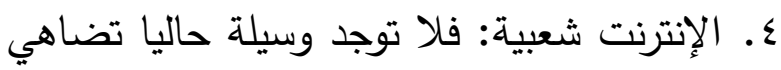
شعبية الإنترنت لأنها وسيلة جماهيرية وليست فيت وندية مقصورة على فئة معينة، فسرعة التواصل عبر الإنترن ولتيل شبكة الإنترنت هي سرعة الضوء ناقلة معها

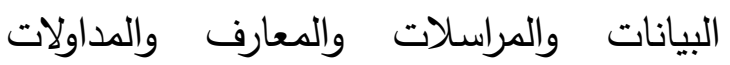
المالية والعقود والاستشارات، فقد أصبح العلم كوكبا لا يعرف فيه التواصل نوما.

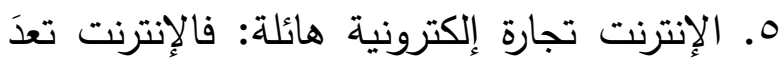
وسيلة تجارية وتسويقية فعالة مقارنة مع الوسائل

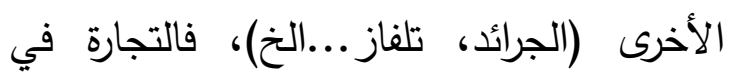
المستقبل وأسواقها ستكون على الثبكة. 7. الإنترنت متطورة باستمرار: فالبحوث في مجال المبكة

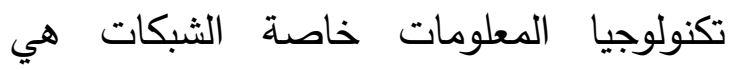
متطورة ومستمرة في النمو نحو الأحسن، فعالم 
يعرف المستفيد أثناء الاتصال على أي حاسوب

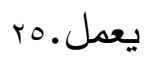

\section{شبكتا الانترنت والاكسترانت:}

أولاً: الشبكة المحلية " الأنترانت ": هي شبكة الانترنب داخلية

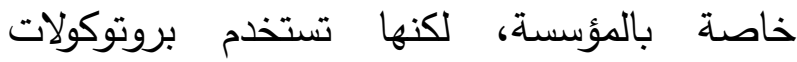

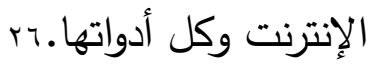

كما تعرف " أنها شبكة محلية تعتمد تقنيات الانترنت والشبكة العنكبوتية والسطح البيني الذي تتميز به

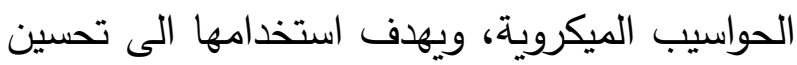

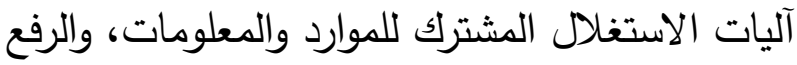
من كفاءة العمل الذي يميز المؤسسة أو الثركة المعنية "rver

ثانياً: شبكة المناطق الواسعة " اكسترانت ": وتعرف على أنها " نتاج (تزاوج) كل من الانترانت والإنترنت، فهي شبكة مفتوحة على المحيط الخارجي بالنسبة للمؤسسات المتعاونة معها والتي لها علاقة بطبيعة نشاطها بحيث تسمح لشركاء أعمال المؤسسة ولهات بالمرور عبر جدران نارية التي تمنع ولوج الدخلاء والوصول الى بيانات المؤسسة وقد يكون هؤلاء الشركاء موردين، موزعين، شركاء، عملاء أو مراكز

وتقسم الاكسترانت من وجهة نظر الأعمال إلى ثلاثة أصناف أساسية هي: ا ـ شبكات الاكسترانت للتزويد: تربط هذه الشبكات مستودعات البضائع الرئيسية مع المستودعات Po العتيبي، عزيزة، مرجع سبق ذكره. ${ }^{26}$ Dildo Fray Darg Nguyen, The Digital Enterprise, (Economic, Paris, France,2001), P.209
الموضوع، منظمين في شكل مجموعات اهتمام كل مجموعة معالجة أو مناقشة موضوع منئ معين، بحيث تأخذ اسمها من نوعية أو صنف او منف موضوع

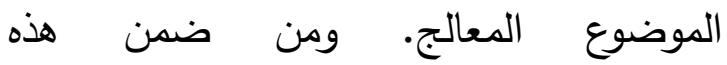
الموضوعات المناقثة نذكر على سبيل المثال: الحاسوب، العلوم، الترفيه، والاستجمام، لإل الموضوعات التجارية، الموضوعات الساخنة، وموضوعات تتعلق بإدارة شبكة الإنترنت العالمية، وموضوعات الأخبار والتحاليل

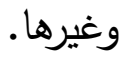

r. برتوكول نقل الملفات "FTP": يستخدم هذا البرتوكول عند تبادل المعلومات بين الحواسيب،

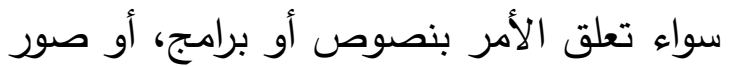

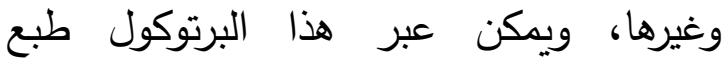

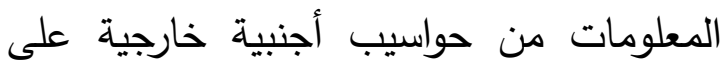
الحواسيب الخاصة والعكس ـ. فهذا البرتوكول يسمح بالاتصال بأي جهاز متصل بشبكة الإنترنت فبواسطة FTP، يمكن القيام بعمليات تحويل الملفات انطلاقا من موزع ليطن بعيد إلى اسطوانتك الشخصية.

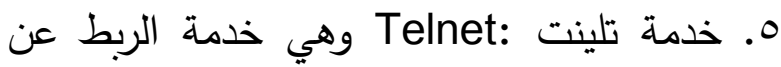
بعد، وهي عبارة عن برنامج خاص لتيني للمستخدم أن يصل إلى جميع الحواسيب في

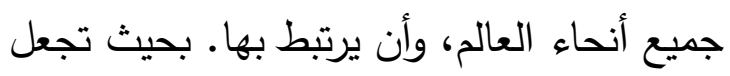

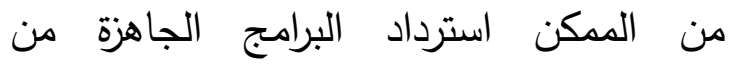
للحواسيب الأجنبية، بل وتجعلها كما لو أنها

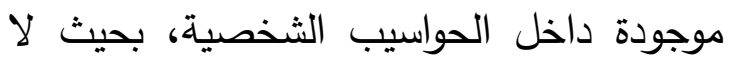


التواصل عن بعد فالثبكة تتيح إمكانية التواصل

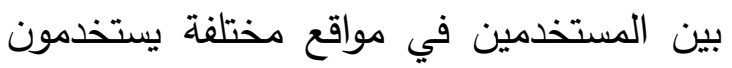

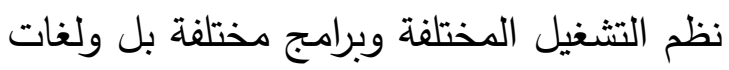
مختلفة، فاللقاءات عن بعد تسمح بالتخاطب

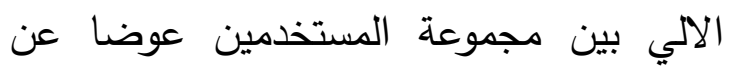
عقد الاجتماعات بالطرق التقليدية، وتجنب تكاليف السفر والإقامة ...الخ. يمكن للمؤسسة من تجهيز طلبيات الموردين

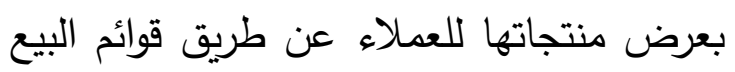
بطريقة لم تكن متاحة تقليديا من قبل.

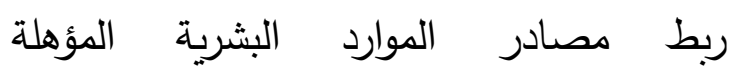
(الجامعات، المعاهد، مراكز التدريب) مع سوق لئل

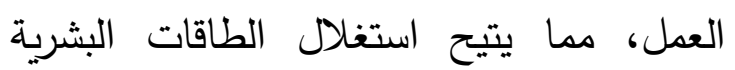
الكامنة في المجتمع من طرف المؤسسات.

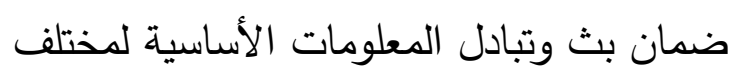
التطبيقات داخل التنظيم، وتمكن أعضاء المؤسسة بالحصول على معلومات من أي وني مكان متواجدين فيه، وتسمح بتبادل المعلومات

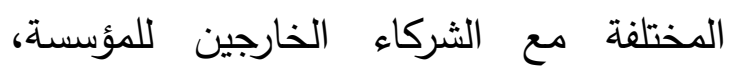
زبائن، موردين ...الخ. إتاحة قاعدة بيانات، تحوي حجم هائل ومهر من لن

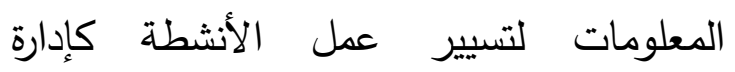

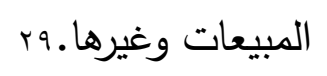

المخاطر التي تهاد شبكات المعلوماتية يمكن تقسيم المخاطر التي تهدد أمن الثبكات المعلوماتية إلى صنفين هما: 1. التهديدات المقصودة:

99 العثيبي، عزيزة، مرجع سبق ذكره.
الفرعية بغرض سير العمل فيها أليا، للمحافظة

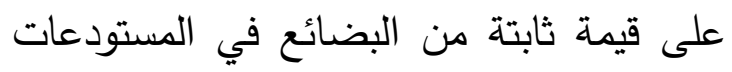
الفرعية استنادا لقاعدة نقطة الطلب للتحكم في لتصني

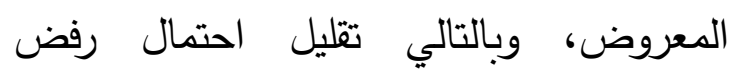
الطلبيات بسبب عجز في المستودع.

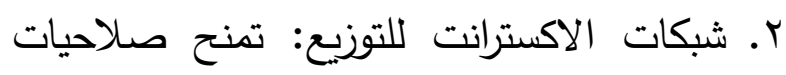

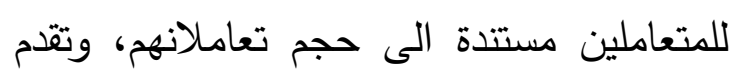

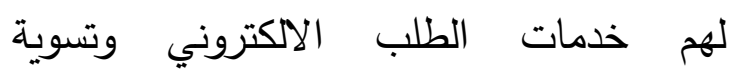
الحسابات مع التزويد الدائم بقوائم المنتجات الجديدة والمواصفات التقنية وما إلى ذلك من لخدابل خدمات أخرى. r. شبكات الاكسترانت التتافسية: تمنح للمؤسسات

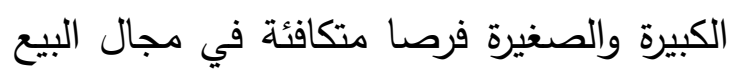
والشراء عن طريق الربط فيما بينها قصد تبادل المعلومات عن الأسعار والمواصفات التقنية الاقيقة للمنتجات، مما يرفع من مستوى الخدمة

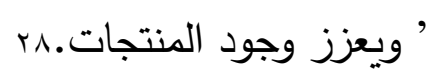

أهمية الشبكات المعلوماتية

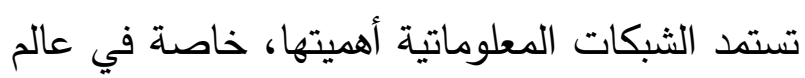
الأعمال، من الايجابيات التي تمتلكها أهمها:

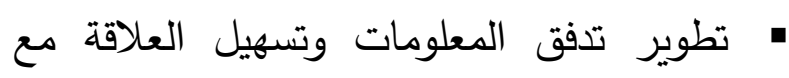
شركاء الأعمال داخل المؤسسة وخارجها منها وإليها. تحسين سلاسة العمل لزيادة الإنتاجية، بالعمل

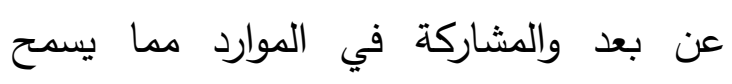
باستغلال موارد الشبكة بالمؤسسة عند وبعد إنجازه الأعمال التي لا تتطلب التأخير. 
خطاء فني ناتج عن سوء تصرف أو سوء تقدير من طرف الساهرين على الشبكات

$$
\text { مستلزمات أمن الثبكات المعلومات.r من }
$$

لقد أصبحت الثبكات اليوم تؤدي دورا مهما وفعلا في حياتا اليومية، فقد جلبت فوائد عظيمة وجليلة للبشرية بأسهل الطرق وأبسطها وأرخصها كذلك. ولكي تؤدي الشبكات المعلوماتية دورها على أحسن وجه وينبغي لها أن تستجيب للأبعاد والأهداف التالية: ا. التواجد: ويقصد به قدرة على توفير الموارد الضرورية لتشغيل الشبكات ووضعها على ذمة المستفيد على جميع المستويات ولذا يجب الحرص على توفير المعلومات وعدم تشويهها أو حذفها وعدم تعطيلها.

r. سلامة وسرية المعلومات: وهذا بالحرص على حماية عمليات تخزين المعلومات، ونقلها عبر الشبكة، ويتمثل في ضمان عدم تغير المعلومات المخزنة في أجهزة الحواسيب أو المنقولة عبر الشبكة إلا من قبل الأطراف المرخص لهم. r. التحقق من الهوية: بالتأكد من هوية الأطراف المعنية بعملية التبادل، لذا يجي على كل طرف معرفة هوية الطرف الأخر لتفادي عملية الخداع، وتتوفر عدة طرق لتأكد من هوية
وهي التي يقوم بها المخترقون عمدا قصد تعطيل عملها أهم هذه المخاطر : صناعة الفيروسات الاككترونية: وهي أكثر الجرائم انتشارا وتأثيرا في عالم الشبكات. الاختراقات: وهي محاولة الدخول إلى الشبكة المعلوماتية من قبل شخص غير مصرح له بذلك، وقد يستغل في هذا ثغرات نظام الحماية. تعطيل الأجهزة: حيث يقوم مرتكبو هذا النوع من الجريمة الافتراضية بتعطيل أجهزة الشبكات المعلوماتية ونظمها جزئيا أو كليا. كما يدخل في هذا المجال من المخاطر: صناعة ونشر الإباحية، التشهير وتشويه السمعة، المضايقة والملاحقة، النصب والاحتيال. r. التهديدات غير المقصودة: وهي التي تكون عموما نتيجة عدم اتخاذ التدابير الوقائية، أو خارجة عن نطاق التحكم فيه أهم هذه التهديدات ينتج عن: الكوارث الطبيعية (العواصف الفيضانات

$$
\text { الحرائق .. الخ) }
$$
تعطل الثبكات بسبب الأشغال. عطب أحد مكونات الشبكة أو خطأ في تنفيذ أحد البرامج المشغلة للحواسيب أو الثبكة. 
من المهارة والدقة في الحصول على المعلومات المهمة والمفيدة وطرق حفظها واسترجاعها ونظم اتصالات متطورة بين المستويات الإدارية المختلفة، ذلك لسهولة انسياب المعلومات بشكل صحيح ومن هنا ظهر تأثير تلك النظم على الإدارة وإدارة الموارد البشرية (موضوع بحثنا) والذي سوف نبين في هذا البحث ذلك التأثير على إدارة الموارد البشرية. وتعتبر تتمية الموارد البشرية من المواضيع البالغة الأهمية، لأنه لا يمكن الحديث عن مؤسسة متطورة ومستمرة دون أن نحدد بدقة درجة كفاءة موردها البشري، ومفهوم التتمية البشرية موضوع هام مرتبط بمدى القدرة على تحقيق الأهداف المرسومة. مفهوم التتمية ويقصد بها تتمية العاملين على الوظائف المستقبلية في التظظيم إذا ما أخذ في الاعتبار تطور المسار الوظيفي للعامل واحتمال تقلده وظائف ذات ذات مستويات أعلى فيجب إعداده لتحمل هذه المسئوليات

اليوم وقبل أن يمارسها عندما تسند إليه مستقبلا.

\section{مفهوم الموارد البشريـة}

هي تلك المجموعات من الأفراد القادرين على أداء العمل والراغبين في أداءه بشكل جاد وملتزم من خلال توافر نظم تحسين هذه الموارد وتطويرها بالتعليم والاختبار والتدريب والتطوير والصيانة. rب مفهوم تتمية الموارد البشرية: وأكد تقرير برنامج الأمم المتحدة الإنمائي ( (... (. ) على أنه "عملية أو نشاط تعمل على أساس المعرفة، والخبرة، والإنتاجية، والرضا، في المدى القريب أو لتصاص
الأطراف المتصلة بالثبكة على غرار كلمة العبور والتوقيع الإلكتروني ... وغيرها. ع. الإثبات: تتمثل في توفير ألية تثبت عملية تبادل المعلومات عبر الثبكة، ولا تدع مجالا للمرسل أن ينكر عملية الإرسال وللمستقبل أن ينكر

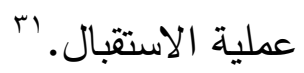

\section{ثانياً: تنمية الموارد البشرية}

في ظل التنافس القائم بين المنظمات والكم الهائل من المعلومات والتطور والتتوع في مصادرها دعت الحاجة الى الاهتمام برأس المال الفكري حيث يعد احد اهم أسباب النهوض بالاقتصاد لما يملك من اهمية حيث انهم اللبنة الأساسية في بداية أي نهضة حديثة بسبب خبراتهم ومعارفهم التي ستساهم بشكل كبير من الحد من المخاطر ودراسة جيدة للسوق لتحقيق الأهداف المرسومة من قبلهم ومواجهة تحديات السوق، فالمنظمة التي تملك موارد بشرية فعالة وقادرة على التكيف مع المتغيرات الاقتصادية تكون قادرة على الاستمرارية والتتافس والتي تكون نابعة من العنصر البشري المدرب. إن الاتجاهات المعاصرة في نظم المعلومات هو الاعتماد المتزايد لتك النظم المبنية على استخدام الحاسب حيث أصبحت المعلومات جزءا تعتمد عليه في دعم العملية الإدارية ودعم القرارات الإدارية والمساعدة في تسويق وتطوير المنتجات الجديدة وفتح أسواق جيدة وتحسين الأداء وتخفيض فولفيز التكاليف ونظراً لتعدد وظائف الإدارة في العصر الحديث وما تتطلب معه أن تكون على مستوى رفيع 
7 . تعليم الإنسان قيمة وأهمية الوقت وتدريبه على

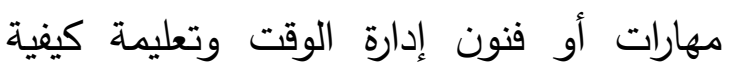
استغلال طاقاته ومواهبه ووضع أهداف لحياته. V. كيفية التعامل مع المشكلات التي تواجه الفرد

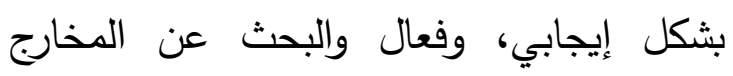
والحلول. أسس تنمية الموارد البشرية:

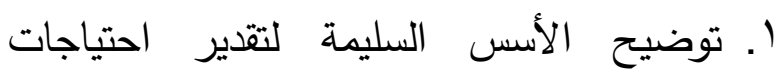
المنظمة من الموارد البشرية، وتحديد مواصفات

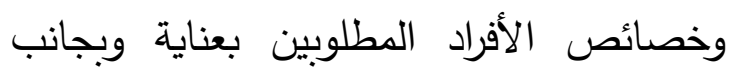

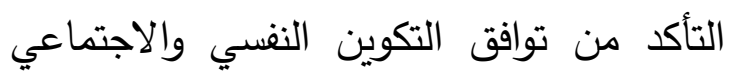

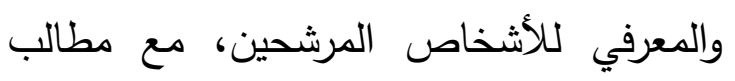
هذه الوظائف وتمتعهم بالسمات والخصائص

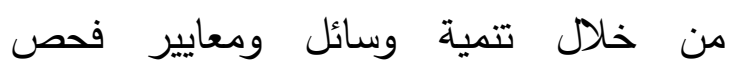
المتقدمين للعمل والمفاضلة بينهم لاختيار أكثر العناصر توافقا مع احتياجات المؤسسة.

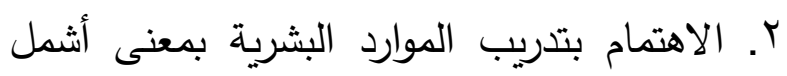
وأعمق مما كانت تتعامل به به إدارة الموارد البشرية التقليدية أي عدم انحصارها على الأفراد الذين يبدون قصور في مستويات أدائهم، بل يجب أن يشمل جميع أفراد المنظمة مهما كان سنهم ومهما كان مستواهم المعرفي والوظيفي، دئحل وقد تبين منهجية إدارة الموارد البشرية الإستراتيجية أن تفعيل التدريب وجرعات تتمية

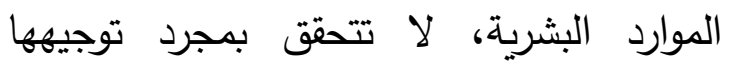

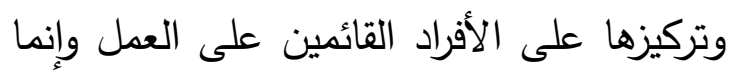

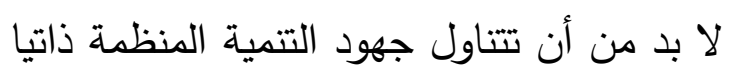

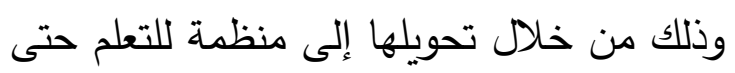

البعيد، وتستهدف هذه العملية أو النشاط تحقيق

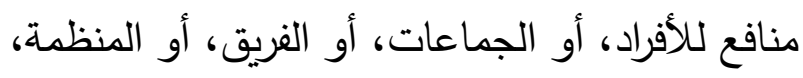

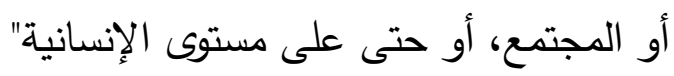
أهداف تنمية الموارد البشريـة: يمكن أن نحدد الأهداف المتحققة من تتمية الموارد

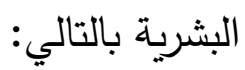
ا ـ بناء إنسان قادر على مواجهة الحياة والتغيرات التي تحدث حوله بشكل إيجابي وفعال. r. مساعدة الفرد على التفكير بشكل إيجابي وتغيير نظرته من نظرة سطحية إلى نظرة أكثر عمقا وبشكل مختلف للحياة من حوله. r. تعليم الفرد على إتقان مهارات الاتصال الفعال وذلك من اجل إثراء تواصل الفرد بالمجتمع بشكل أخلاقي ومؤثر يعبر فيه الفرد عن نفسه ويتولد شيء من الارتياح بينه وبين أسرته وأصدقائه وزملاء العمل وقائديه. ـ. مساعدة الغرد في تطوير أدائه وقدراته وذلك من ونائه اجل إيجاد الوظيفة المناسبة له وكيفية الحصول عليها وما يحتاجه لذلك من مؤهلات ودورات سمات في الثخصية. 0. تعليمة مهارات وفنون التعامل وكيفية تعامله مع فع التحية. فريق العمل ومع قائد الفريق ويجب أن يتفهر الفرد انه مهما كان دوره صغيرا إلا انه سيكون

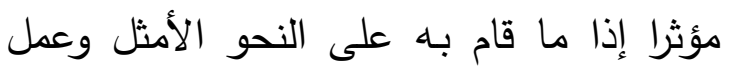
على إظهار إبداعاته الخلاقة به. فهو قائد الدأد المهمة التي يقوم بها مهما صغرت. الحادي والعشربين، ـ التبريب الإداري والمهني رؤية معاصرة للقرن 
في الأرباح وتوزيع أسهم مجانية لتحفيزهم وتتمية اهتمامه بالعمل.

V. فتح قنوات الاتصال وتسيير تدفقات المعلومات والمعرفة بين قطاعات وجماعات العمل المختلفة لتحقيق الفائدة الأعلى الناشئة من هذا النمو المتصاعد لمعرفة نتيجة التداول والتعامل فيها باعتبار أن ما يفرق المعرفة على الموارد

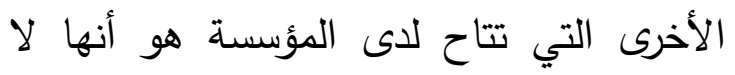
تنقص بالعكس فهي تتمو وتتطور كلما زاد انتشارها وتداولها بين الأفراد.

^. تطبيق نظام إدارة الأداء والاهتمام بجميع عناصره البشرية والمادية والتقنية والتصميمية في إطار متناسق ومتكامل، والاهتمام بالأبعاد الثقافية والاجتماعية للموارد البشرية واختلاف مستوياتهم الفكرية وأخذ الفروق في الاعتبار عند تصميم الأعمال ومعايير التقييم إلى جانب تزويد العاملين بالمعلومات المتجددة عن طريق التدريب أو الاجتماعات الحوارية بين العاملين والرؤساء والكثف عن أفكار جديدة لتحسين فرص الأداء حسب الخطط المعتمدة. 9 . من اجل تتسيق جهود تلك الموارد البشرية متتوعة الخيارات والكفاءات والاهتمامات

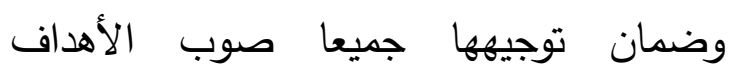
المحددة وفق الأساليب والأولويات المعتمدة، ويجب التركيز على القائد الإداري الذي يختص في ممارسة وظائف التوجيه والمساندة والتسيق وغيرها من الوظائف والذي يلعب دور الرائد في
تهيئ الفرص للعاملين فيها بالتعلم و لتميز معارفهم في تطوير الأداء.

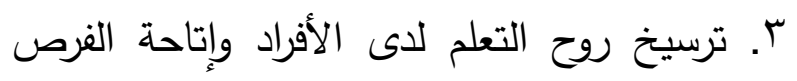
للمشاركة في المؤتمرات والندوات العلمية والمهنية المختلفة، وتطبيق نظام يقضي بتحمل المنظمة عنهم رسوم الاشتراك ورسوم العضوية في الجمعيات والهيئات العلمية والمهنية، فضلاً عن تسيير فرص استكمال الدراسات العليا المتخصصة وتحمل النفقات عنهم كليا أو جزء منها وعلى حساب وقت المؤسسة. ع. تتمية استثمار الطاقات الفكرية و والقدرات الإبداعية للأفراد وتوفير الفرص للممتازين منهم لتجريب أفكارهم ومشروعاتهم الخلاقة، والعمل بمبدأ الابتكار ونذكر هنا أن المؤسسة الأكثر نجاحا في العالم المتقدم تحاول أن تجعل كل فرد رجل أعمال في ذاته وليس مجرد موظف يؤدي أعمال روتينية بل هو يفكر ويبتكر ويشارك في المسؤولية ويتحمل المخاطر • ๑. تتمية أساليب العمل الجماعي وتكريس روح الفريق للموارد البشرية في المؤسسة وضرورة توفير المناخ السائد لتنمية الاتصالات الإيجابية والتواصل بين شرائح العاملين المختلفة وتحقيق أسس الانتماء والولاء للمنظمة. 7 . مراجعة هيكل الرواتب والتعويضات المالية وإجراء المقارنات مع المستويات السائدة في سوق العمل وفي هذا المضمار يمكن الإتاحة للعناصر البشرية الفرصة في المشاركة في عوائد إنتاجهم الفكري بتطبيق نظام المشاركة 
11 ا. القضاء على الخوف والتوتر المرتبط بتطوير

$$
\text { وتجديد الوظائف. }
$$

عناصر تنمية الموارد البشرية: أولاً: التدربب

ويعد التدريب من السبل المهمة لتكوين منظمات تستند على موارد ذات كفاءة قادرة على تحمل أعباء التتمية الاقتصادية والاجتماعية لمجتمع بعامة ومنظمات الأعمال بخاصة كونها جزء من هذادهاه

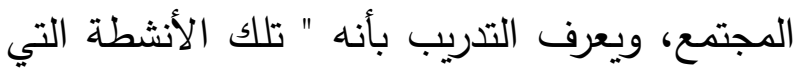
تعمل على إكساب العاملين المزيد من المعارف

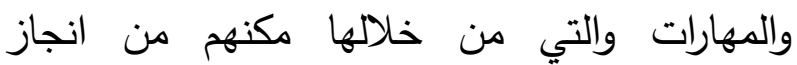

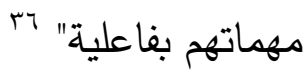
ثانياً: التعليم والتثقيف المنظم التعليم: - (التيخ:

إن التعليم يدخل ضمن الخطط الأساسية لمنظمات

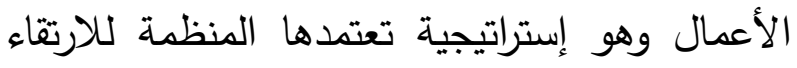
بالعاملين فكرا وسلوكا على اعتبار أن التعليم يؤدي

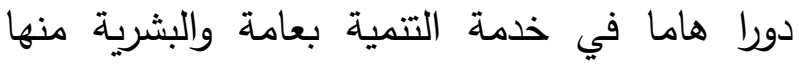
بخاصة، إذ يتم من خلاله (إكساب المتعلم الأسس فئس

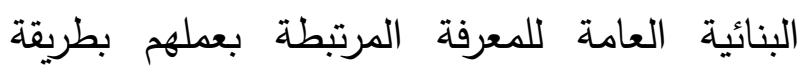

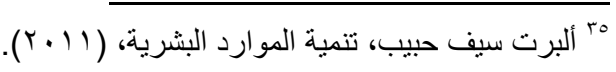

${ }^{36}$ Briscoe, D. and Others, International Human Resource Management: Principles and Practices for Multinational Enterprises (Global HRM), 2012.
تهيئة الدخول إلى عصر المتغيرات واستكمال

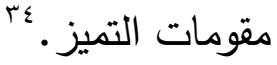

الثروط الواجب توافرها لتنمية وتطوير الموارد البشريـة:

ا. اعتبار تتمية الموارد البشرية أحد مسئوليات الإدارة العليا بالمنظمة. r. تعتبر التنمية الذاتية لكل فرد أحد شروط نجاح التنمية الوظيفية. r. يجب ربط الترقية بتقييم الأداء والنتائج لكل فرد ولكل وظيفة. ع. يجب احترام الفروق الفردية بين العاملين من حيث القدرات والرغبات والاستعدادات ودرجة تحمل ضغوط العمل والقدرة على التعلم. ه. يجب تخطيط ومراقبة برامج تنمية الموارد البشرية. 7. يجب تحقيق التفاعل بين التعليم والتدريب مع

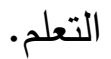
V. يجب أن يركز التدريب، على العمل والوظيفة في حين أن التعليم يجب أن يركز على قدرات

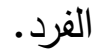
^. ربط التدريب والتطوير بواجبات الوظيفة وخلال أدائها. 9. تحديد المهارات اللازمة لأداء كل وظيفة (المهارات السلوكية- الإدارية- الفنية وغيرها). • ا ـ قبول التحدي اللززم لتحديث كل وظيفة بصفة مستمرة.

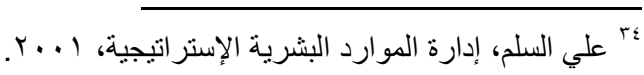


وسائل تنمية الموارد البشرية:

اولاً: الإدارة

وهي المدخل الرئيسي لعملية تنمية الموارد البشرية،

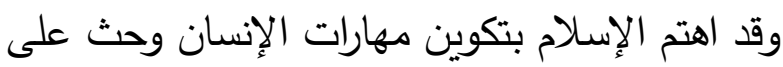
ذلك، ولقد كانت سيرة المصطفى صلى الله عليه وسلم وصحابته الكرام نموذجا الإدارة الناجحة، وإذا لفال

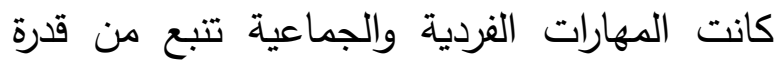
الإنسان على استيعاب ما يتلقاه، فإن الإسلام اهتم

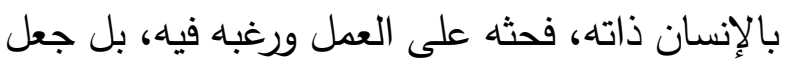

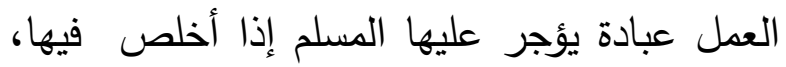
وأتقن أداءها إذ أن نجاح برامج تتمية الموارد البشرية

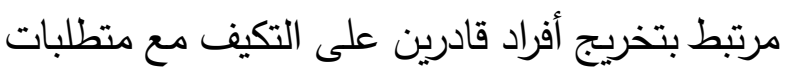
العمل والتأثيرات الاقتصادية العالمية. ثانياً: التخطيط فالتخطيط سمة إنسانية يتميز بها البشر على سائر المخلوقات، فالله سبحانه وتعالى أعطى الإنسان عقلاً

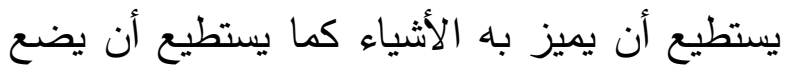

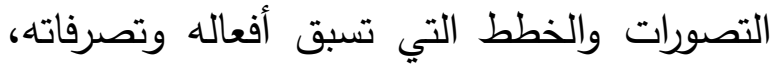
ولذلك فإن أي عمل ناجح لابد أن يسبقه تخطيط جيد6، ويعرف التخطيط بأنه عملية فكرية تعتمد على المنطق والترَتيب حيث يبذل فيها الجهد لتوضيح

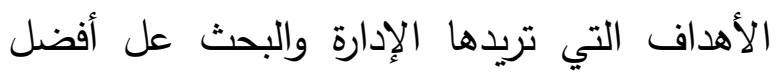
الوسائل لتحقيقها، وكذلك محاولة التنبؤ بالمعوقات الإدات

التي يمكن أن تعثَرضها وكيفية التغلب عليها.

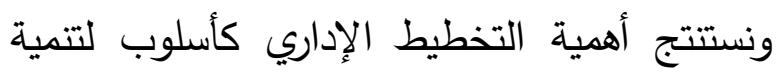
الموارد البشرية فيما يلي: الهميه التيطيط 1. القدرة على التفكير في الأهداف.

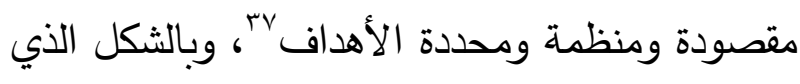

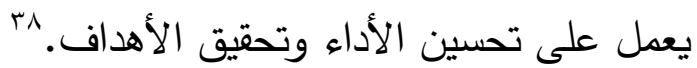
التثقيف المنظم: يعمل التثقيف المنظم بكافة مستوياته على تطوير وتتمية الموارد البشرية في منظمات الأعمال، إذ من بن بطن

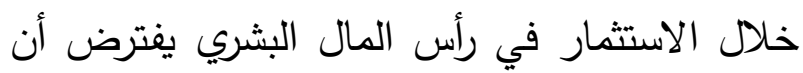
يُمارس كل من التعليم والتثثيف مهمة مزدوجة تتمثل بتزويد الأفراد العاملين بمؤهلات من شأنها أن توسع مئح فرص العمل المتاحة لهم، فضلا عن تحسين القدرات الإنتاجية للأفراد العاملين من اجل رفع مستويات

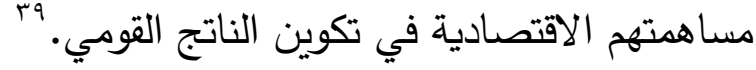

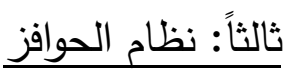
وتمثل أنظمة الحوافز أهمية متجددة بالأخص مع الحصات

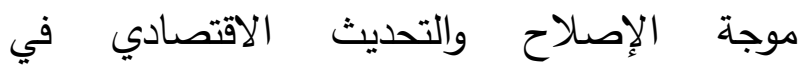
الاقتصاديات الناجحة بما ينعكس وفي كل المراحل

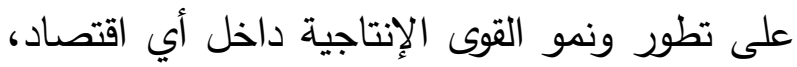
لتوسيع الإنتاج كما ونوعا، بما يعزز نمو لإنداهيه داخل الدخل

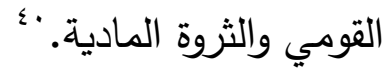

\footnotetext{
${ }^{37}$ Hokka, Paivi, \& Etelapelto, Anneli, Seeking New Perspectives on the Development of Teacher Education A Study of the Finnish Context, 2014.

${ }^{38}$ Abdulrahaman W. Lawal, Technical and vocational education- a tool for national development in Nigeria, 2014.

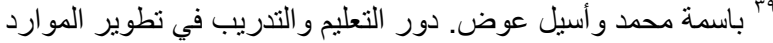

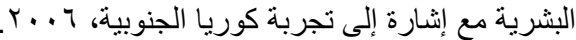

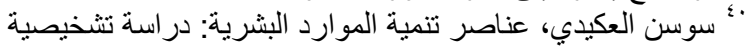

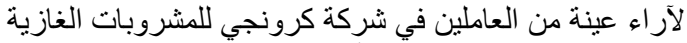 و العصائر و المياه الصحية والألبان المحدودة في محافظة كركوك، لكني


سياسات وإستراتيجيات تنمية الموارد البشرية: تتعدد سياسات واستراتيجيات تتمية الموارد البشرية ومن هذه السياسات ما يلي:

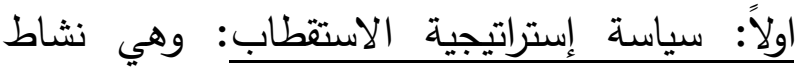
تتوجه به الإدارة إلى أسواق العمل للتعرف على العيد

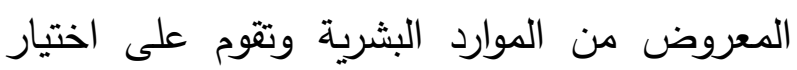
العنصر البشري متعدد المواهب والمهارات والقدرات والإمكانيات التي تمكنه من العمل في وظائف متعددة داخل المنظمة.

ثانياً: تصميم العمل وتوصيف الوظلئئف: هي إعلادة هيكلة العمل من أجل توفر وظائف المنظمة العيا لثاغليها عناصر الإقبال على العمل والحماسة إليه والتحفيز تشجيعهم واستخراج طاقتهم. ثالثاً: سياسة لتتييم أداء الأعمال: تحدد الأساس والمعايير للحكم على كفاءة الفرد في أداء عمله وهي عاملا هاما في حسن توجيه باقي السياسات مثل مدى صلاحية الفرد للترقية لمستوى وظيفي أعلى. هذه السياسة تخضع لأنظمة وبرامج ومعايير تقييمه حديثة تعتمد على العمل الجماعي وهي: (التكلفة_ الوقت _الجودة_ خدمة العملاء_ قياس مدى رضاء العملاء). رابعاً: سياسة علاقات العمل: أصبحت تقاس بمدى العياء تحقيق درجة التعاون والتتسيق بين المنظمة التئية والعاملين.

خامساً: سياسة التدريب: إن وجود سياسة تدريبية واضحة شرطا أساسيا لاستخدامه كعنصر هام في التيان إستراتيجية التنمية للموارد البشرية. r. r. القدرة على الرؤية المستقبلية. r. القدرة على تحديد الاتجاه والحشد خلف الاتجاه وتحفيزهم لتفجير الطاقات الكامنة. ع. القدرة على توضيح الأهداف وتحديدها بدقة.

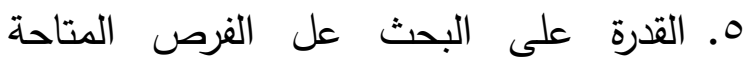
والأستفادة منها. 7. القدرة على تحديد الأولويات. V. القدرة على وضع إستراتيجية فعالة تتسم بالمرونة والثمول والتكامل وتكون جسراً يصل الماضي بالمستقبل. ثالثاً: القيادة إن الهجف الأساسي من تتمية الموارد البشرية هو

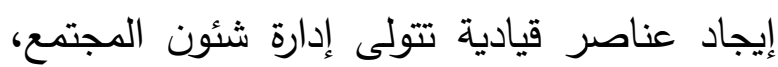
وتقوده نحو التطور والتقدم، والقيادة هي الدفتاح لأئي عمل إداري، فإذا كانت القيادة على قدر من الوعي الوعي

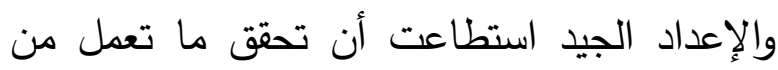

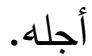
والقيادة هي" نشاط التأثير على الناس لكي يعملوا

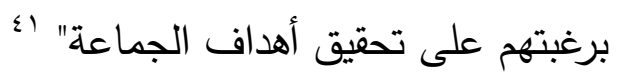
مناهج تنمية الموارد البشرية الثبان تتعدد مناهج تتمية الموارد البشرية وتتمثل في الاتيي:

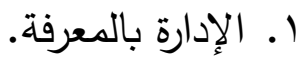

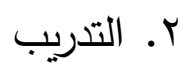

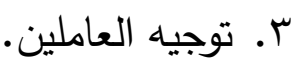

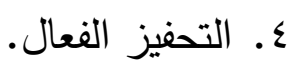
ه. الاختيار والاستقطاب والتعيين. 
إذ تعدّ تكنولوجيا المعلومات أداة يمكن من خلالها

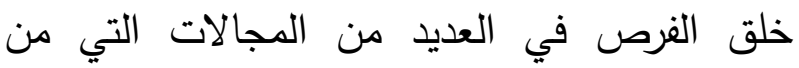
أهمها؛ رفح كفاءة الأداء الوظيفي، وتحسين نوعية

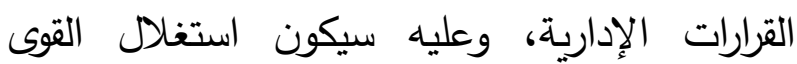
العاملة في أعلى درجاته، فإن العلاقة بين تكنولوجيا المعلومات، والأداء الوظيفي هي كالآتي باء؛ أحدثت تكنولوجيا المعلومات، تحسنًا كبيرًا في

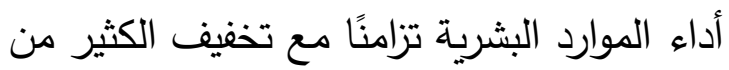
الأعمال الروتينية، ممّا أدى إلى إنجاز الأعمال

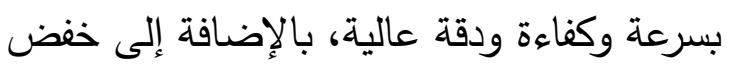
التكاليف عمومًا. - الئ قلت تكنولوجيا المعلومات من أعباء الوظائف

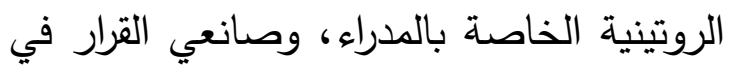

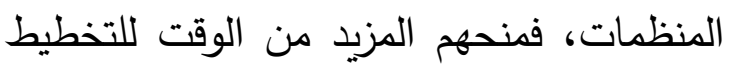
ورسم السياسات.

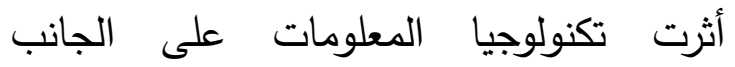
المعنوي للعاملين عمومًا؛ إذ أصبح بمقدورهات الوصول للمعلومات التي تخدم وظائفهر بسهولة

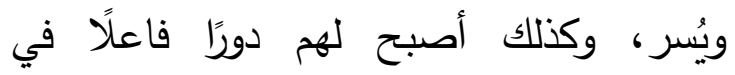
المساهمة في صنع القرار . أدى وجود تكنولوجيا للمعلومات في المنظمات، إلى زيادة الدور التنافسي، ممّا دفعهم للبحث

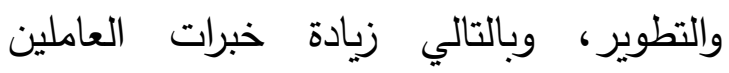
القائمين على هذه الأبحاث، وتتمية قدراتهم

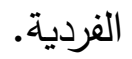

rأ "استخدام البنية التحتية لتكنولوجيا المعلومات أثرها على على الموارد

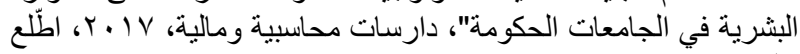

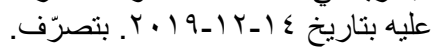

سادساً: سياسة الترقية: تطور مفهوم الترقية التقليدي من مجرد نقل الموظف من وظيفة في مستوى تتظيمي أدنى إلى آخر أعلى على أساس الأقدمية

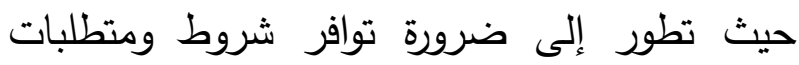
ومقومات نجاح الوظيفة الأعلى فيمن يرقي إليها.

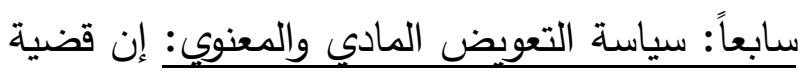

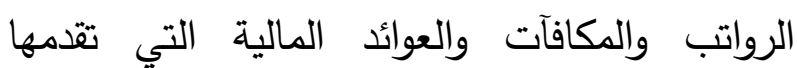
المنشآت أو المنظمات تمثل عنصرا حاكما في نجاح أو فثل خطط تتمية وحسن استخدام الموارد البشرية بالإضافة إلى أهمية التعويض المعنوي للعاملين مثل

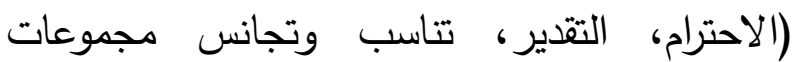

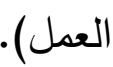
القضايا الإستراتيجية في إدارة وتنمية الموارد البشرية: - (البة ا ـ زيادة الاعتماد على التكنولوجيا الحديثة. r r. التغيرات في تركيب القوي العاملة. r. بـ المع المعلومات في الأفراد. ع. تغير القيم والاتجاهات. ه. العائد والتعويض المادي للعاملين. 7. آـ زيادة حجم القوي العاملة.

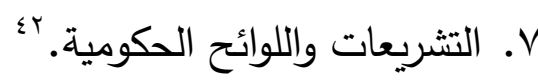
أثر تكنولوجيا المعلومات على تنمية أداء الموارد

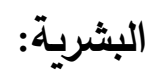
تعدّ تكنولوجيا المعلومات اليوم، من أهم أسباب تحفيز المنظمات التي تسعى للتميز وخوض المنافسة

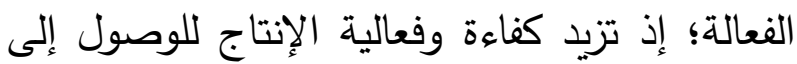
مخرجات مرضية ومطابقة لأهداف هذه المنظمات؛ rألبرت سيف حبيب، تتمية الموارد البشرية، 11. 


\section{تكيف الموارد البشرية لتكنولوجيا المعلومات:} أصبحت الفترة المعاصرة التي تعيشها المنظمات،

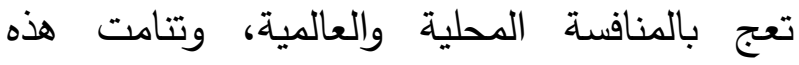
المنافسة، وظهرت تزامنًا مع الثورة المعلوماتية، وثورة

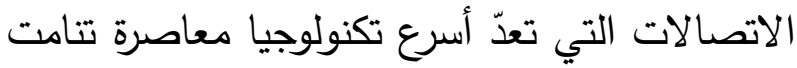

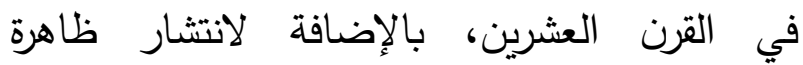
العولمة، الذي ضاعف الحاجة لوجود كفاءات بشرية تُحسن استغلال التكنولوجيا المعلوماتية وفي مجال

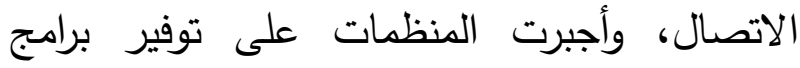
تطويرية للموارد البشرية، لأنّ المنظمات تُعاني في تُوني

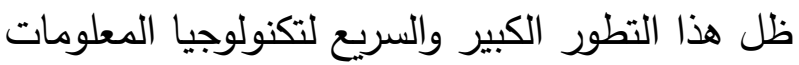
من ندرة وجود عناصر بشرية قادرة على تشغيلها وتحليلها وبرمجتها، وعليه لزم على المنظمات الاهتمام بما لديها من عناصر بشرية قادرة على ولى

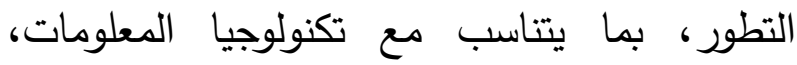

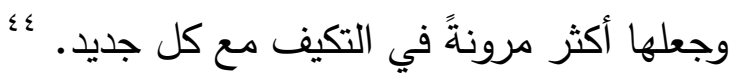
تأثر أداء الموارد البشرية بتكنولوجيا المعلومات: يوجد في المنظمات العديد من مستويات الأداء فيها؛

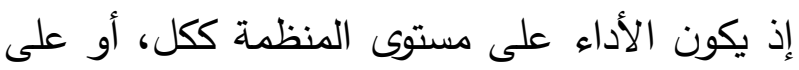

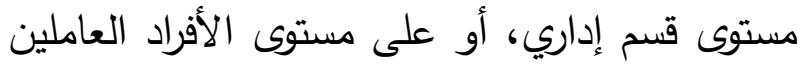

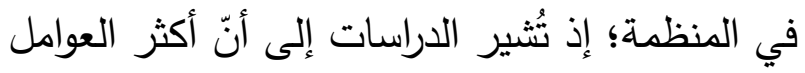

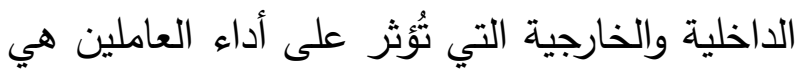
عوامل فنية، الذي يعذّ التقدم التكنولوجيا من أهمها

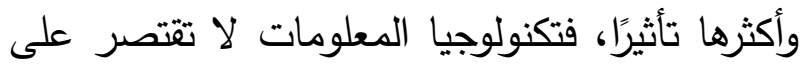
استخدام الحواسيب الثخصية المتصلة مع بعضها

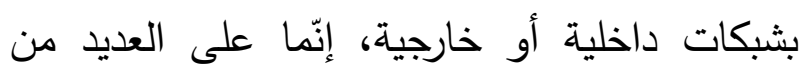

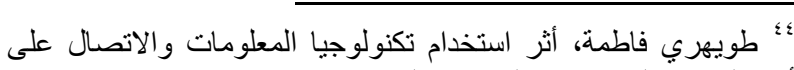

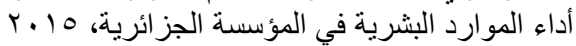

هنتت تكنولوجيا المعلومات من البيئة التنظيمية للمنظمة عمومًا، أيّ أنّ العملية الإدارية برمتها،

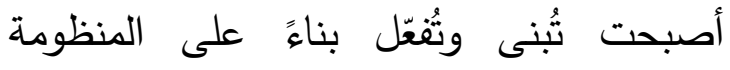
المعلوماتية في المنظمات. ساهمت تكنولوجيا المعلومات في رفد المنظمات بمعارف ومواد تعليمية، يسهل الوصول إليها، سواء كانت موجودة على شبكاتها الداخلية أو الثبكات العالمية، وبالتالي عززت قدرة المنظمة في صياغة أهدافها وتحقيقها على المدى البعيد، وضمان البقاء والنمو والاستمرار -

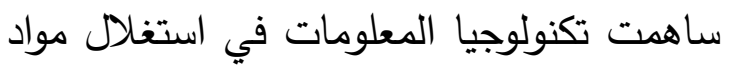
المنظمة البشرية، لتوليد مخرجات دقيقة خالية من التفاوت فيها، ممّا أدى إلى تقليل التباين في لئي الأداء الخاص بالسلع أو الخدمات المقدمة.

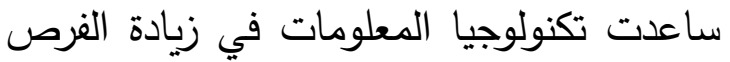
المتاحة للمنظمات في الأسواق المحلية والعالمية، فمنحت مواردها البشرية القدرة على الانى التأقلم مع هذه الفرص، وزيادة خبراتهم. فرضت فئت تكنولوجيا المعلومات وجود برامج تدريبية، ترفع قدرة العاملين باستمرار؛ إذ تُعدّ البرامج التدربيبة في عصر المعلومات؛ استثمارًا وليس تكلفة. أصبحت درجة التحكم في التكنولوجيا مؤشرًا

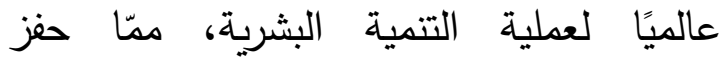
المنظمات التي تسعى إلى تطوير مجالها، من خلال البرامج التدريبية المكثفة، وضعها ضمن لإنير هن تقييم الأداء الخاص بالعاملين في المنظمة، وبمستوياتهم ومراكزهم المختلفة. 
r. مدى تشجيع أفراد المؤسسة لمواجهة المخاطر

$$
\text { واكتساب الخبرة. }
$$

ع. التغذية الراجعة المعطاة للعاملين لجعلهم على والى

وعي بنقاط القوة والضعف لديهم.

○. توفير مناخ عام من الثقة في المؤسسة.

7. الثقة في قدرت الأفراد والعاملين.

V . مدى رغبة العاملين في التعاون ومساعدة

$$
\text { بعضهم البعض. }
$$

^. إشاعة روح الفريق بين أفراد المؤسسة.

9 ـ الرغبة في تثبيط الأفكار المسبقة والوساطة.

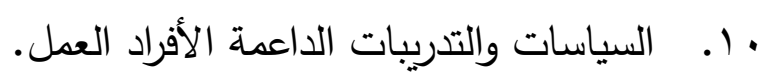
وبذلك يتجلى جوهر مناخ تتمية الموارد البشرية في

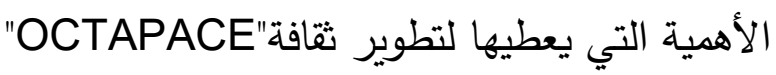
في المؤسسة والتي تشير إلى ثمانية قيم ترمز إلى:
الآلات والأجهزة التي تستخدم تكنولوجيا المعلومات في إنتاجها. فلسفة تنمية الموارد البثرية بالجامعات: تتبثق الفلسفة التي تقوم عليها تتمية الموارد البشرية بالجامعات من التحديات التي تقف حائلا أمامها لتنمية مواردها البشرية، حيث أن التحدي اليوم أمامها

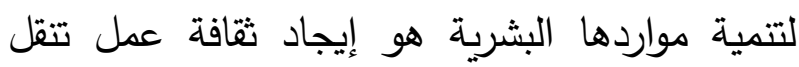

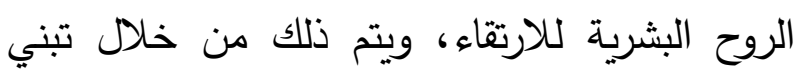
بعض سياسات التتمية البشرية، ودعم مناخ تتمية

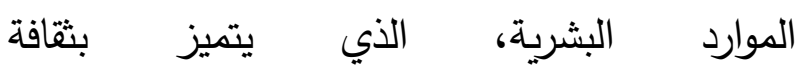
"OCTAPACE" المناخ المؤسسي، وتعرف هذه الثقافة بمدى قدرة

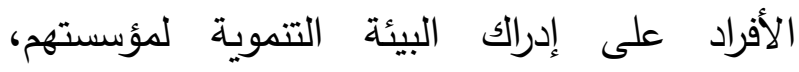
وتتضمن عددا من الخصائص هي: ا ـ. مقدار الأهمية المعطاة للموارد البشرية. r. ددى انفتاح عملية الاتصال بين أفراد المؤسسة.

$$
\text { المؤشر }
$$

القيمة

$$
\text { التعرف على مشاعر الفرد. }
$$

الانفتاح

مواجهة المشكلات وإيجاد حلول لها. الثقة المشتركة. المواجهة الثقة

$$
\text { الرغبة في معرفة مشاعر الفرد. }
$$

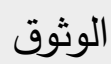

رغبة المؤسسة في السبق في التأثير على الموقف، ولليس مجرد التفاعل معه. التأثير

درجة لجوء الفرد إلى طلب المساعد من الآخرين دون الثعور بتقليل الذات.

الاستقلال

$$
\text { الأعضاء العاملين في فريق. }
$$

التعاون

القيام بالعمل على أساس التجربة بشكل فيقاء أساسي.

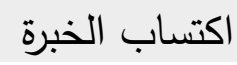


V. تحقيق الفعالية المؤسسية، وذلك عن طريق أداء العمليات الأكثر مناسبة أو ملائمة وأخذ أفضل فولئل

$$
\text { القرارات الممكنة. }
$$

الآليات المتبعة لتحسين إنتاجية الموارد البشرية

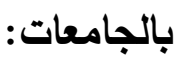

ا. إنشاء قاعدة معرفية بكل جامعة تخدمها شبكة

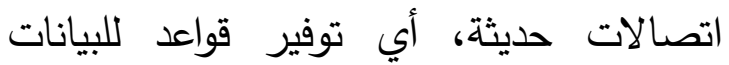

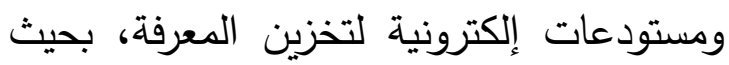

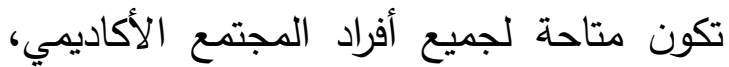
وتكون ذات بنية تنظيمية فائقة تيسر الحصول

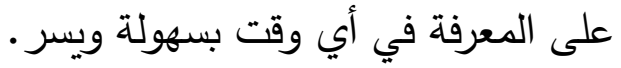
r. استحداث نظم اتصال فعالة بين الجامعات

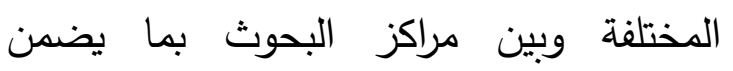
التكامل وعدم التكرار للموضوعات. r. تبني ثقافة تتظيمية بالجامعة تشجع أعضائها في جميع التخصصات على مشاركة المعرفة

وتبادلها بشكل فعال، وتكافئ من يملكها. 9. مبريلت تنمية الموارد البشرية بالجامعات: تعزى تتمية الموارد البشرية بالجامعات إلى عدة

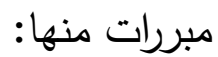

ا. النمو المعرفي في مئ فيع التخصصات والمجالات، مما يتطلب ضرورة متابعة الأفراد للتطورات العمية في مجال تخصصهم من أجل •. الارتقاء بمستوى أدائهم.

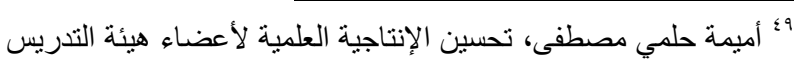

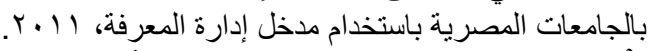

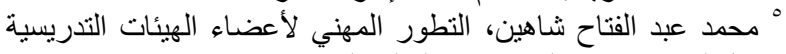

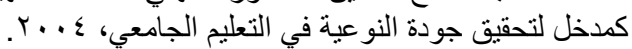

ويتضح مما سبق أن ثقافة "OCTAPACE" تعد مطلبا أساسيا للمؤسسة الفعالة، ومناخا أكثر دعما لنجاح برامج تتمية الموارد البشرية، حيث يجلب

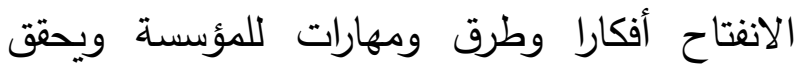
الرضا، ويقدم التعاون والقوة للمؤسسة لكي تعمل وتواجه المشكلات وتعمل على حلها، والاستقلالية وخوض التجربة تمنح الأفراد فرصة للابتكار ، وهكذا.

الأهداف التي تدعمها تنمية الموارد البشرية بالجامعات ما يلي: ا. دعم العدالة، من خلال توفير الفرص المتكافئة

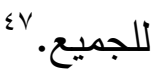
r. دعم الديمقراطية وما تفجره من طاقات الإبداع والتحرر والمشاركة.

r. دعم الإنتاجية، عن طريق ترشيد استهلاك

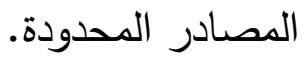

ع. دعم التتمية المستدامة، عن طريق تأمين قدرات

$$
\text { وطاقات ومصادر لأجيال لم تولا بعد. }
$$

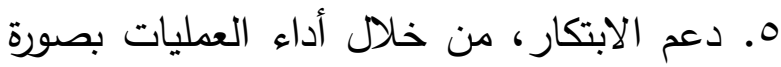
مبدعة وحديثة، مما تؤدي إلى تحسين الفعالية

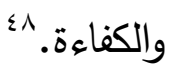

7. زيادة الكفاءة عن طريق أداء العمليات بسرعة وبأقل تكلفة.

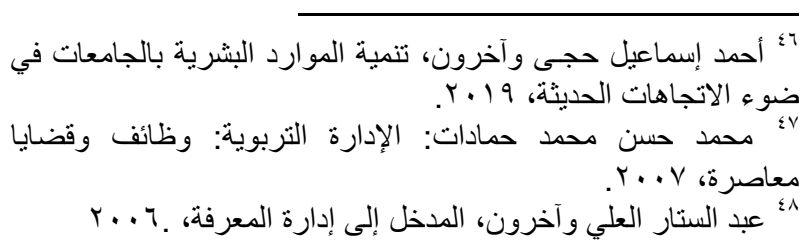


ـ. حاجة الجامعات لتأهيل القوى البشرية، وإعدادها

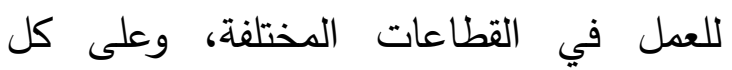
المستويات، من أجل: - المبل

التزويد بالمعارف والمهارات والقيم اللازمة للعمل المستهدف.

V. حاجة معظم الجامعات إلى دعم برامج "جودة

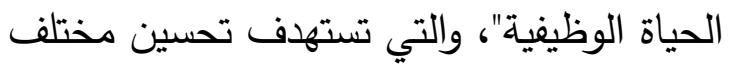
الجوانب التي تؤثر على الحياة الوظيفية للعاملين وحياتهم الشخصية أيضا، والتي تساهم بدورها في تحقيق الأهداف الإستراتيجية

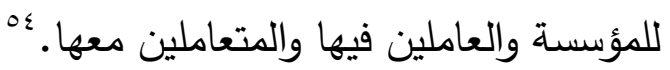
أثر استخدام تكنولوجيا المعلومات على تنمية أداء الموارد البشرية في كلية الآداب والعلوم الإنسانية:

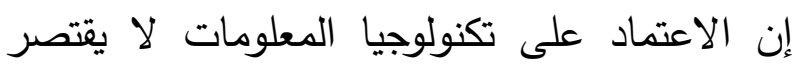
أثره على وظيفة واحدة من الوظائف الإنى الإدارية

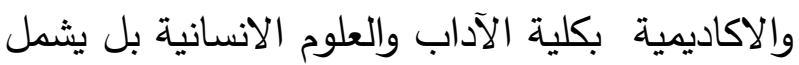

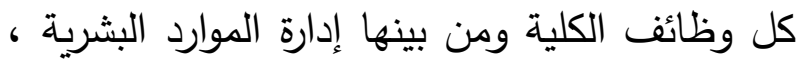

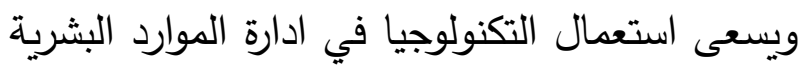
بالكلية قصد تحسينها بالإدارة الالكترونية للموارد البشرية .حيث تمس تكنولوجيا المعلومات كل وظائف إدارة الموارد البشرية بهدف تطويرها وخدمة اهداف الكلية ، إذ تتغير المهام الى الكترونية : التخطيط الإكتروني ، التوظيف الإكتروني، التعليم

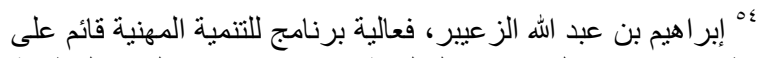

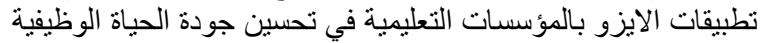

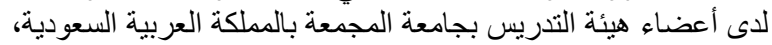

r. تزايد أعداد الطلبة بمؤسسات التعليم العالي خلال العقود الثلاثة الماضية في مختلف أنحاء

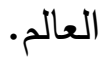

r. تحدي جودة النوعية في التعليم العالي، والذي أصبح يشكل تحديا يواجه المسئولين والقيادات

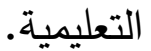

التتمية للتعايش مع العصر التقني وتطوير وسائله قوميا، ويتطلب هذا التركيز على العلوم الطبيعية، النظرية والتطبيقية، وتمكين التعليم

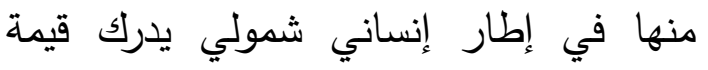
العلوم والمعارف الأخرى. ه. حاجة الجامعة إلى ربط العملية التعليمية داخلها بالتدريب في مواقع الإنتاج ومجالات التطبيق

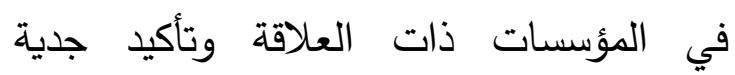
التدريب وإدماجه في صلب المناهج الدراسية، وتقويم أدوار الطلاب، وتحديد انجازاتهح لمتطلبات الحصول على الدرجة العلمية.

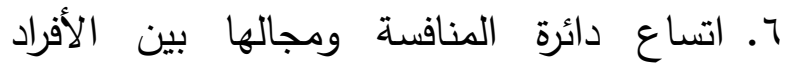
والجامعات بفعل العولمة- وهذا يفرض على نظم التعليم بها إعداد أفراد قادرين على التنافس

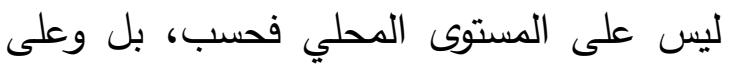

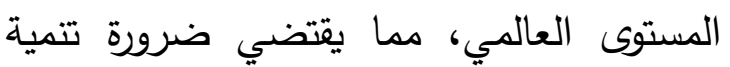
كافة العاملين بها، لتطوير أدائهر.

اه مجدي عزيز إبراهيم، رؤى مستقبلية في تحديث منظومة التعليم،

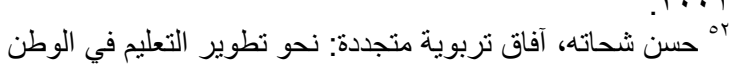

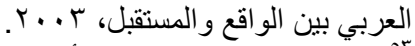

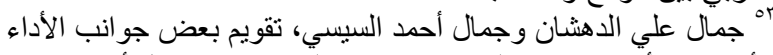

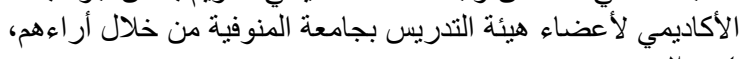


دائرة المنافسة سريعاً لعدم توفر الخطط المستقبلية او

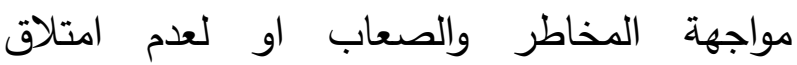
المعلومات في الوقت والزمن المطلوب. ولذلك سعت

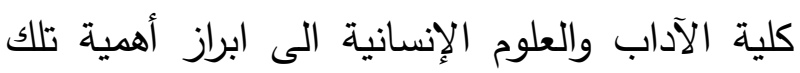

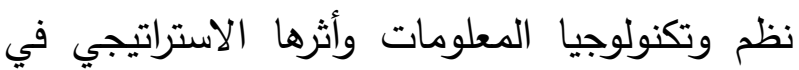
اداء وتتمية الموارد البشرية. الاراسات السابقة

اولاً: الدراسات العربية: العابة

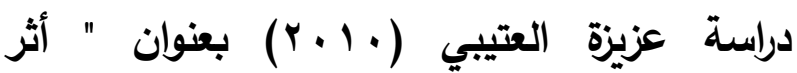
استخدام تكنولوجيا المعلومات على أداء الموارد البشرية دراسة ميدانية على الأكاديمية الدولية

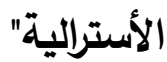

"تهدف هذه الدراسة إلى التعرف على أثر استخدام

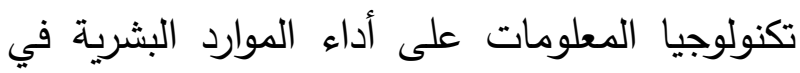
الأكاديمية الدولية الأسترالية في ملبورن، وأثر ذلك الك الكاء

$$
\text { على الأداء الوظيفي. }
$$

وتهدف الدراسة أيضا إلى التعرف التهاء على أنظمة

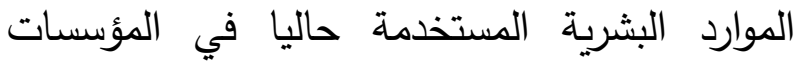
التعليمية، وأنظمة الخدمات التعليمية الإكترونية لما لماليها لها من دور كبير في التوجه نحو استخدام التكنولوجيا في إدارة الموارد البشرية. وقد تكون مجتمع الدراسة من المستويات الإدارية

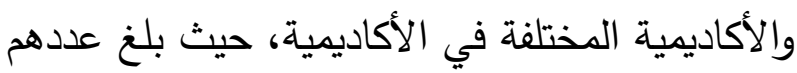
نحو (VY) موظفا، واستخدمت الباحثة استبيان مكون من Vr فقرة كأداة للدراسة، والمنهج الوصنفي المسحي من خلال استخدام أسلوب دراسة الحالة لتحقيق أهداف الدراسة.
الالكتروني ،المعاملات الإلكترونية، والتدريب

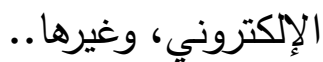
حيث كانت المؤسسات التعليمية ولازالت هي مقياس تطور الأمم وأسباب نهضتها وتقدمها حيث انها تضم النخب من رجال العلم الذين حملوا على عاتقهم نشر العلم والوعي والارتقاء بمستوى المجتمع في كافة المجالات العلمية والمعرفية ويعتمد نجاح هذه في ولئي المؤسسات على الإمكانيات الحديثة وراس المال

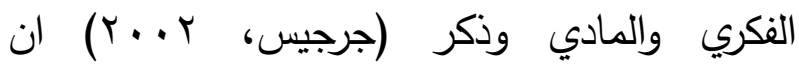
المشاركة في عصر المعلومات لا تحتاج الى قاعدة إنتاجية واسعة او راس مال ضخم او ثروات طبيعية

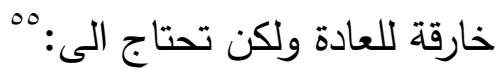
1. اعداد برامج مكثقة لنشر ثقافة الحاسب الى الآلي

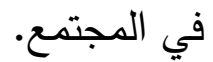
r. تدريب عدد من الخبراء المتميزين في وسائل التعامل مع المعلومات.

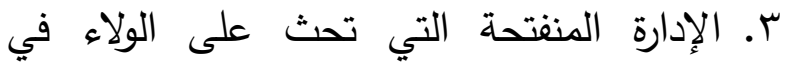

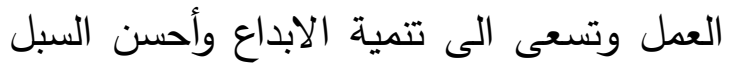
في استخدام التكنولوجيا الحديثة. مما سبق يبدو جلياً أن لتكنولوجيا المعلومات دوراً حيوياً في احداث تغيرات إيجابية على ادارة تنمية ليكان الموارد البشرية، من خلال تقليل التكاليف، وزيادة الاتصالات، وتسهيل إجراءات العمل، تحصيل المعلومات الدقيقة والمفيدة واستعمالها في القرارات باستقلالية، الثي الذي بدوره يرفع من ادائها، وبالتالي يحسن من ادارتها ويجعلها لا تخرج من لنائن

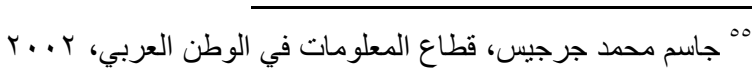


ولقد توصلت الدراسة إلى العديد من النتائج نورد

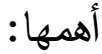

وجود علاقة ذات دلالة إحصائية عند مستوى لهات

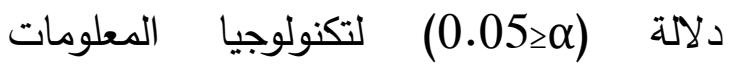
(المكونات المادية، والموارد البشرية، والبرمجيات، وقواعد البيانات، والثبكات) في ولئية

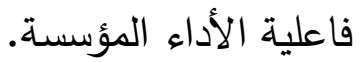

وجود علاقة ذات دلالة إحصائية لتوظيف تكنولوجيا المعلومات (البرمجيات، وقواعد البيانات، والثبكات) على رضا العاملين.

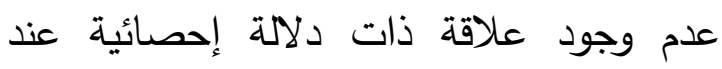

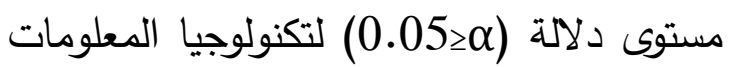

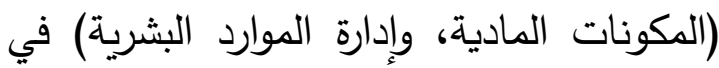
تحقيق رضا العاملين بأجهزة الخدمة المدنية. ولقد أوصت الدراسة بالعديد من التوصيات كما بالهرة لخدهانهان يلي:

ضرورة العمل على مواكبة أحدث ما توصلت إليه تكنولوجيا المعلومات والعمل على تطبيقه في الأجهزة الحكومية. ضرورة العمل على تطوير البرامج والأجهزة

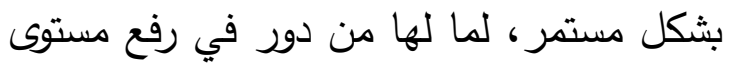
أداء الأجهزة الحكومية. العمل على تدريب العاملين في الأجهزة الحكومية على كافة البرامج والأجهزة، لما لذلك الكين من أثر إيجابي على تحسين ورفع مستوى الأداء." - من اتر
وقد قمت هذه الدراسة إلى ثلاثة فصول ومقدمة، وقد تتاول الفصل الأول الحديث عن طبيعة عصر المعلومات ومفهوم تكنولوجيا المعلومات الحديث، والتطرق للحدث عن الثبكات المعلوماتية وجاء الفصل الثاني موسوماً ب " متطلبات الموارد

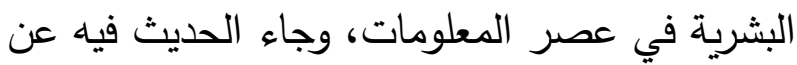
ماهية إدارة الموارد البشرية، وكذلك الحديث عن نظم

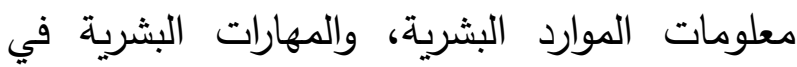
عصر المعلومات. أما الفصل الثالث: أثر استخدام تكنولوجيا المعلومات

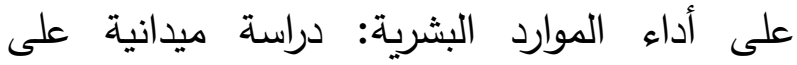

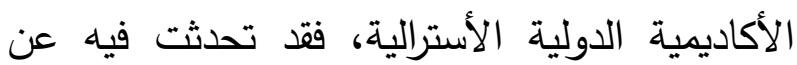
الأكاديمية الدولية الأسترالية، وعن الهيكل التنظيمي لالتئ،

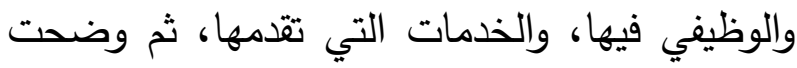
منهجية الدراسة الإحصائية وتفسير نتائجها، لأختتم هذا الفصل في إبراز أهم النتائج التي توصلت إلئية الدراسة والتوصيات المقترحة"

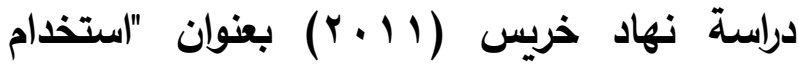
تكنولوجيا المعلومات وأثرها في الأداء في أجهزة الخدمة المدنية في الأردن" "هدفت الدراسة إلى التعرف على أثر تكنولوجيا المعلومات في الأداء المؤسسي في أجهزة الخدمة المدنية في الأردن. ولقد تكون مجتمع الدراسة من الادي العوني

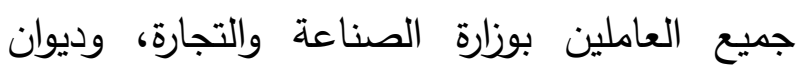
الخدمة المدنية، وزارة الاتصالات وتكنولوجيا المعلومات، والأحوال المدنية بمستوياتهم الإدارية ولكاتية العليا والوسطى، وبلغت عينة الدراسة سل ال موظفا وموظفة في أجهزة الخدمة المدنية ولغنية 
الإداريين العاملين على استخدام أدوات تكنولوجيا

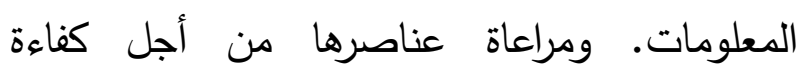
وفاعلية الأداء في المؤسسة.

توصي الدراسة أيضا بضرورة استخدام تكنولوجيا المعلومات في جميع شركات الكقاولات والبناء السوداني وضرورة العمل بمفهوم التغيير التتظيمي.

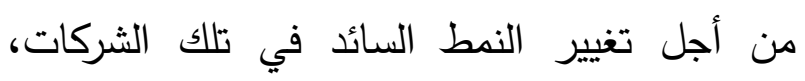
وتغيير الاسلوب التقليدي في أداء جميع الأعمال الإدارية والاهتمام بالكوادر البشرية وتطوير مهاراتهم.

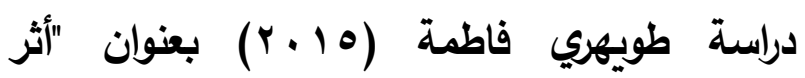
استخدام تكنولوجيا المعلومات والاتصال على أداء الموارد البشرية في المؤسسة الجزائرية - ـراسية حالة شركة انتاج الكهرباء بتيارت-"

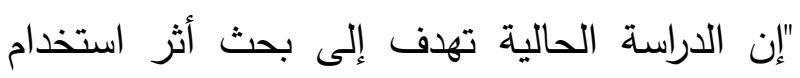

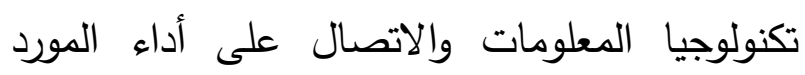
البشري لاى شركة إنتاج الكهرباء بتيارت بالاعتماد

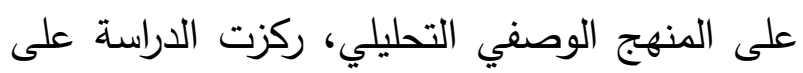

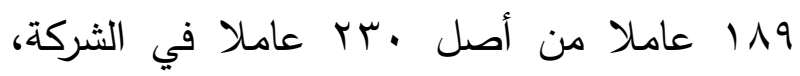

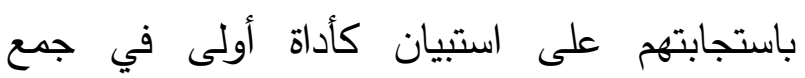
البيانات، وتدعيما لتلك استعنا ببطاقة فنية للشركة لتحديد مدى اعتمادها على تكنولوجيا الجديدة. وبعد

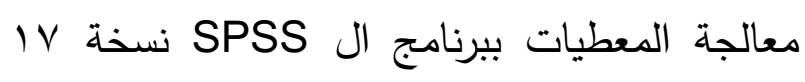
توصلت النتائج الى ما يلي: التئي 1. يعد استخدام تكنولوجيا المعلومات والاتصال شركة إنتاج الكهرباء بتيارت العامل المحفز في الأهات تتمية قدرات المورد البشري وتحسين أدائه.

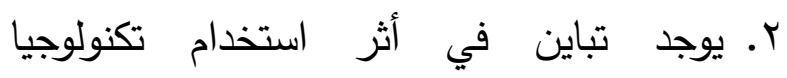
المعلومات والاتصال في أداء المورد البشري في

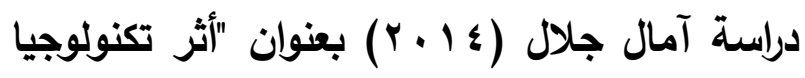

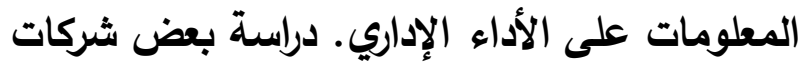
المقاولات والبناء السوداني" الماء الإلي " تهدف هذه الدراسة إلى التعرف على أهمية

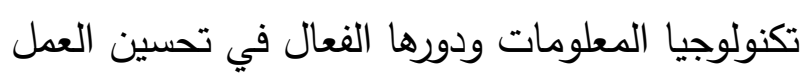
الإداري في الثركات الخدمية في السودان. وأثر الثران

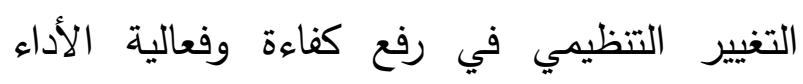
الإداري، ولقد تم اتباع المنهج الوصفي التحليلي في هذه الدراسة، وتم جمع بيانات للاراسة الميدانية الدانية بواسطة الاستبانة التي صمدت بناء على مقاييس

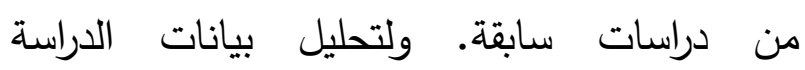

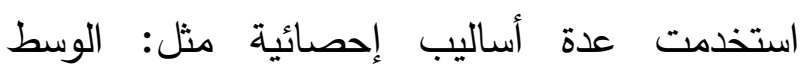
الحسابي، والانحراف المعياري، والتكرار، ومعامل الفاكرونباخ، واسلوب التحليل العاملي، و ومعامل ارتباط بيرسون، والانحراف الدتعدد. وتمثل مجتمع الإني الدراسة من الإدارة العليا في شركات الدقاولات والبناء السودانية بالعاصمة الخرطوم.

توصلت الدراسة لعدة نتائج أهمها وجود علاقة إيجابية بين مكونات تكنولوجيا النظم الدحوسبة وعناصر الأداء الإداري (الفاعلية والكفاءة). كما لئات بينت الدراسة بأن هناك علاقة الإدابية الإبية بين توجاه الإدارة العليا وبين العمل الإداري كما أشارت نتائج الدراسة بأن عملية التغيير التنظيمي لها أكبر الأثر الثاري في تحسين الأداء الإداري وكسب ثقانة العملاء.

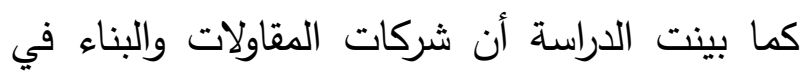

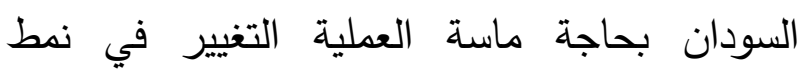
وسلوك الأداء الإداري من أجل التحسين المستمر.

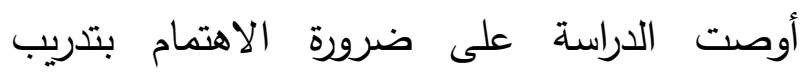


البحث بتوضيح أن درجة تأثير تكنولوجيا المعلومات

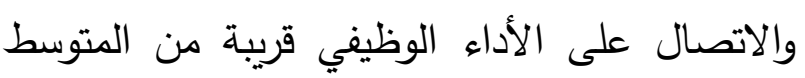

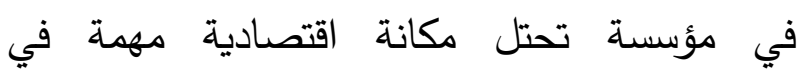

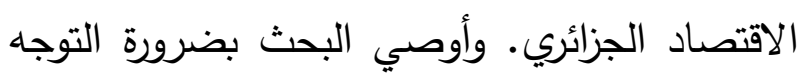

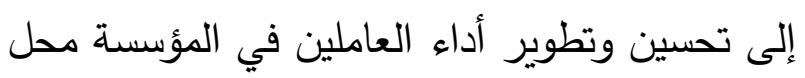
الدراسة عن طريق حملة توعية بضرورة استخدام تكنولوجيا المعلومات والاتصال في أداء مهامهح. وضرورة إخضاع العاملين لدورات تدريبة متخصصة

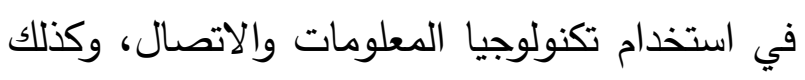

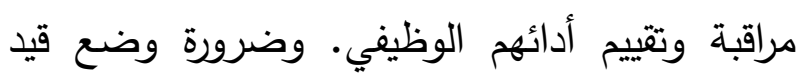

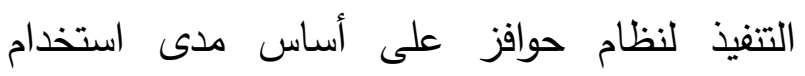
العاملين لتكنولوجيا المعلومات والاتصال في أداء مهامهم الوظيفية."

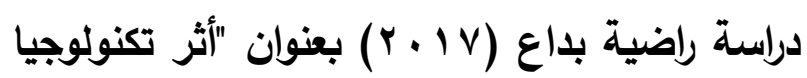

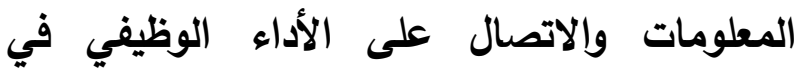
المؤسسات الصغيرة والمتوسطة: حالة مؤسسة رغوة الجنوب - تقرت "تهدف هذه الدراسة إلى التعرف على لجى مدى تأثير

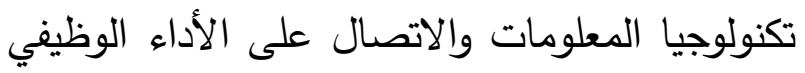

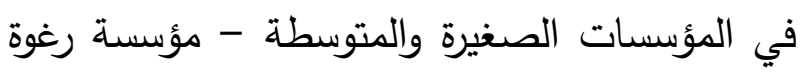
الجنوب - تقرت، ورقلة - ولتحقيق أهداف الدراسة

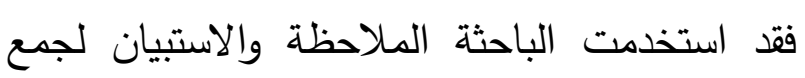
البيانات والمعلومات. واقتصرت عملية التوزيع على أسلوب العينة القصدية

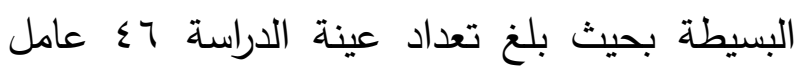
من المؤسسة. تم تحليل البيانات الواردة في تلعين الاستبيانات عن طريق استخدام الحزمة الاحصائية

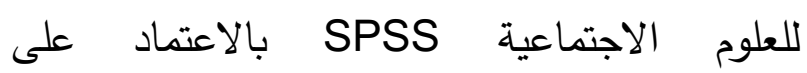

الثركة وفقا لـتغيري الجنس والمستوى التعليمي، لصالح كل من الذكور وحاملي شهادة ليسانس وعدم وجود الأثر على الأداء بالنسبة لألية للأقدمية والدرجة الوظيفية r. توجد علاقة وطيدة بين التدريب على استخدام التكنولوجيا وأداء المورد البشري في شركة إنتاج الكهرباء بتيارت. ـ. لشركة إنتاج الكهرباء بتيارت نظرة مستقبلية تحمل في طياتها جملة من التحديات والتطلعات

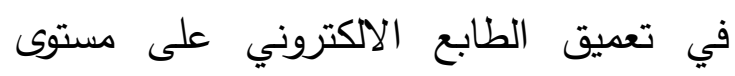
جميع إداراتها."

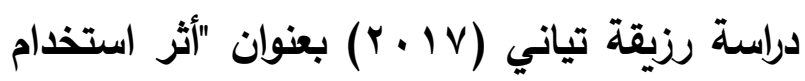

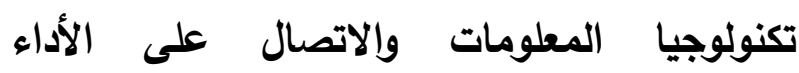
الوظيفي: دراسة حالة مؤسسة نفطال، الجزائر" "هدف البحث إلى "دراسة أثر استخدام تكنولوجيا

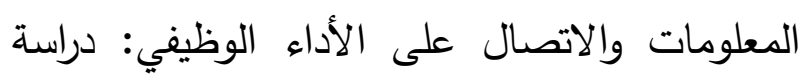

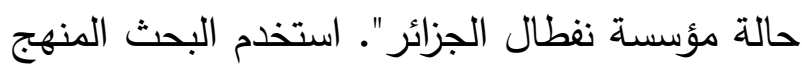
الوصفي والتحليلي. تكونت أداة البحث من استبيان

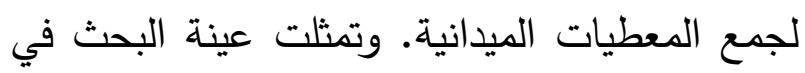
الإطارات العاملة في مؤسسة نفطال بالجزائر العاصمة. وتتاول البحث عدد من المحاور الرئيسية

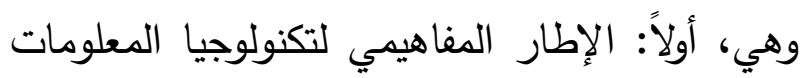
والاتصال وعلاقته بالأداء الوظيفي من خلال، مفهوم الإلئي تكنولوجيا المعلومات والاتصال، أهمية استخدام تكنولوجيا المعلومات والاتصال، أبعاد تكنولوجيا المعلومات والاتصال. ثانياً: مفهوم وأبعاد الأداء الوظيفي من حيث، تعريف الأداء الوظيفي، أبعاده

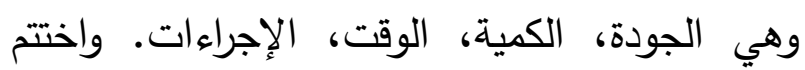


تكنولوجيا المعلومات وأساليب الموارد البشرية في

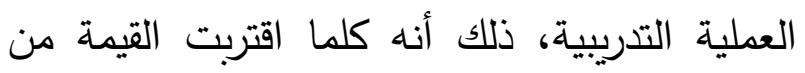
. . . . . ل

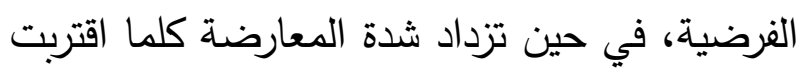
القيمة من •,, ·. كما توصل البحث إلى أن أفراد العينة يقرون بأن هناك صعوبات تعرقل استخدام تقنيات المعلومات المختلفة لدى كثير من الأفراد؛

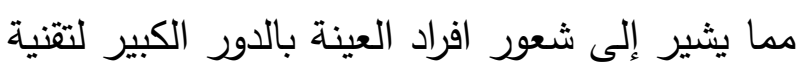
المعلومات في حياة الفرد العلمية والعملية." دئل

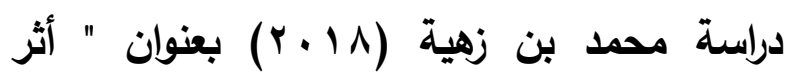
استخدام تكنولوجيا المعلومات في تنمية رأس المال البثري: دراسة حالة مؤسسة كوندور - بيرج

"بوعربريج"

"يهدف هذا البحث إلى دراسة أثر تكنولوجيا المعلومات (الأجهزة والمعدات. البرامج. قواعد البيانات والثبكات) على تتمية رأس المال البشري

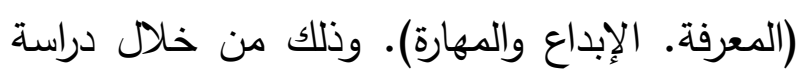

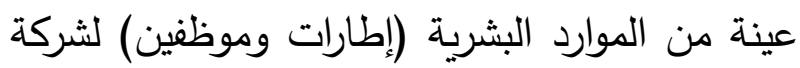
كوندور ببرج بوعريريج. خلصت الدراسة إلى أن الن النئ إلى

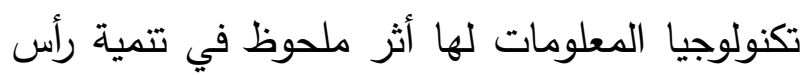
المال البشري من خلال أبعاده الثلاثة." ثانياً: الدراسات الأجنبية:

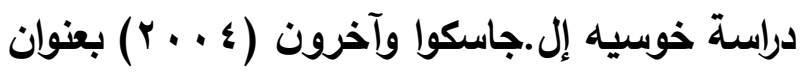
" استخدام تكنولوجيا المعلومات في تدريب الموارد البشرية - دراسة حالة التعلم الإكتروني"

Jose' L. Gasco \& Others (2004) study entitled " The use of information technology in training
المتوسطات الحسابية، الانحرافات المعيارية، ومعاملات الارتباط، وتحليل الانحدار الخطي لإتيطي وخلصت الدراسة لعدد من النتائج أهمها: أن مؤسسة رغوة الجنوب تطبيق تكنولوجيا المعلومات

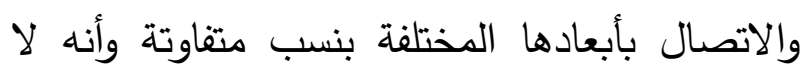
يوجد مستوى جيد للأداء الوظيفي في المؤسسة محل الدراسة، كما أنه توجد علاقة ارتباطية بين استخدام

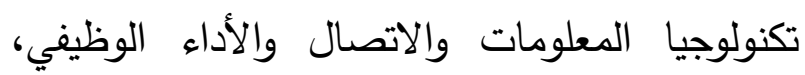
وكذا عدم وجود فروق ذات دلالة إحصائية في درجة

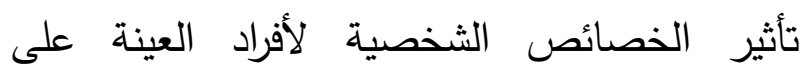
اجاباتهم حول مستوى الأداء الوظيفي."

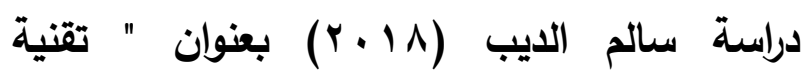
المعلومات ودورها في تنمية الموارد البشرية لوائ "بجامعة المرقب" "هدف البحث إلى الكثف عن تقنية المعلومات ودورها في تتمية الموارد البشرية بجامعة المرقب. وتكمن أهمية البحث في التعرف على أثر تكنولوجيا

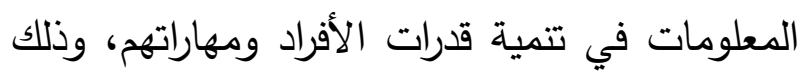
من خلا استخدام الأساليب الحديثة التي توفرها وسائل تقنية المعلومات المختلفة، والمساهمة في دعم

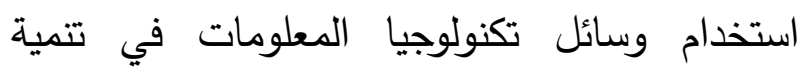
الأفراد من خلال التعرف على المشاكل التي تعرقل

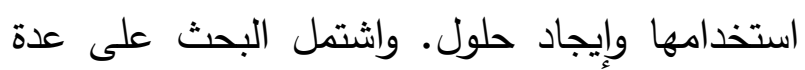
نقاط جاءت على الترتيب بعنوان: مفهوم تكنولوجيا

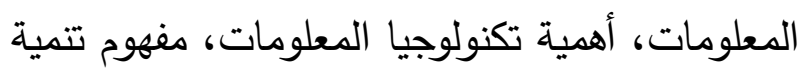

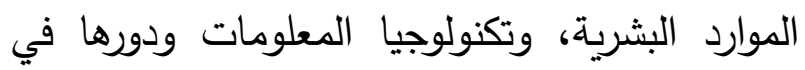
تتمية الموارد البشرية. وتوصل البحث إلى أن أفراد

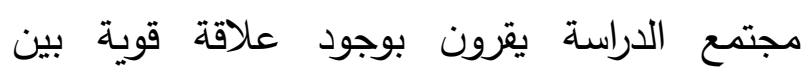


فهمت غالبية المنظمات الآن أهمية تخزين

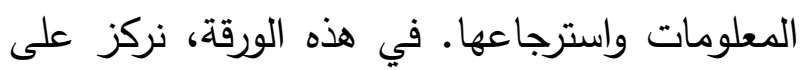

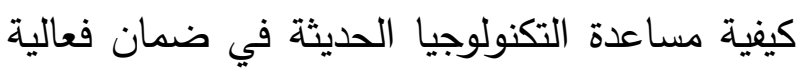
وظائف الموارد البشرية. يعد نظام معلومات الموارد

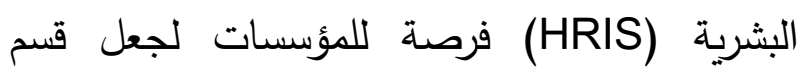
الموارد البشرية إداريًا واستراتيجيًا تشاركيًا في تشغيل فئل المؤسسة. الهذف الرئيسي هو فهم مدى استخدام

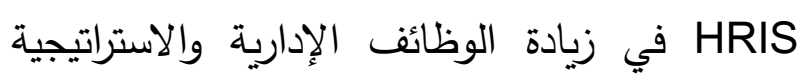
لقسم الموارد البشرية. لهذا الغرض، أجرينا دراسة الإدائة الاستراتية

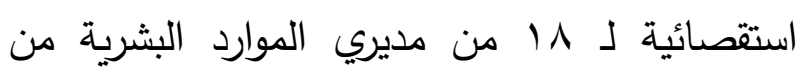

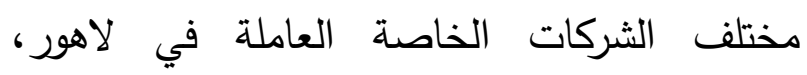

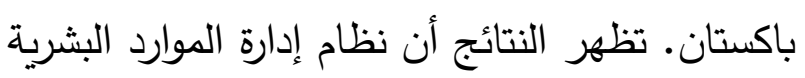

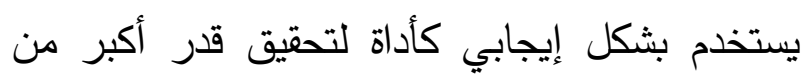
الكفاءة الإدارية من خلال إضافة قيمة في القسم. ومع ذلك، فإن جميع فوائدها صعبة. لا يزال لم يتم

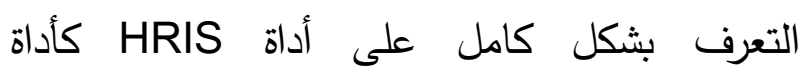

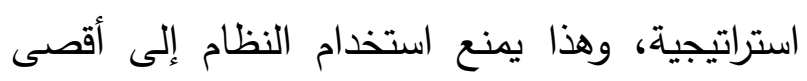

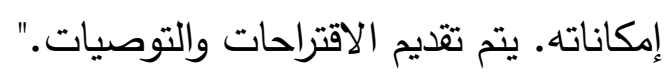

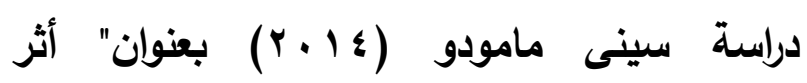
تكنولوجيا المعلومات في إدارة الموارد البشرية" دولئية Seyni Mamoudou (2014) study entitled " Impact of Information Technology in Human Resources

\section{Management"}

يدرك كبار القادة تمامًا قوة أدوات تكنولوجيا المعلومات للوصول إلى أهداف العمل. لا يساعد

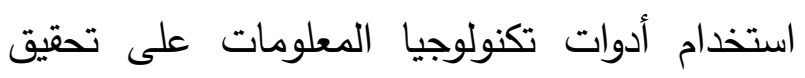
أهداف الشركة المحددة فحسب، بل يساعد على لكئ human resources an e-learning case study "

"تتناول هذه الورقة تأثير تكنولوجيا المعلومات في

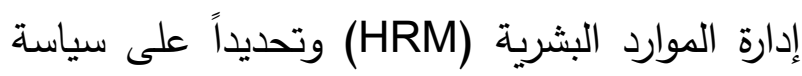
التدريب من خلال تجربة شركة اتصالات إسبانية (Telefonica) التدريب الذي صممته هذه الشركة لمواجهة بيئات جديدة ويتم اكتثاف التقنيات المستخدمة والإجراءات الرئيسية والعيوب وعوامل النجاح في محاولة تنمية

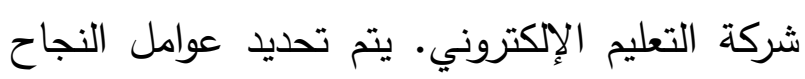
في سياسة التدريب. وتشمل هذه المرونة في إدارة الوقت للتدريب؛ المشاركة الفعالة للمدربين؛ إنشاء

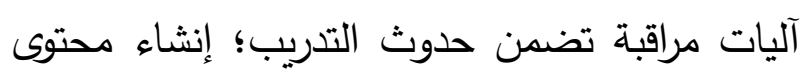
عالي الجودة؛ تعزيز العناصر التفاعلية بين المدربين والطلاب ومع بعضهم البعض؛ استخدام التقنيات

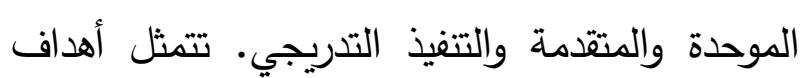
الثركة للمستقبل في الحفاظ على التقدم في استخدام التعليم الإكتروني كوسيلة لتكييف العملية التدريبية مع ثقافة الأعمال الإلكترونية الجديدة."

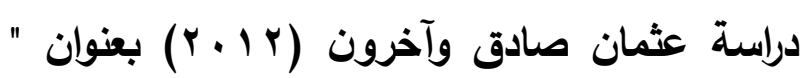

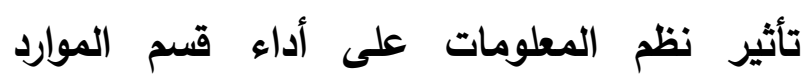
البشرية"

Usman Sadiq \& Others (2012) study entitled " The Impact of Information Systems on the Performance of Human Resources Department" " بسبب ثورة تكنولوجيا المعلومات، أصبحت الأنظمة أكثر فاعلية من خلال إدخال تقنيات جديدة. لقد 
النهاية، كثفت مجموعة من الدراسات عن إمكانية تأثير نظم المعلومات سلبًا على الكفاءة الذاتية التهات للموظف. ومع ذلك، لم يتم العثور على أدلة مفاهيمية في الدراسات تشير إلى أن تكنولوجيا

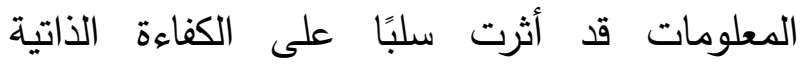

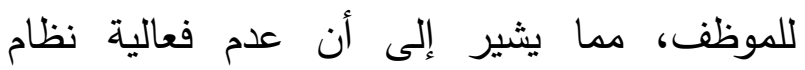
المعلومات قد ينتج عن أتمتة العمليات غير الفعالة."

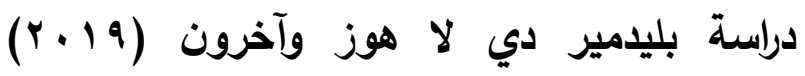
بعنوان "آثار استخدام تكنولوجيا المعلومات

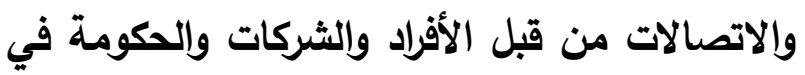
التنمية البشرية: تحليل دولي"

Pladimir de la Hoz- Rosales \& Others (2019) study entitled "Effects of Information and Communication Technology Usage by Individuals, Businesses, and Government on Human Development: An International Analysis"

"تصت دراسة آثار تكنولوجيا المعلومات والاتصالات على التتمية في المقام الأول من منظور مساهماتهاتها

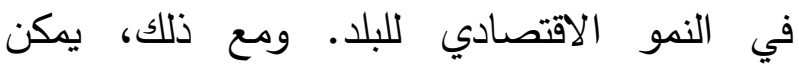
لتكنولوجيا المعلومات والاتصالات أن تقدم للأفراد أكثر من مجرد دخل نقدي، بل يمكنها تحسين العديد

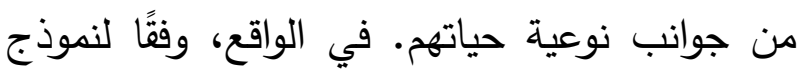
التنمية البشرية، لا يمثل الدخل سوى مورد واحد يساعد الأفراد على تلبية احتياجاتهم الاقتصادية.

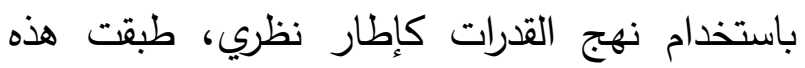
الاراسة تقنية لوحة البيانات على عينة من
تحسين عمليات العمل أيضًا. تؤكد اتجاهات ونتائج

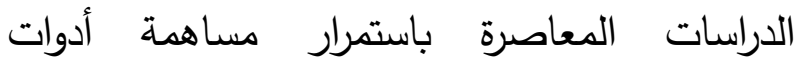
تكنولوجيا المعلومات في مجال الموارد البشرية بالي لإنجاز مهام الموارد البشرية المعينة باستخدام مصدر قدرات تكنولوجيا المعلومات. تقدم الورقة التالية لهحة عامة موجزة عن إمكانيات استخدام تكنولوجيا المعلومات في مجال الموارد البشرية لقياس وتتبع رأس المال البشري واستخدام نظام معلومات الموارد البشرية بشكل عام."

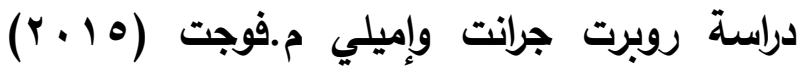

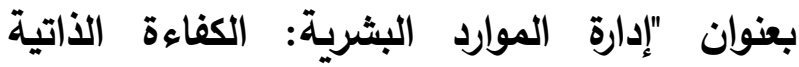
كمحد لفعالية تكنولوجيا المطلومات" Robert Grant \& Emily M. Vogt (2015) study entitled "Human Resources Management: Self-Efficacy as a Determinant of Information Technology Effectiveness"

"تتألف أنظمة المعلومات من الأفراد والعمليات

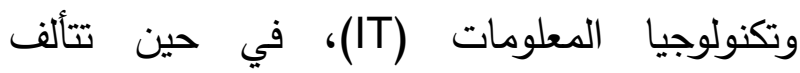
تكنولوجيا المعلومات من الأجهزة والبرامج والبيانات. في هذه الورقة القاء نظرة فقط على تكنولوجيا المعلومات (الأجهزة والبرامج والبيانات) وكيفية استخدامها لتنفيذ عمليات ووظائف محددة في مجال

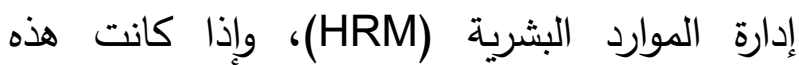
التطبيقات تعتبر فعالة. تم تحديد مفهوم الفعالية من

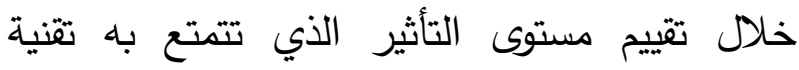
المعلومات على الكفاءة الذاتية للموظف ذات الصلة بإكمال عمليات إدارة الموارد البشرية المحددة. في لهماهي 
الدراسات الاخرى من حيث الهدف العام للدراسة مثل دراسة نهاد خريس (1) (1) التي هدفت الى التعرف على أثر تكنولوجيا المعلومات في الأداء المؤسي في أجهزة الخدمة المدنية في الأردن و و

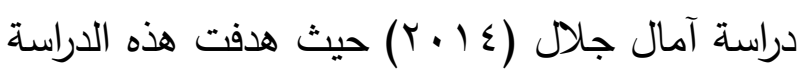
إلى التعرف على أهمية تكنولوجيا المعلومات ودورها الفعال في تحسين العمل الإداري في الثركات الخدمية في السودان ، ودراسة طويهري فاطمة (Y. 10) حيث هدفت إلى بحث أثر استخدام تكنولوجيا المعلومات والاتصال على أداء المورد البشري لاى شركة إنتاج الكهرباء بتيارت ودراسة

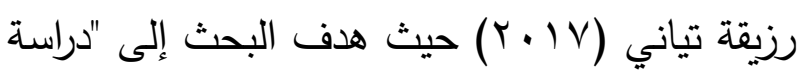
أثر استخدام تكنولوجيا المعلومات والاتصال على رلى لألى الأداء الوظيفي: دراسة حالة مؤسسة نفطال الجزائر ودراسة راضية بداع (Y.IV) حيث هدفت هذه الدراسة إلى التعرف على مدى تأثير تكنولوجيا المعلومات والاتصال على الأداء الوظيفي في المؤسسات الصغيرة والمتوسطة - مؤسسة رغوة الجنوب - تقرت، ورقلة و دراسة محمد بن زهية

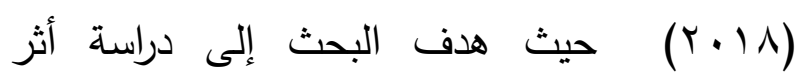
تكنولوجيا المعلومات (الأجهزة والمعدات. البرامج. قواعد البيانات والثبكات) على تتمية رأس المال البشري (المعرفة. الإبداع والمهارة) ودراسة 'Jose'
دولة لاستكثاف كيف يؤثر استخدام تكنولوجيا المعلومات والاتصالات واعتمادها، من قبل الأفراد

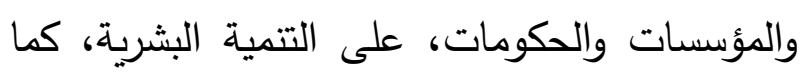
تم قياسه بواسطة مؤشر التقدم الاجتماعي ومؤشر على

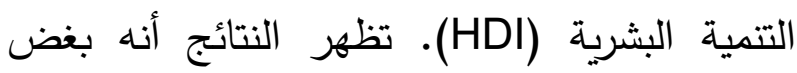
النظر عن مستوى التتمية في أي بلد، فإن الاستخدام الفردي لتكنولوجيا المعلومات والاتصالات لله تأثير إيجابي على التتمية البشرية؛ لا سيما على الأبعاد التي تقاس HDI (حياة طويلة وصحية، أن تكون على دراية، ومستوى معيشة لائق). علاوة على ذلك،

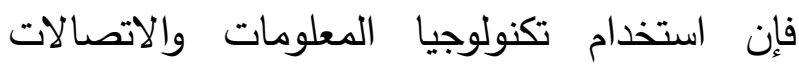
للأغراض التجارية له تأثير إيجابي على التنمية البشرية على المستوى العالمي، ولكن إذا أجرينا التحليل على البلدان المتقدمة فقط، فإن علاقة هذا المتغير بالتتمية البشرية لم تعد مهمة. فيما يتعلق التقان

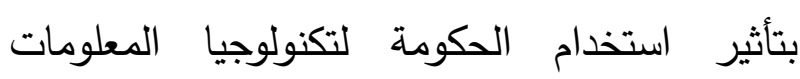

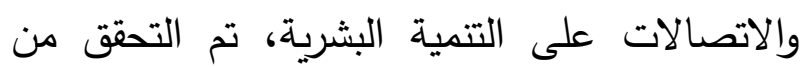
أهميتها بالنسبة للبلدان المتقدمة. يمكن استخدام هذه

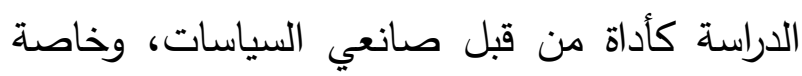
في البلدان النامية، لتعزيز نواياهم لدعم استخدام تكنولوجيا المعلومات والاتصالات وتتفيذها." ثالثاً: التعقيب على الدراسات السابقة: اتفقت الدراسة الحالية مع دراسة العتيبي (• • (ب)

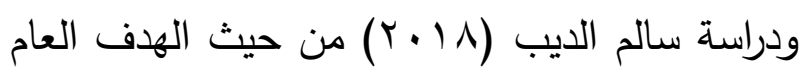
للدراسة ، حيث التركيز على مجال وميدان التعليم الجامعي(الجامعات) وامكانية تطبيق تكنولوجيا المعلومات فيها ، واختلف الدراسة الحالية مع 


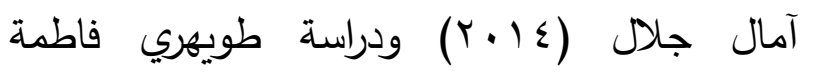

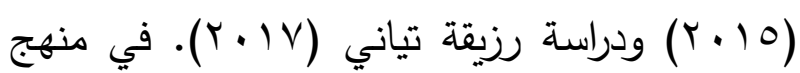
الدراسة حيث انتهجت دراساتهم المنهج الوصفي التحليلي. وقد تم الاستفادة من الدراسات السابقة

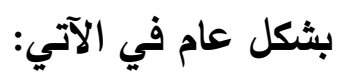

ا ـ وضع الإطار العام للأساس النظري لهذه الدراسة سواء بطريقة مباشرة او غير مباشرة. r. المساعدة في تحديد مشكلة الدراسة وصياغة تساؤلات الدراسة وتحديد مفاهيم الدراسة وتحديد المعالجة الاحصائية اللازمة والتي تتاسب وطبيعة الدراسة بالإضافة للاستفادة من المراجع الواردة فيها. r. الاستفادة من توصيات ونتائج الدراسات السابقة في مناقشة نتائج وتوصيات الدراسة الحالية. ء. الاستناد اليها في تصميم أداة الدراسة

$$
\text { (الاستبانة). }
$$

نبذة تعريفية عن كلية الآداب والعلوم الإنسانية نثاءة الكلية: نشئت كلية الآداب والعلوم الإنسانية في العام

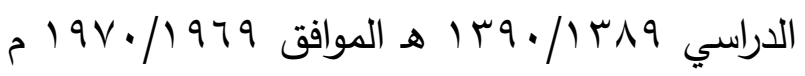
بناء على توجيه لجنة الخبراء الاستشارية التي رفعت

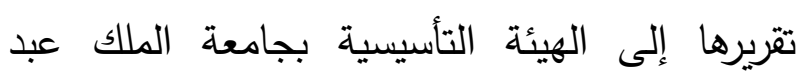
العزيز بعد دراسة دقيقة أوضحت العلاقة بين إنشاء هذه الكلية واحتياجات المملكة من الكفاءات العلمية
تأثير تكنولوجيا المعلومات L. Gasco (2004) في إدارة الموارد البشرية (HRM) وتحديداً على سياسة التدريب من خلا تجربة شركة اتصالات Usman Sadiq (Telefonica)، ودراسة (2012) التي هدفت الى التعرف على كيفية مساعدة التكنولوجيا الحديثة في ضمان فعالية وظائف الموارد البشرية في لاهور، ودراســة Seyni Mamoudou (2014) التعرف على إمكانيات استخدام تكنولوجيا المعلومات في مجال الموارد البشرية لقياس وتتبع رأس المال البشري واستخدام نظام معلومات الموارد البشرية بشكل عام، ودراسة برام Rosales (2019) آثار تكنولوجيا المعلومات والاتصالات على التنمية في المقام الأول من منظور مساهماتها في النمو

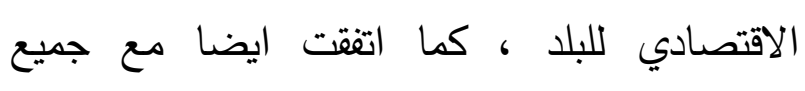
الدراسات العربية والاجنبية في اداة الدراسة وهي

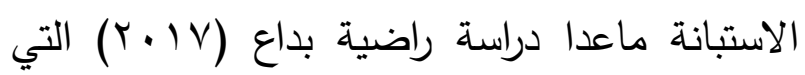
استخدمت الى جانب الاستبيان ايضا الملاحظة، واتفتت دراستان فقط معها في مجتمع الدراسة وهي

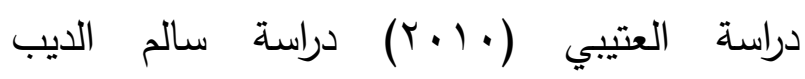
(1) الحالية اختلفت عن دراسة العتيبي (• ( • ) ودراسة 
مهاراته.

0. تطوير الخطط الدراسية واستحداث تخصصات

$$
\text { ومسارات بيئية. }
$$

7. تأهيل وتطوير الكفاءات الأكاديمية والكوادر الإدارية والفنية.

V. عقد الشراكات مع المؤسسات المختلفة فيما

$$
\text { ينسجم مع تخصصات الكلية. }
$$

^. التوسع في برامج التعليم عن بعد للمراحل المختلفة.

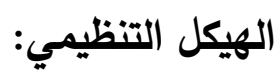

يوضح الثكل التالي الهيكل التنظيمي لكلية الآداب

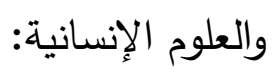

المؤهلة وذلك لإمداد أجهزة الدولة بالكفاءات الوطنية للإسهام في خطط التتمية في مختلف المجالات. رؤية الكلية: "تحقيق الجودة التعليمية من خلال برامج أكاديمية وبحثية متنوعة وكفاءات مؤهلة وشراكات متعددة." رسالة الكلية: "التميز في مجال الآداب والعلوم الإنسانية ضمن

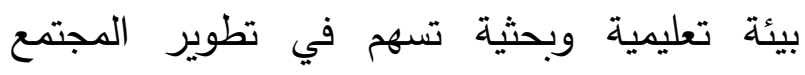
وتحافظ على هويته."

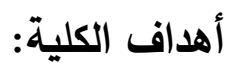
1. الحصول على الاعتماد الأكاديمي. r. التوسع في برامج الدراسات العليا. r. تشجيع البحث العلمي وتطويره.

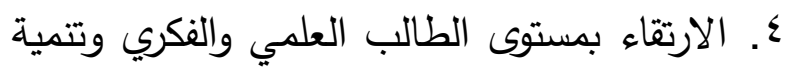

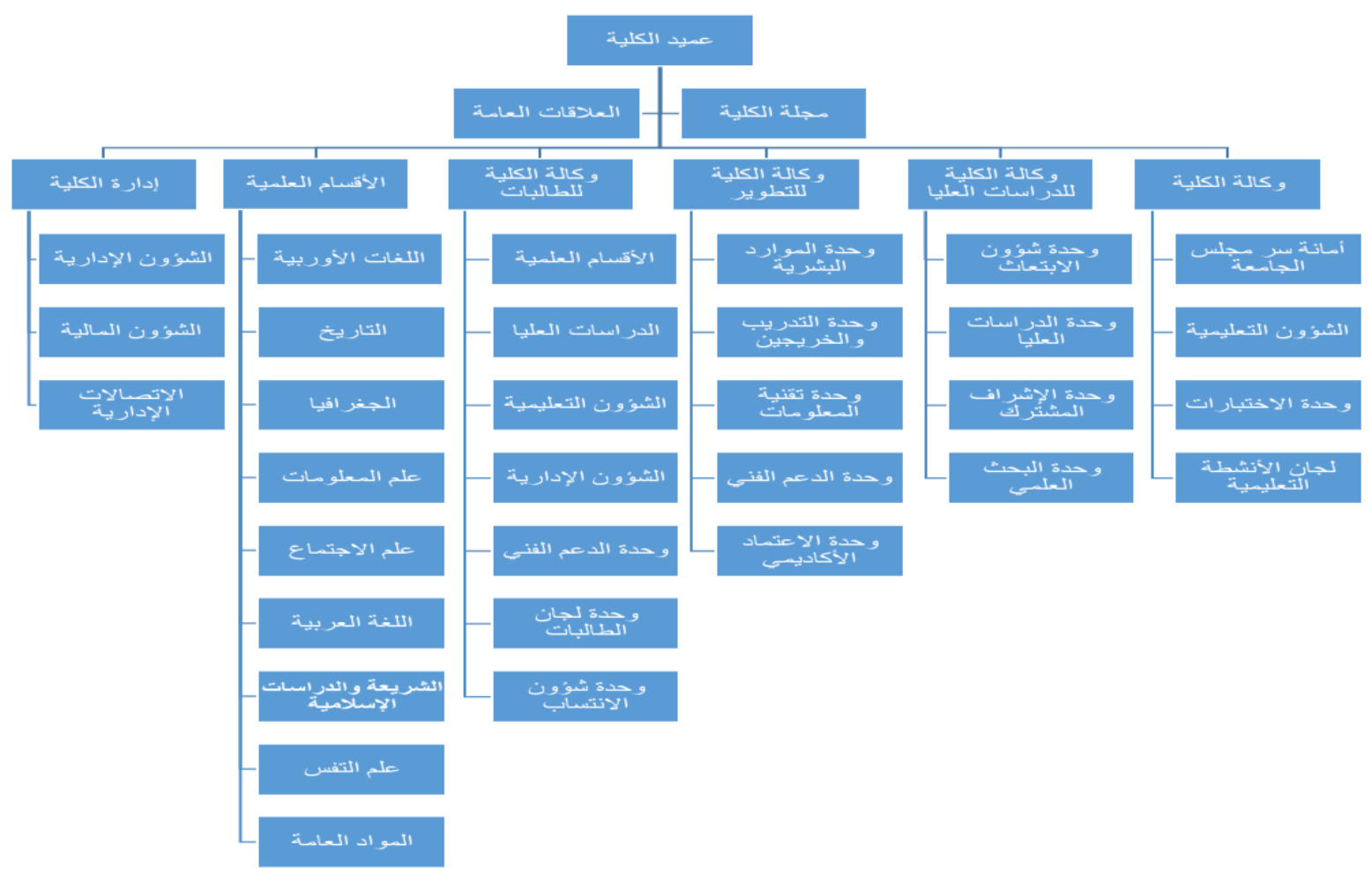


حيث يغوص في خبايا تفاصيل المعلومة ليعرض لنا الحقيقة بشكلها وتحليلها الكامل وبكل شفافية. وفي هذا النظام يتم الدخول على التطبيقات الموجودة داخله ويكون ظهورها بحسب الصهلاحيات الممنوحة

لعميد الكلية ويوجد فيها أربع تطبيقات كما يلي: ا ـ التطبيق الخاص بمؤشر القياس التحليلي لشؤون الموظفين.

r. التطبيق الخاص بمؤشر القياس التحليلي

$$
\text { لبيانات الطلاب. }
$$

r. التطبيق الخاص بتحليل تقديرات الطلاب. ء. التطبيق الخاص بمؤشر الحالة المالية.

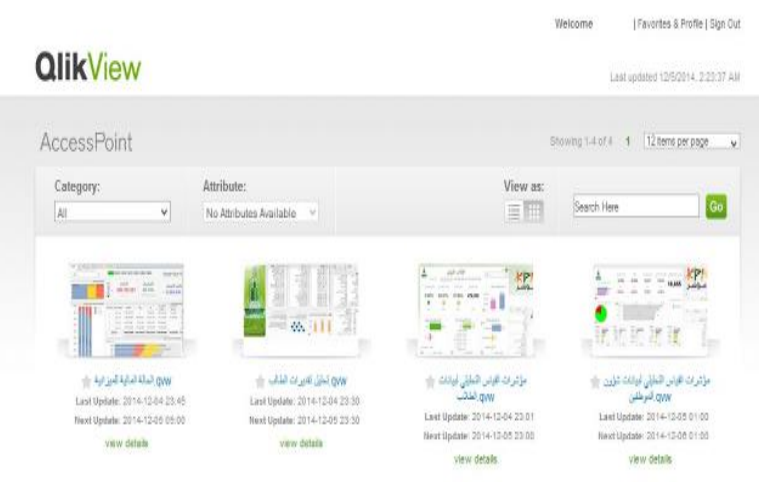

نظام إدارة الأداء (PMS):

هو نظام يتيح لوكيل الكلية ورؤساء الأقسام العلمية باستعراض بيانات الطلاب، وتوزيعات الطلاب، والثعب الدراسية، ومتابعة الترصيد سواءً في الفصل الحالي او في الفصول السابقة واللاحقة. كما يتيح استعراض التقارير العامة عن الموارد البشرية وأماكن عملهم والمراتب العلمية والعملية، وكذلك التعداد الاداري لهم حسب الجهة والجنسية،

\section{التكنولوجيا في كلية الآداب والعلوم الإنسانية:} التكنولوجيا بشكل عام تشير إلى كيفية عمل شيء ما، والأدوات المستخدمة في القيام بهذا العمل. وتعتبر المصدر الرئيسي لزيادة الإنتاجية، والمحدد الأساس لكثير من مهام الوظائف، كما أنها تحدد حجم مجموعات العمل ونمط العلاقات والتفاعل في التي بيئة العمل. وتكنولوجيا المعلومات تعد من المحاور الرئيسية للتنمية في كل المجالات، وخاصة التنمية الإداريـة. وتدور تكنولوجيا المعلومات حول الحاسب الآلي وما ارتبط به من ملحقات. لذا لا يكاد يخلو مكتب في كلية الآداب والعلوم الإنسانية من جهاز الحاسب الآلي. والموارد البشرية في كلية الآداب والعلوم الإنسانية تتعامل مع العديد من الأنظمة المختلفة كل في مجال عمله، وفيما يلي نسرد لبعض هذه الأنظمة ووظائفها: نظام مؤشر (KP!): هو نظام يساهم في مواكبة حجم وكمية التطور الهائل في بيئة صنفت المعلومة كأغلى سلعة متداولة في هذا الزمن خصوصاً عندما تتوفر بشكل صحيح وفي وقت قياسي بيد صناع القرار الذين على أيديهم تتغير المجريات والاستراتيجيات ذات التأثير الفعال. ويعتبر (مؤشر) نظام يستهدف صناع القرار لاحتوائه على أغلب المؤشرات التي تغطي كثير من الإجابات على الأسئلة الذكية ومن عدة زوايا وبوجهات نظر اعر التربرات مختلفة. بل ويذهب نظام (مؤشر)إلى أبعد من ذلك 
والرجوع إليها لاحقاً، كما تتيح للمعلم فرص الالتقاء

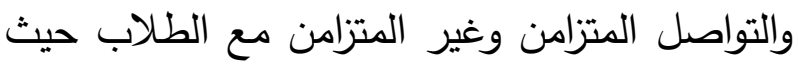
تعطى لهم المحاضرة عن بُعد من أي مكان وفى أي الي وقت.

\section{نظام (ODUS plus):}

يتيح هذا النظام للجامعة التحكم ومراقبة عمليات التسجيل بصورة فعالة. كما يسهل لوكيل الكيلة ورؤساء الأقسام العلمية والمرشدين الأكاديميين

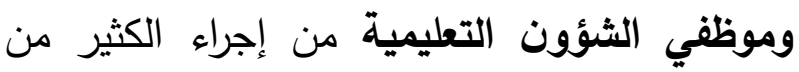
العمليات مثل إعداد جداول الشُعب وفتحها وتوسيعها

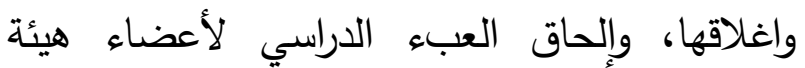

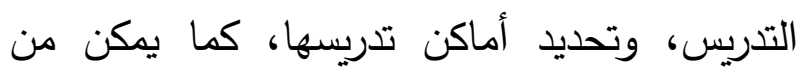
خلاله الحذف والإضافة في جداول الطلاب.

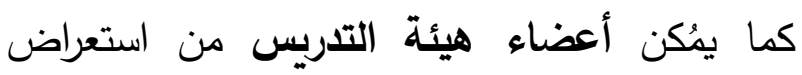

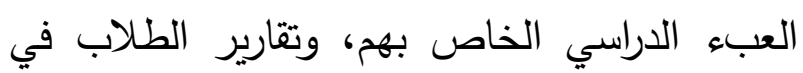
الثعبة الدراسية، ومتابعة حالات الطلاب، وأيضا

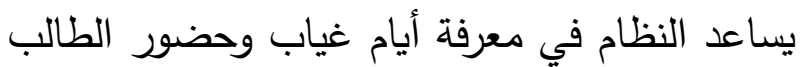
من خلال التسجيل عليه عن طريق رقم الطالب الجامعي، كما يمكن من خلاله رصد درجات

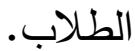

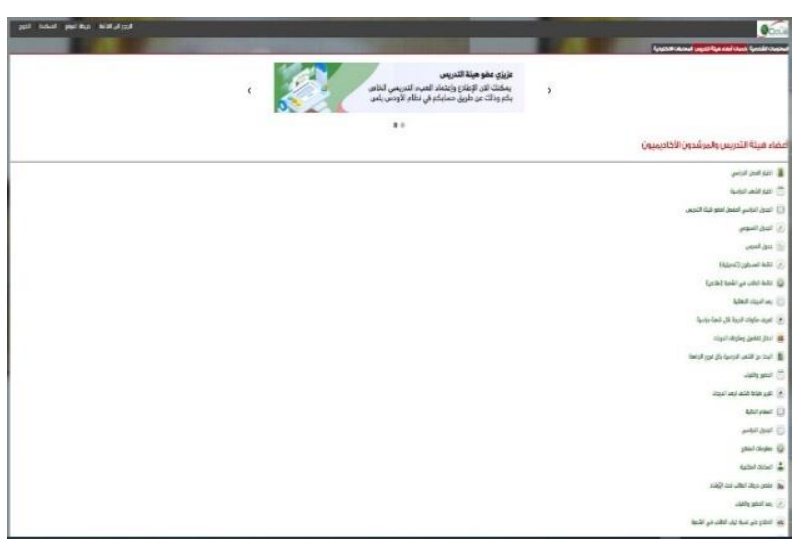

كما يستعرض بيانات المكلفين بمناصب إدارية

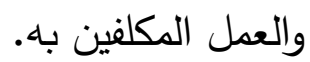

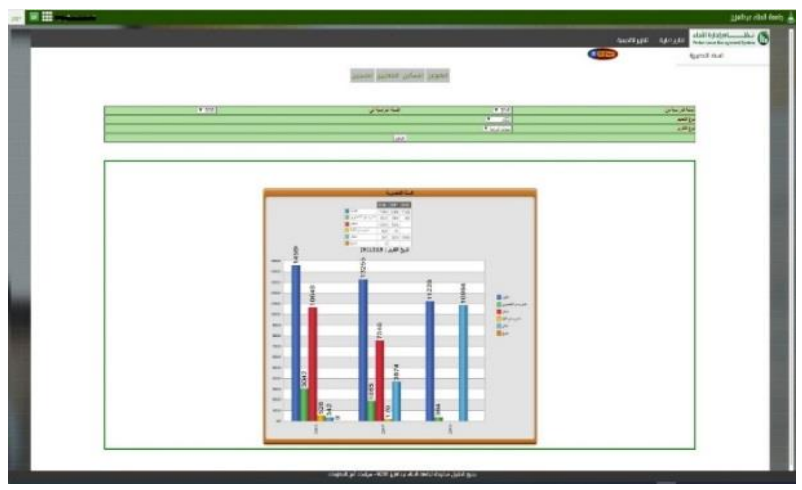

نظام إدارة التعلم الإكتروني (Blackboard): هو نظام يتيح لعضو هيئة التدريس بالكلية إمكانية

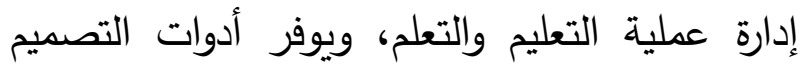
والإنتاج التي تسهم في تطوير المقررات إلكترونياً، وطرق استراتيجيات عرضها وتدريسها وكيفية استخدامها، وكذلك أدوات متابعة وتقييم الطلاب وقياس مستوى أدائه ومعرفة مدى عملية التحصيل

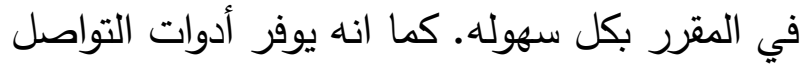

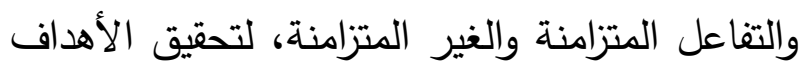

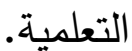

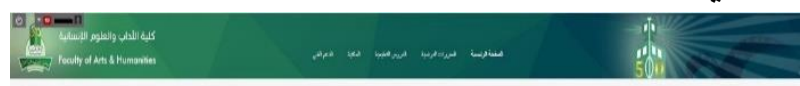
(6)

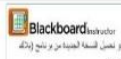

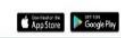

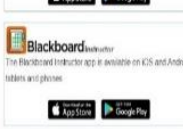

كما يحتوي على فصول إلكترونية للتعلم من بعد، توفر إمكانية عقد جلسات دراسية يقدم فيها المعلم المحتوى العلمي، مع إمكانية حفظ الدروس المتزامنة 
موظفي وحدة تقنية المعلومات بالكلية لإدارة محتوى الإقى

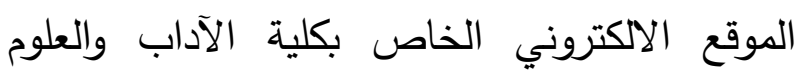
الإنسانية.

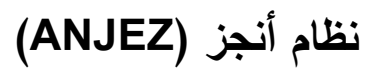
هو نظام يسهل إجراءات العمل الإداري والمالي

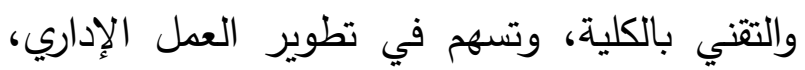
ويساعد في أداء مهامها بصورة احترافية. كما يهتم بعلميات الإدارة وميكنتها وتبسيط إجراءاتها مما يغني

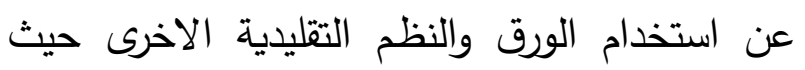
يكون بالإمكان القيام بأي عمليه مالية او إدارية بكل سهولة ويسر بدون بذل أي جهد. ويعتبر نظام انجز متاح لجميع الموارد البشرية بالكلية والذي من خلاله يمكن تقديم الاجازات،

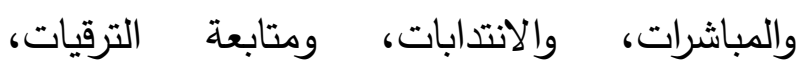

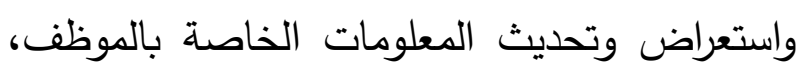
وطلب المشاركات العلمية والابتعاث، وايضاً متابعة

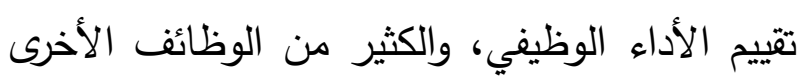
بحسب الصلاحيات الممنوحة.

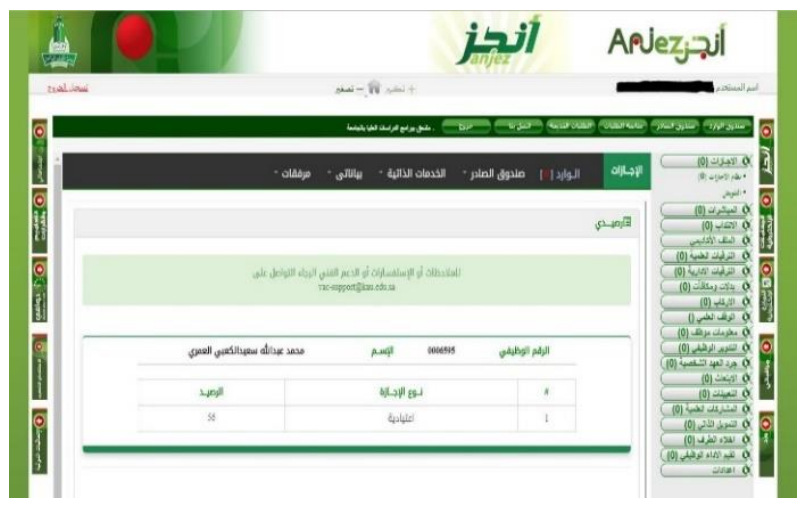

كما يتفرع منه عدة أنظمة منها نظام متابعة التعاميم

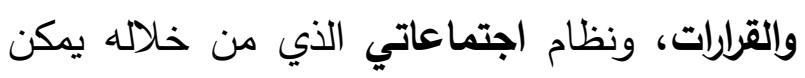

ويتميز نظام ODUS plus أيضا بكونه يُمكن الطالب من معرفة الخطة الدراسية وسجل الحضور

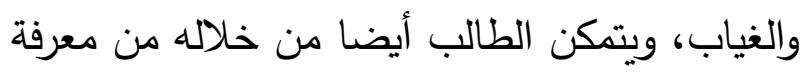
المواد الدراسية بشكل مثالي وحذف شعبة أو إضافة أخرى، ويهدف النظام بشكل كامل إلى تطوير المنظومة التعليمية بمثالية كبيرة وزيادة خبرات

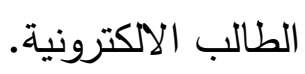
نظام مارز (MARZ) ظهرت الحاجة إلى توحيد بوابة المحتويات الرقمية على مستوى الجامعة، وإنثاء بوابة رقمية أكاديمية كبيرة، وبناء على ما تتمتع به الجامعة من إمكانيات

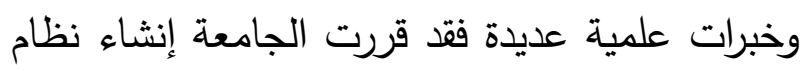
إدارة محتوى خاص بها على شبكة الانترنت

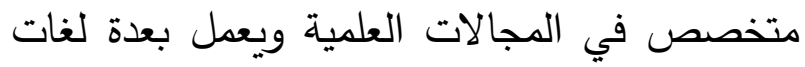

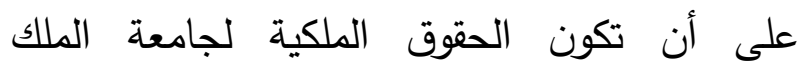
عبدالعزيز . عبان كما يمكن من خلال هذا النظام نشر وإدارة المحتوى الالكتروني على موقع الجامعة، وإدارة قائمة الموقع، هلئ

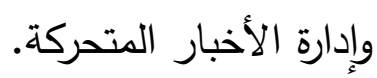

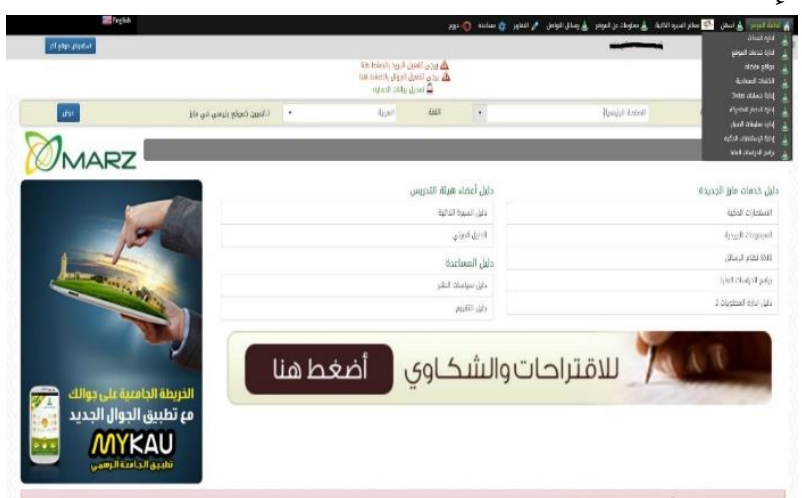

وهو نظام يستهدف اعضاء هيئة التدريس ليمكنه من انشاء وتحديث مواقعهم الالكترونية، وكذلك لكهاء 
الضروري. لإرسال الوثائق التي تتطلب عملا من

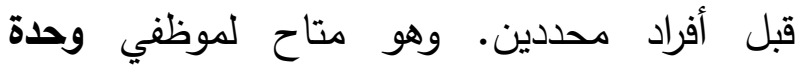
الاتصالات بالكلية وسكرتارية الأقسام العلمية بصلاحيات أعلى مختلفة عن باقي الموارد البشرية

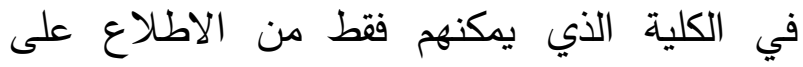
المعاملات الخاصة بهم والرد عليها. وتعددت وظائف هذا النظام نذكر بعض منها فيما يلي: استقبال المعاملات في صندوق الوارد العام للموظف في البوابة الإكترونية دعم الرقم التسلسلي (BarCode) لجميع أنواع

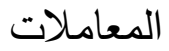
القدرة على اضافة مسارات جديدة لنوع المعاملة. القدرة على انشاء عدد غير محدد من أنواع

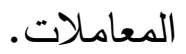
اعداد المعاملة وانشاء الحركات والأرشفة والربط مع المعاملات من خلال شاشة موحدة.

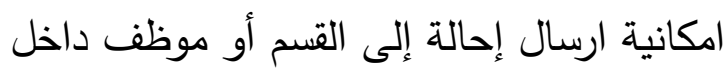
القسم حسب الهيكل التنظيمي الموحد. • التكامل مع نظام الأرشفة الالكتروني. انشاء كثوف البريد والتسليم بشكل الكتروني. مع إمكانية ارشفتها وربطها مع المعاملة.

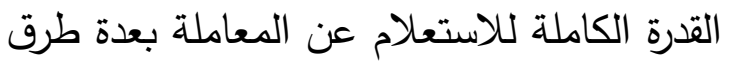
من خلال شاشة موحدة. القدرة على ارفاق الوثائق الاككترونية للمعاملة.

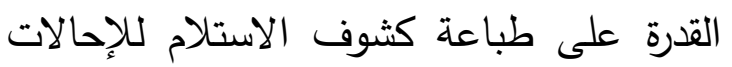
بشكل آلي.
توقيع محضر الاجتماع وتقديم التوصيات واعتمادها،

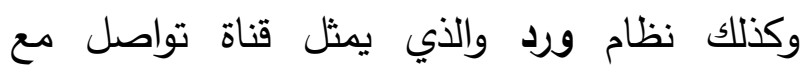
الثركات والمؤسسات المرتبطة مع الجامعة بعلاقات ولفي تعاقدية، حيث يوفر النظام تفعيل مندوبي الشركات واستلام المخاطبات الرسمية المتعلقة بتلك العقود،

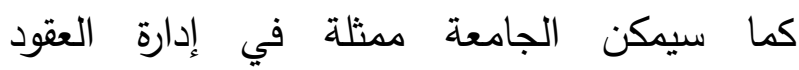

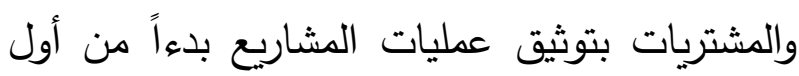

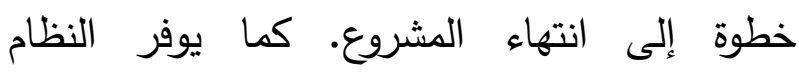
للشركات متابعة صرف المستحقات إلكترونياً ويمكن مختلف جهات الجامعة من متابعة مشروعاتها

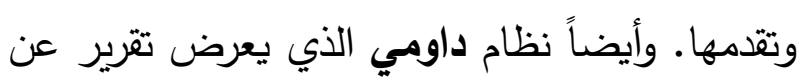

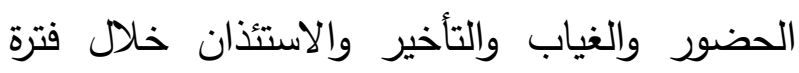
زمنية محددة، ونظام النماذج الاكترونية وفيها ولافيا

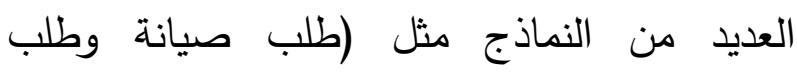
صلاحيات وطلب استئذان ...الخ). ومن أهم الأنظمة الفرعية لنظام أنجز هو نظئن النظام

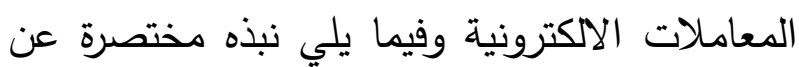
خصائصه وأهم وظائفه. نظام المعاملات الاكترونية تم إنشاء نظام المعاملات الالكترونية لتلبية

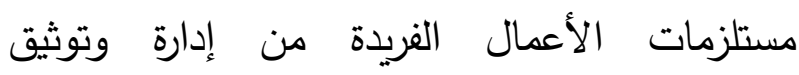
المعاملات إلكترونياً. وقد تم تصميم هذا النظام

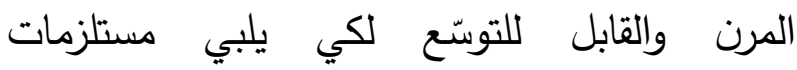

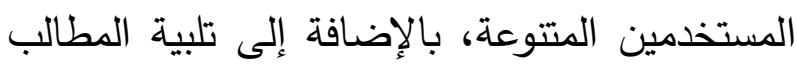

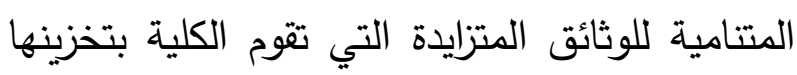

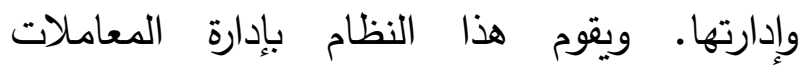

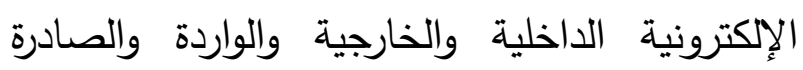
ومتابعتها وأرشفتها الكترونياً، ويؤمن مسار الأعمال 
البريد الجامعي متاح لجميع الموارد البشرية بكلية الآداب والعلوم الإنسانية. أنظمة الاختبارات بالكلية

هناك عدة أنظمة يتعامل معها موظفي وحدة الاختبارات بالكلية لتسيير وتنظيم وإدارة الاختبارات،

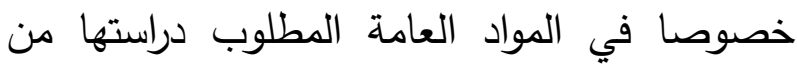

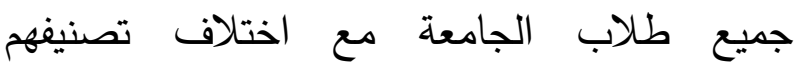
وتخصصاتهم. وفيما يلي نعرض عرض موجز عن

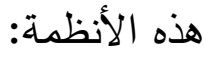
توزبع المراقبات: تعد عملية توزيع المشرفين والمراقبين من المن

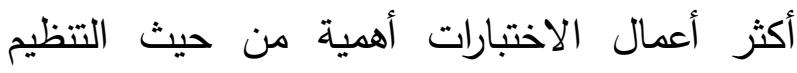
الميداني لسير الاختبارات، وهي في الوقت نفسه من الاحن

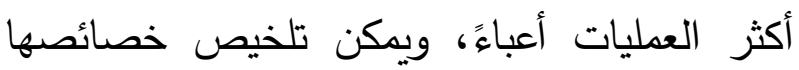
فيما يلي: ا. كثرة أعداد الطلاب (انتظام - انتساب - تعليم عن بعد) المسجلين في كلية الآداب والعلوم الإنسانية وخصوصاً المواد العامة التي تعد التدابل

$$
\text { متطلباً لجميع طلاب الجامعة. }
$$

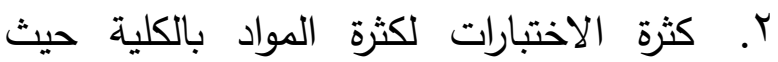
تصل الى · . ب اختبار تقريباً.

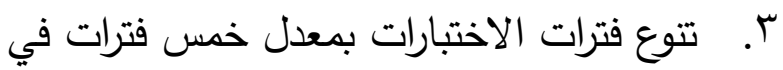
اليوم في كل فترة مجموعة من المواد. ع. ـتوع مباني وقاعات الاختبارات. ومما سبق يتضح أن الحاجة ماسه لبذل جهود كبيرة

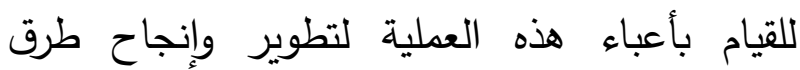
استخدمها ولتحسين أداءها، فضلاً عما يحتاج إليه من سرعة الانجاز في كل تلك الخطوات. لذا تم
أرشفة المعاملات داخل القسم واعادة استخدامها ضمن نظام تدفق الأعمال الخاص بها. القدرة على البحث والاستفسار عن أي معاملة

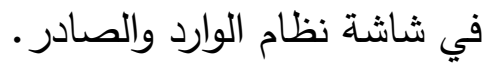
القدرة على ارسال أصل ونسخ للمعاملة. القدرة على طباعة تقرير لـعاملة يضم معلوماتها وجميع الإحالات التي تمت عليها.

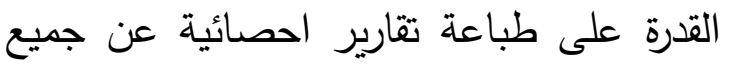
المعاملات.

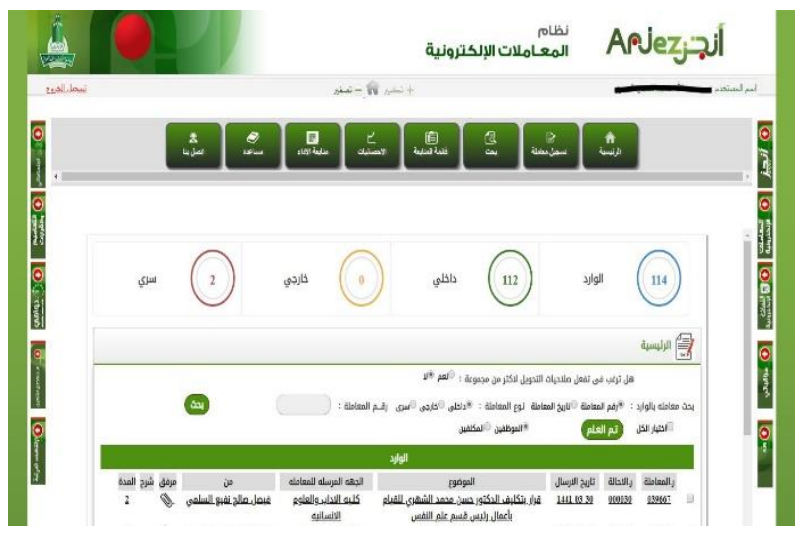
بريد الجامعة يمتاز البريد الجامعي بمميزات غاية في الدقة

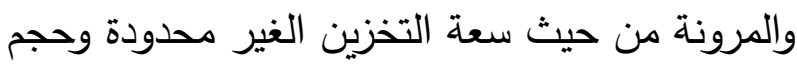
المرفقات وبرامج الدردشة وترجمة الرسائل ومميزات مثل إتاحة خدمات التقويم وارسال رسائل نصية. كما يمكن رؤية كل ما هو جديد بشكل سريع وفوري في

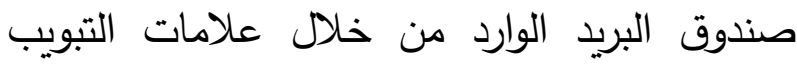
الجديدة القابلة للتخصيص مثل الرسائل الترويجية والرسائل الاجتماعية والتحديثات. وكذلك يمكن باستخدام الحساب البريدي الجامعي حفظ الملفات المتنوعة على السحابة الالكترونية بسعات تخزينية عالية. ويعتبر (Google Drive) 


\section{التصحيح الآلي:}

حيث إن جل الانظمة التي تقدمها شركات أجهزة

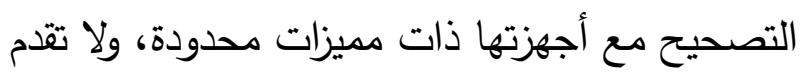

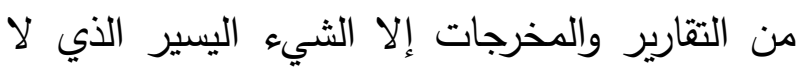

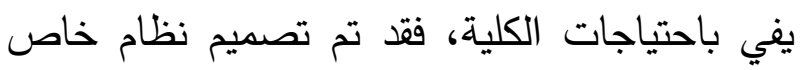
بها للتصحيح الآلي، يقدم جميع الخدمات والتقارير

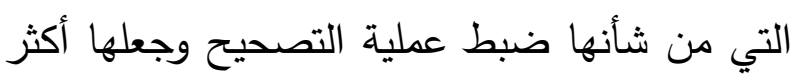
دقة. ومن مميزات هذا البرنامج: 1 ا ـ سهولة التعامل معه. r. عدم التعامل المباشر مع البيانات. r. وجود أكثر من طريقة لحساب الدرجة النهائية

مع اعتبار عدد الأسئلة ودرجة كل اختبار . ـ. ربط البيانات الخارجة من القارئ الضونئي ببيانات الطالب المأخوذة من عمادة تقنية

$$
\text { المعلومات مباشرة. }
$$

ه. كثف أخطاء تظليل الطلاب للرقم الجامعي. 7 7. إمكانية التعديل في مفاتيح الإجابة وإعادة التصحيح في لحظة، دع إمكانية حذف سؤال

$$
\text { ومنح درجته لكل الطلاب. }
$$

V. تعدد وتتوع التقارير التي يقدمها البرنامج.

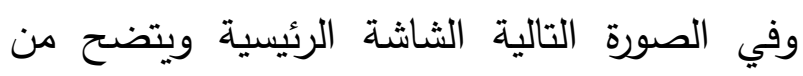

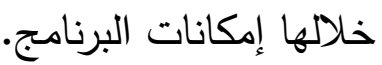

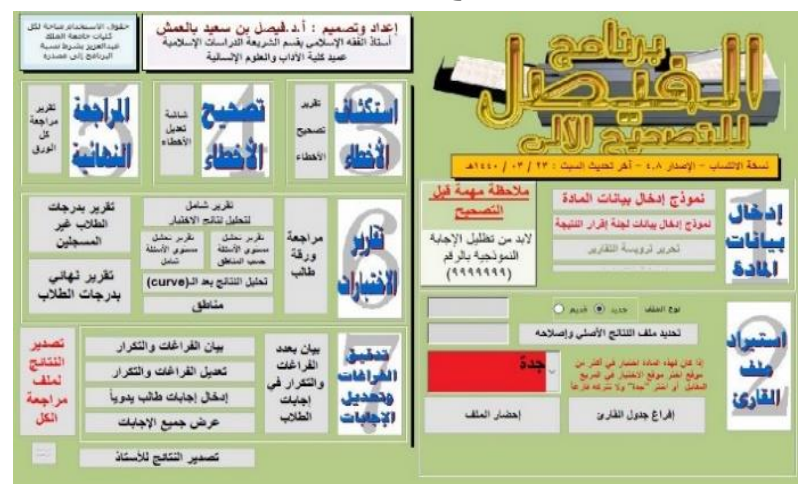

تصميم نظام قائم على قواعد البيانات يمكن من خلاله أداء الوظائف التالية: 1. تحديد المباني والقاعات المخصصة لكل لكل اختبار •

r. تحديد مشرفي القاعات والمراقبين من جميع كليات الجامعة، مع الحرص على لعلى اختيار الأكفأ. r. التوزيع الآلي للمشرفين والمراقبين في المباني والقاعات المحددة. ع. إعداد خطابات بجداول المراقبات.

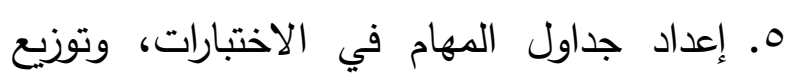
العمل بين اللجان المساندة المختلفة (لجنة تنظيم المبنى، لجنة المادة، لجنة استلام الإجابات، الأمن والسلامة .... إلخ). 7 . إعداد تقارير لملفات المشرفين.

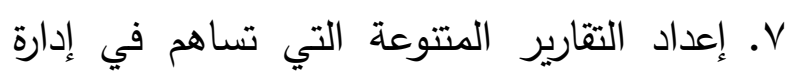
الاختبارات مثل (الحضور والانصراف، قاعات الاختبار واستيعابها، المشرفين والمراقبين حسب الاختب

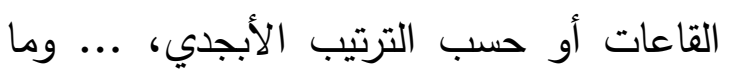
الى ذلك) كما يمكن إعداد تقارير مستحدثة

$$
\text { حسب الحاجة. }
$$

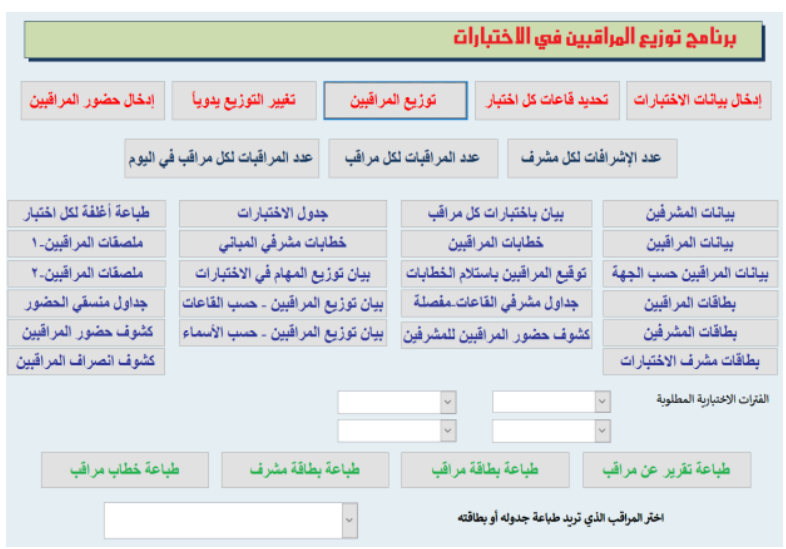


لمنسوبي كلية الآداب والعلوم الانسانية، وخطوات

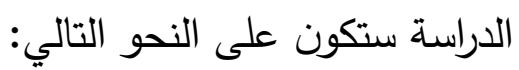

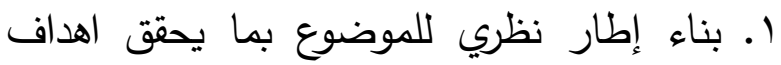

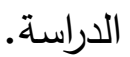

r. بناء استبانة مفصلة لتغطية جوانب الدراسة

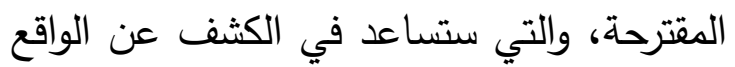
والصعوبات والنظرة المستقبلية.

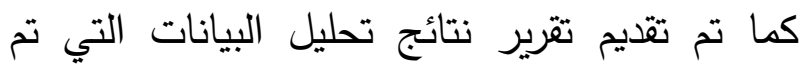
الحصول عليها من الاستطلاع الذي قام به الباحثون تصني

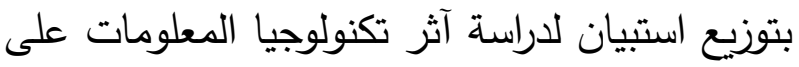
تتمية الموارد البشرية بكلية الآداب والعلوم الإنسانية.

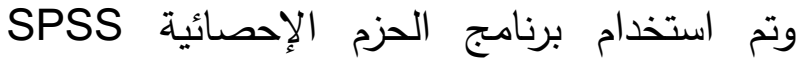

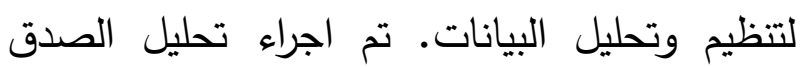
والثبات لأداة الدراسة (الاستبانة)، ثم عرض نتائجها ونتائج التحليل الوصفي والاستدلالي، باستخدام مستوى دلالة ه.,...

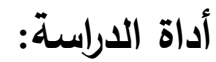
استخدم الباحثون استبانة تتضمن ست مقاييس أساسية لقياس متغيرات الدراسة بهدف تحقيق اهداف

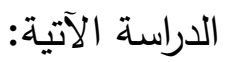
1. التعرف على ماهية تكنولوجيا المعلومات التهة واستخداماتها.

r. التعرف على ماهية تتمية الموارد البشرية. r. التعرف على العلاقة بين تكنولوجيا المعلومات وتتمية مواردها البشرية. ـ. التعرف على واقع استخدام تكنولوجيا المعلومات بكلية الآداب والعلوم الإنسانية.
الاختبارات الإكترونية:

تعد أنظمة الاختبارات الإكترونية من أحد الوسائل التقنية الحديثة لتقييم وقياس مخرجات ومستويات التهات العملية التعليمية باستخدام الحاسوب والأجهزة الذكية المحمولة. وتعتبر من الحلول البديلة الفعالة للاختبارات التقليدية (الورقية) متميزةً عنها بالكفاءة والمرونة في جميع مراحل تطبيقها.

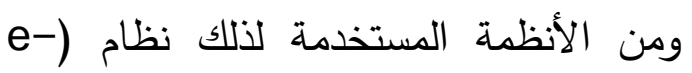
Exam لاستخدام نظام (Questionmark) العالمي.

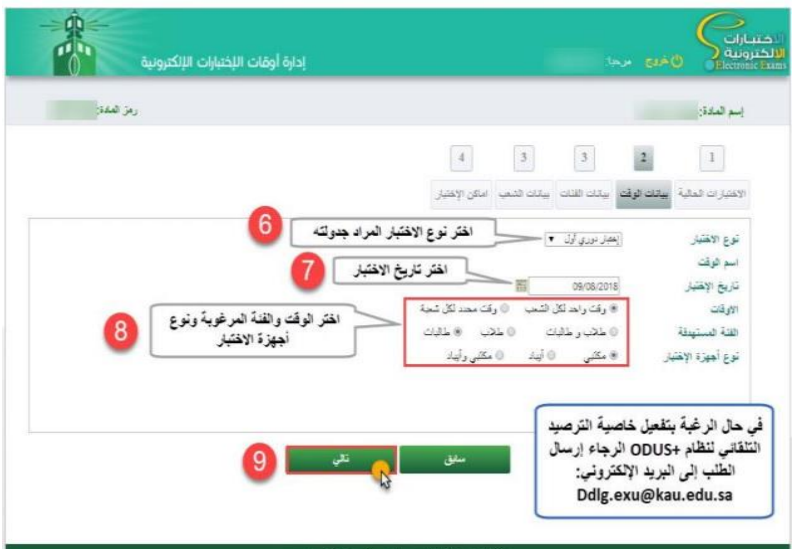

\section{إجراءات الاراسة}

منهجية الدراسة:

تعتمد هذه الدراسة على المنهج الوصفي المسحي من

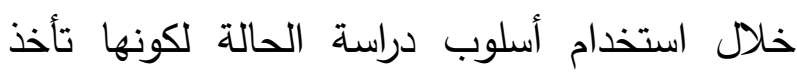

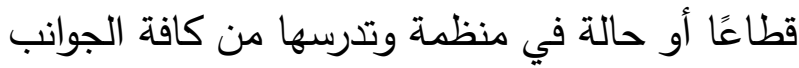

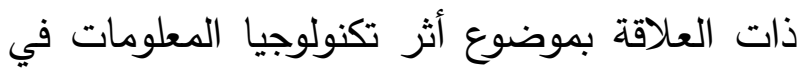
تتمية الموارد البشرية من وجهة نظر منسوبي كلية الآداب والعلوم الانسانية، باعتباره المنهج الملائح

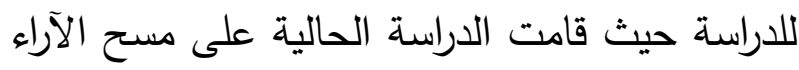


7. تقديم مقترحات وتوصيات لاستغلال تكنولوجيا

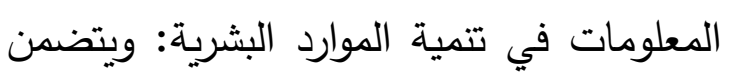
(1)

الخصائص السيكومتربية لأداة الدراسة:

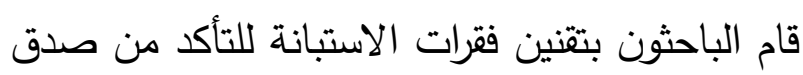
وثبات أداة الدراسة بالطرق الإحصائية الموضحة

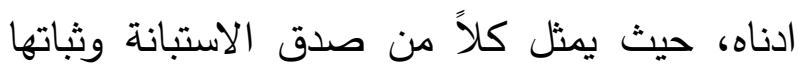
اهم المرتكزات الأساسية لبناء أي مقياس من اجل هن لهن الهن تحديد المقياس الملائم لموضوع الدراسة.

أولاً: الصدق (Validity)

يعد الصدق من الثروط الضرورية لبناء الاختبارات والمقاييس، اذ يدل على مدى قدرة فقرات الاستبانة

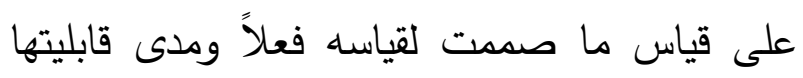

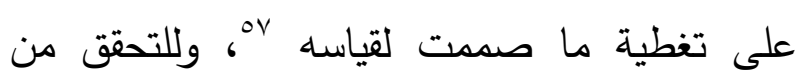

صدق المقياس، اعتمد الباحثون على طريقتين: ا ـ صدق الاتساق الداخلي لفقرات الاستبانة تم قياس الاتساق الداخلي لفقرات الاستبانة على الاتسات لإنيانه عينة الدراسة البالغ حجمها ع V، حيث قام الباحثون

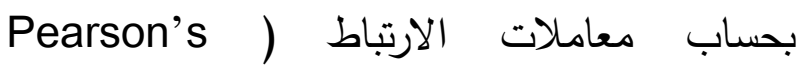
(Correlation Coefficient بين كل فقرة والدرجة الكلية للبعد التابعة له، كما هو موضح في جلول 1 .

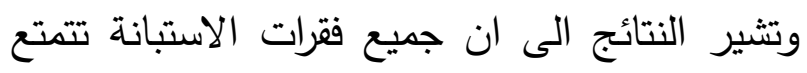

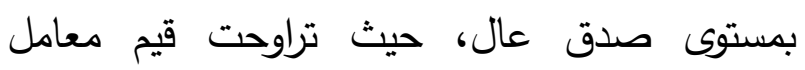

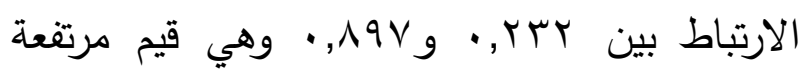

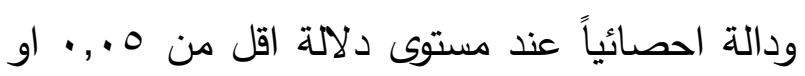

$\ldots, \cdot 1$

$$
\begin{aligned}
& \text { "ه نبراس ناجي رزوقي، تأثير استراتيجية تقويم الأداء في الفاعلية }
\end{aligned}
$$

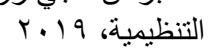

$$
\begin{aligned}
& \text { or نبراس ناجي رزوفي، مرجع سبق ذكره. }
\end{aligned}
$$

○. الكثف عن تأثير استخدام تكنولوجيا المعلومات على تتمية الموارد البشرية بكلية الآداب والعلوم الإنسانية.

7. تقديم مقترحات وتوصيات لاستغلال تكنولوجيا المعلومات في تتمية الموارد البشرية بكلية

$$
\text { الآداب والعلوم الإنسانية. }
$$

وقام الباحثون باستخدام مقياس ليكرت الخماسي Five-Point Likert Scale

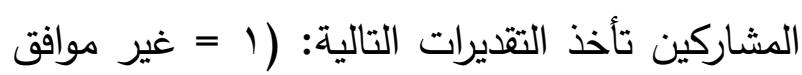
بشدة، r= غير موافق، r= محايد، ع= موافق، موافق بشدة). وتكون المقياس في صورتي صوته النهائية من •0 فقرة من نوع التقرير الذاتي، يجاب عليها

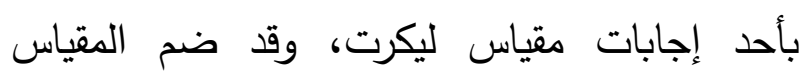

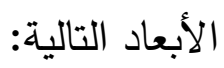

ا. مدى الإعادرفة لماهية تكنولوجيا المعلومات واستخداماتها لدى الموارد البشرية: ويتضمن 7 فقرات. r. مدى المعرفة لماهية تتمية الموارد البشرية: ويتضمن 7 فقرات. r. التعرف على العلاقة بين تكنولوجيا المعلومات

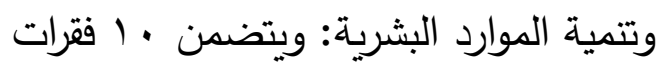

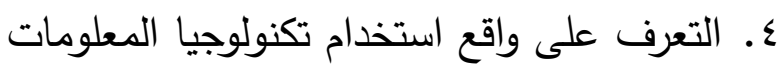
بكلية الآداب والعلوم الإنسانية: ويتضمن فقرات. 0. الكثف عن تأثير استخدام تكنولوجيا المعومات

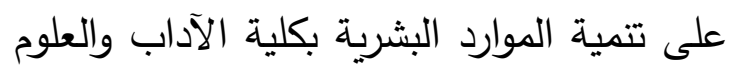
الإنسانية: ويتضمن 9 فقرات. 


\begin{tabular}{|c|c|c|c|c|c|c|c|c|c|c|c|}
\hline \multicolumn{2}{|c|}{ البعد السادس } & \multicolumn{2}{|c|}{ البعد الخامس } & \multicolumn{2}{|c|}{ البعد الرابع } & \multicolumn{2}{|c|}{ البعد الثالث } & \multicolumn{2}{|c|}{ البعد الثاني } & \multicolumn{2}{|c|}{ البعد الأول } \\
\hline معامل الارتباط & الفقرة & الارتباط & الفقرة & الارتباط & الفقرة & الارتباط & الفترة & الارتباط & الفقرة & الارتباط & الفقرة \\
\hline$\cdot, 770$ & 1 & $\cdot, \Lambda \backslash \vee$ & 1 & $\cdot, 0 \cdot V$ & 1 & $\cdot, 719$ & 1 & $\cdot, \wedge \ldots$ & 1 & $\cdot, \wedge 70$ & 1 \\
\hline$\cdot, T V$. & r & $\cdot, \vee \backslash \leq$ & r & $\cdot, \vee \wedge 1$ & r & $\cdot, 7) \leq$ & r & $\cdot, \wedge \vee \top$ & r & $\cdot, \wedge \leq \varepsilon$ & r \\
\hline$\cdot, V Y \varepsilon$ & $r$ & $\cdot, \vee \wedge \wedge$ & $r$ & $\cdot, \Lambda \cdot r$ & $r$ & $\cdot, V Y V$ & $r$ & $\cdot, \vee \vee 0$ & $r$ & $\cdot, \wedge \cdot \wedge$ & $r$ \\
\hline & $\varepsilon$ & $\cdot, \vee \wedge$ & $\varepsilon$ & $\cdot, \Lambda \cdot V$ & $\varepsilon$ & $\cdot, \nabla \vee r$ & $\varepsilon$ & $\cdot, T Y$. & $\varepsilon$ & $\cdot, 1 \vee 99$ & $\varepsilon$ \\
\hline$\cdot, \vee \vee$. & 0 & $\cdot, T \vee \wedge$ & 0 & $\cdot, \Lambda \cdot 7$ & 0 & $\cdot, T \leq Y$ & 0 & $\cdot, T Y 1$ & 0 & $\cdot, V Y T$ & 0 \\
\hline$\cdot, \vee Y \wedge$ & 7 & $\cdot$, , Y O & 7 & $\cdot, \wedge \wedge \neg$ & 7 & $\cdot, 0 \vee 1$ & 7 & $\cdot, 0.0$ & 7 & $\cdot, \vee \vee 乏$ & 7 \\
\hline & V & $\cdot, \vee \vee 7$ & V & $\cdot, \wedge 9 \vee$ & V & $\cdot, \vee \vee q \varepsilon$ & V & & & & \\
\hline$\cdot, 1 \wedge \wedge$ & $\wedge$ & $\cdot, \vee \vee 79$ & $\wedge$ & $\cdot, \wedge \uparrow$. & $\wedge$ & $\cdot, \wedge \varepsilon$ & $\wedge$ & & & & \\
\hline., $07 \varepsilon$ & 9 & $\cdot, \vee \vee \vee$ & 9 & & & •, & 9 & & & & \\
\hline$\cdot, 7) \leq$ & 1. & & & & & $\cdot, \vee \vee q$ & 1. & & & & \\
\hline • ז৭V & 11 & & & & & & & & & & \\
\hline
\end{tabular}

جدول ا ـ معاملات الارتباط بين الفقرات والدرجة الكلية للمجال التابعة له

\section{r. T. صدق الاتساق الداخلي للأبعاد:}

في جلول r • وكانت جميع قيم معاملات الارتباط

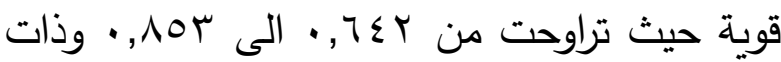

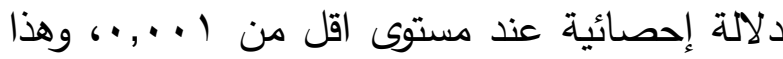
مؤشر على صدق الاستبانة.
تم حساب معاملات الارتباط بين درجة كل بعد من ابعاد الاستبانة والدرجة الكلية للاستبانة، وذلك لكاتل لمعرفة مدى ارتباط كل بعد بالاستبانة بهدف التحقق

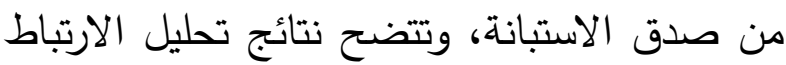

\begin{tabular}{|c|c|c|}
\hline معامل الارتباط & ابعاد الاستبانة & \\
\hline$\cdot, T \leq r$ & مدى المعرفة لماهية تكنولوجيا المعلومات و استخداماتها لدى الموارد البشرية & .1 \\
\hline$\cdot, \mathrm{V} T \mathrm{~V}$ & مدى المعرفة لماهية تتمية الموارد البشرية & $r^{r}$ \\
\hline 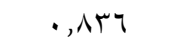 & التعرف على العلاقة بين تكنولوجيا المعلومات وتتمية الموارد البشرية & r \\
\hline$\cdot, \wedge ґ \wedge$ & التعرف على و اقع استخدام تكنولوجيا المعلومات بكلية الآداب و العلوم الإنسانية. &.$\xi$ \\
\hline$\cdot$, , & الكثف عن تأثثير استخدام تكنولوجيا المعلومات على تتمية الموارد البشرية بكلية الآداب و العلوم الإنسانية. & .0 \\
\hline$\cdot, \wedge \cdot 0$ & تقديم مقترحات وتوصيات لاستغلال تكنولوجيا المعلومات في تتمية الموارد البشرية & .7 \\
\hline & جدول r ـ معاملات الارتباط بين الأبعاد والدرجة الكلية للاستبانة & \\
\hline
\end{tabular}

ثانياً: الثبات (Reliability)

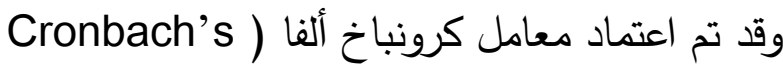
يعبر مفهوم الثبات عن مدى اتساق نتائج المقياس،

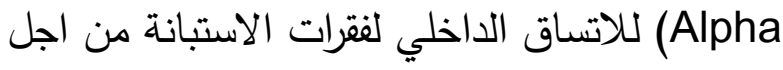

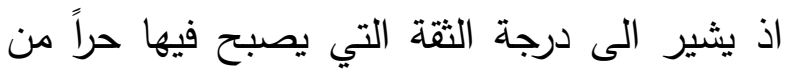
معرفة ددى التتاسق في إجابات المبحوثين والتحقق 
7 0 من البعد الخامس)، مما يدل على ان الابعاد تتمتع

جلولr . بمعاملات ثبات مرتفعة، كما هو موضح في

من درجة ثبات الاستبانة، وقد أظهرت نتائج

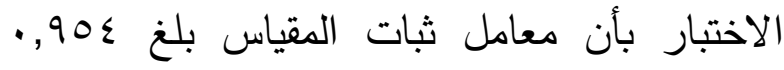
وهي نسبة ممتازة جدا تؤكد صدق وثبات المقياس وصلاحية نتائجه للتطبيق. كما تبين ان معاملات الثبات لجميع أبعاد الاستبانة أكبر من نقطة القطع

\begin{tabular}{|c|c|c|}
\hline كرونباخ & الفقر ات & 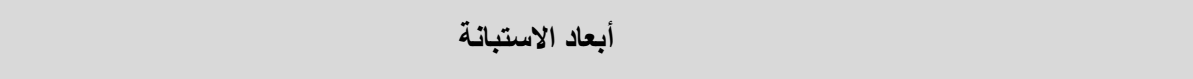 \\
\hline$\cdot, \wedge 9 \mathrm{r}$ & 7 & مدى المعرفة لماهية تكنولوجيا المعلومات و استخداماتها لدى الموارد البشرية \\
\hline$\cdot, \vee \vee \vee q$ & 7 & مدى المعرفة لماهية تنمية الموارد البشرية \\
\hline$\cdot, \wedge 9 \mathrm{r}$ & 1. & التعرف على العلاقة بين تكنولوجيا المعلومات وتتمية الموارد البشرية \\
\hline$\cdot, 911$ & $\wedge$ & التعرف على و اقع استخدام تكنولوجيا المعلومات بكلية الآداب و العلوم الإنسانية. \\
\hline$\cdot, 9 \cdot 4$ & 9 & الكثف عن تأثنير استخدام تكنولوجيا المعلومات على تتمية الموارد البشرية بكلية الآداب و العلوم الإنسانية. \\
\hline$\cdot, \wedge 0$ & 9 & تقديم مقترحات وتوصيات لاستغلال تكنولوجيا المعلومات في تتمية الموارد البشرية \\
\hline$\cdot, 90 \varepsilon$ & $\leqslant \Lambda$ & الارجة الكلية للاستبانة \\
\hline
\end{tabular}

جدول ـ معاملات الثبات لأبعاد الاستبانة بطريقة كرونباخ ألفا

الواحدة One-sample t test لفحص الاندانلة

مجتمع وعينة الاراسة:

الإحصائية لكل فقرة.

البعد الأول: التعرف على ماهية تكنولوجيا المعلومات واستخداماتها للتعرف على ماهية تكنولوجيا المعلومات واستخداماتها لدى الموارد البشرية، قام الباحثون بدراسة النتائج الموضحة في جدول؛ ، حيث يتضح ان المتوسط الحسابي لجميع الفقرات مجتمعة يساوي • .

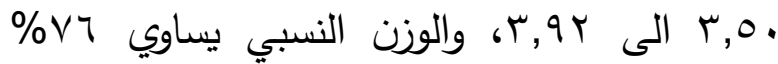
وهو أكبر من الوزن النسبي المحايد • ، \%، وكانت قيم مستوى الدلالة حسب اختبار ت احتب للعينة الواحدة لجميع الفقرات أكبر من 0 ., •، مما يدل على ان مستوى معرفة المبحوثين بماهية تكنولوجيا المعلومات واستخداماتها اعلى من المتوسط، فيما عدا الفقرة (Y)، حيث كان اختبار ت لهذه الفقرة دال

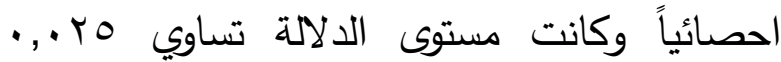
مجتمع الدراسة هو الموارد البشرية بكلية الآداب

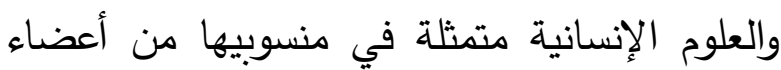
هيئة التدريس المكلفين بأعباء إدارية والاداريين والفنيين، وقد كان عدد المبحوثين في هذه الدراسة ع فرداً، كانوا ممن يشغلون مراكز وأعمال إدارية وفنية مختلفة، كما أن أغلبيتهم من ذوي الخبرن هرات

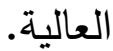

تحليل إجابات المبحوثين لتحقيق اهداف الدراسة: في هذا الجزء قام الباحثون بعرض نتائج التحليل الوصفي بغرض الإجابة عن تساؤلات الدراسة وتحقيق أهدافها. وذلك باستخدام الأساليب الإحصائية الملائمة، حيث قام الباحثون بحساب مجموع درجات كل استجابة، المتوسطات الحسابية، الانحرافات المعيارية، والوزن النسبي، والاهمية النسبية (الترتيب) لكل فقرة من فقرات البعد الذي ولتي تتتمي اليه. كما قام الباحثون باختبار ت للعينة 
الى ان مستوى المعرفة الشاملة للمبحوثين عن استخدامات تكنولوجيا المعلومات كان متوسطاً.
وقيمة المتوسط الحسابي تساوي •r,0 وهي قيمة اقل من المتوسط الحسابي العام للبعد، مما يشير

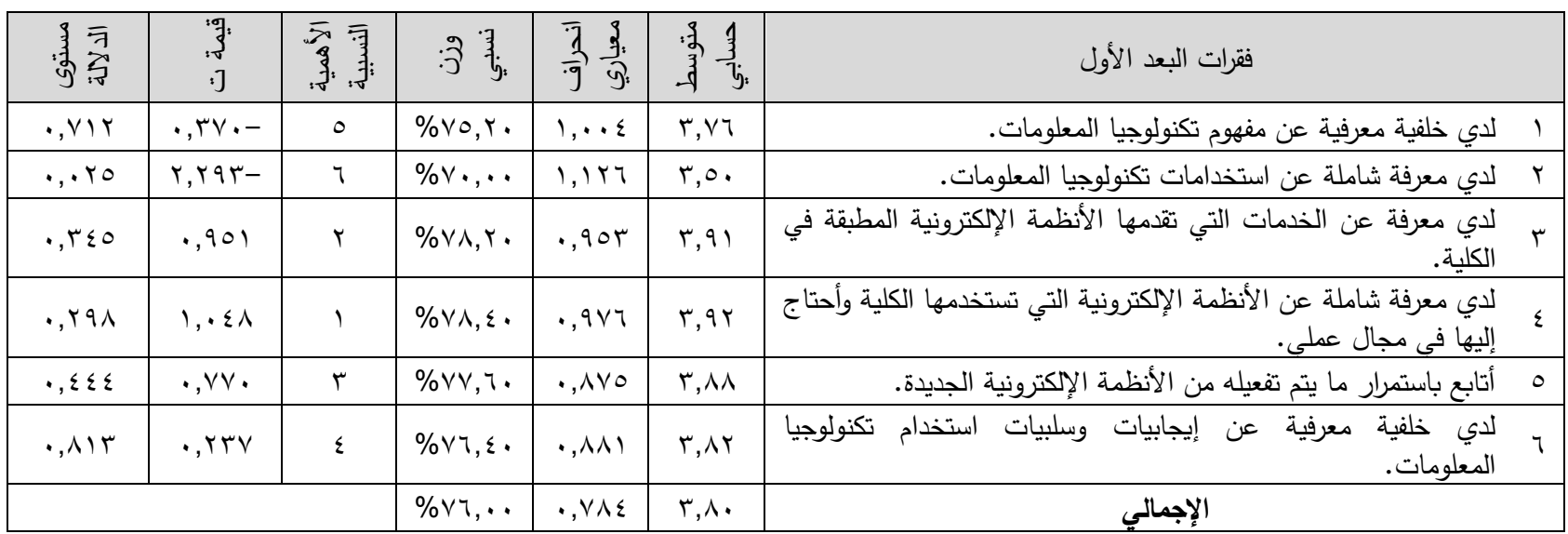

جدول ء. تحليل وصفي للبعد الأول: مدى المعرفة لماهية تكنولوجيا المعلومات واستخداماتها

مستوى مرتفع من المعرفة بماهية تتمية الموارد

البعد الثاني: التعرف على ماهية تنمية الموارد

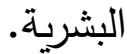

توضح النتائج المسجلة في جلوله إن المتوسط وكانت الفقرة "يعتبر التدريب من أهم ركائز تتمية

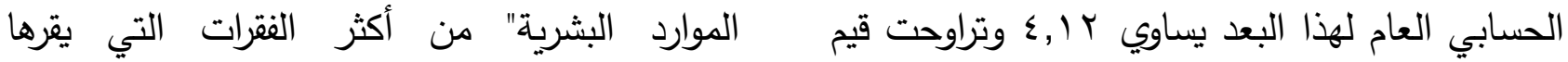

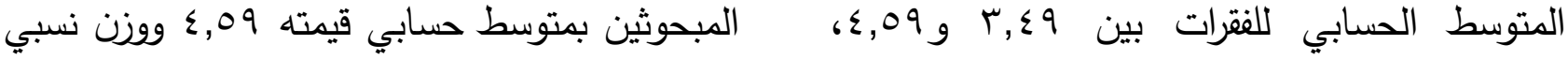

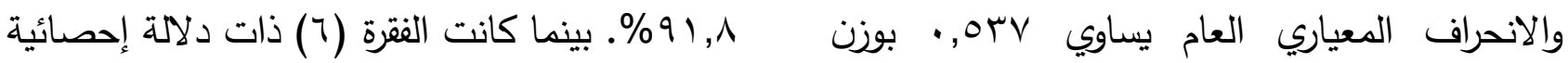

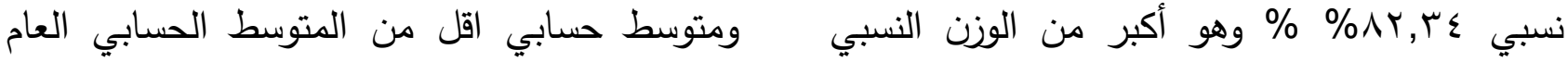

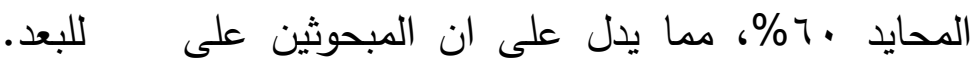

\begin{tabular}{|c|c|c|c|c|c|c|}
\hline 劣 & : & 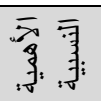 & 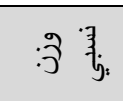 & $\frac{\bar{y}}{\bar{g}} \frac{\xi}{y:}$ & 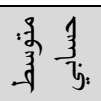 & فقرات البعد الثاني \\
\hline$\cdot, 11 \varepsilon$ & $1, T \cdot r-$ & 0 & $\% \vee q, \ldots$ & ס & $r, 90$ & العلمى والعملى والفنى والسرلوكية في تنمية المهارات وصنقلها من الجانب \\
\hline$\cdot, \wedge \vee q$ & ., & $\varepsilon$ & $\% \wedge r, \wedge$. & $\cdot, \wedge \leq q$ & $\varepsilon, 1 \leq$ & r الأداء والإنتاج في الموارد البشرية في تكوين طرق وأساليب فنية متطورة في \\
\hline$\cdot, \cdot 9$ & $1, V Y 1$ & r & $\% \wedge \bullet, r$. & $\cdot, T \wedge \varepsilon$ & $\varepsilon, Y_{Y}$ & r إضافية. تمية الموارد البشرية وسيلة فنية تمنح الفرد مهارات وخبرات \\
\hline$>\cdot, \cdots 1$ & $\Lambda, Y \circ 9$ & 1 & $\% 91, \wedge$. & $\cdot, \leqslant 9 \leqslant$ & $\varepsilon, 09$ & يعتبر التدريب من أهم ركائز تتمية الموارد البشرية. \\
\hline$\cdot, \cdot \varepsilon$ & $r, \cdot 9 \leq$ & r & $\% \wedge \bullet, \uparrow$. & $\cdot$ & $\varepsilon, \Upsilon \wedge$ & ه تعزز تتمية الموارد البشرية من قبول وتحمل الأعباء والمسؤوليات. \\
\hline$>\cdot, \cdots 1$ & $0, \vee 9 \wedge-$ & 7 & $\% \curlyvee 9, \wedge$. & $\cdot, 9 \leq$ & $r, \varepsilon q$ & 7 \\
\hline & & & $\% \wedge r, r \varepsilon$ &., $0 \mathrm{VV}$ & $\varepsilon, 1 r$ & الإجمالي \\
\hline
\end{tabular}



(1) و(Y) ذات متوسط حسابي اقل من المتوسط

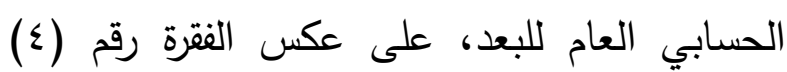
و(0)، حيث كانتا ذاتا متوسط حسابي اعلى من على لعنى المتوسط الحسابي العام. وكانت اهم علاقة يعرفها المبحوثين هي ان استخدام تكنولوجيا المعلومات يساهم في خفض عدد المعاملات الورقية، وان

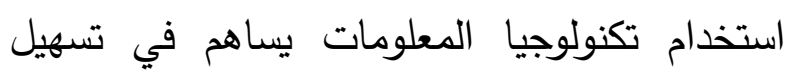
عمليات الاتصال بين الأقسام والإدارات المختلفة.
البعد الثالث: التعرف على العلاقة بين تكنولوجيا المعلومات وتنمية الموارد البشرية

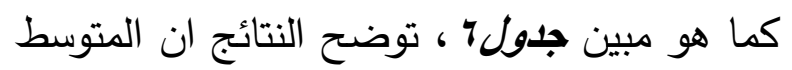

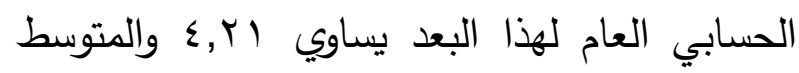

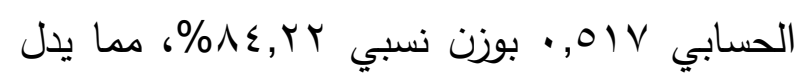
على ارتفاع معرفة المبحوثين بالعلاقة بين تكنولوجيا

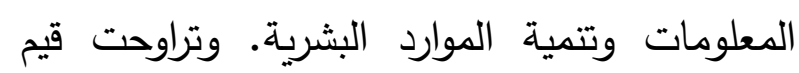

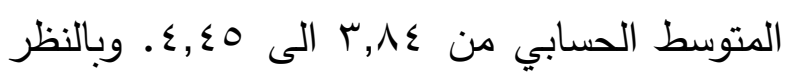
الى قيم مستوى الدلالة لاختبار ت، يتبين ان الفقرة

\begin{tabular}{|c|c|c|c|c|c|c|c|}
\hline 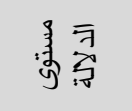 & : गु, & 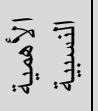 & : & $\frac{\bar{y}}{\frac{3}{9}} \frac{3}{9:}$ & $\frac{1}{3} \frac{1}{3}$ & \multicolumn{2}{|l|}{ فقرات البعد الثالث } \\
\hline$\cdot, \ldots 1>$ & $r, q 1 \leq-$ & 1. & $\% \vee \vee, \ldots$ & $\cdot, \vee \vee \wedge \wedge$ & $r, \wedge \bullet$ & 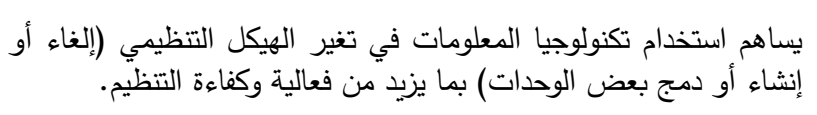 & 1 \\
\hline$\cdot, \ldots 1>$ & $r, \wedge \wedge \varepsilon-$ & 9 & $\% \vee \vee, r$. & $\cdot, \vee \vee \neg \leq$ & 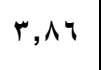 & يساهم استخدام تكنولوجيا المعلومات في التحول إلى إدارة لا مركزية. & r \\
\hline$\cdot, 17 \mathrm{~V}$ & 1, ए৭१ & $\varepsilon$ & $\% \wedge \uparrow, \xi$. & $\cdot, \mathrm{V} \cdot \varepsilon$ & \& & يساهم استخدام تكنولوجيا المعلومات في تبسيط الإجراءات الإدارية. & $r$ \\
\hline$\cdot, \cdot 10$ & Y, ะ १५ & 1 & $\% \wedge 9, \ldots$ & $\cdot, \Lambda ו r$ & $\leq, \leq 0$ & يساهم استخدام تكنولوجيا المعلومات في خفض عدد المعاملات الورقية. & $\varepsilon$ \\
\hline$\cdot, \ldots \leq$ & $r, .11$ & r & $\% \wedge \wedge, \varepsilon$. & $\cdot, 09 \vee$ & $\leq, \leq r$ & 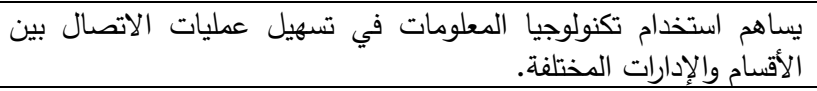 & ○ \\
\hline$\cdot, \leqslant \vee \wedge$ & $\cdot, v i r$ & 7 & $\% \wedge \bullet$, ६. & $\cdot, V Y V$ & $\varepsilon, r V$ & التعامل مع التغيرات الطارئة. & 9 \\
\hline$\cdot, .91$ & $1, \times 11$ & $r$ & $\% \wedge \vee, \ldots$ & $\cdot, V \backslash 1$ & ه & يسناهم استخدام تكنولوجيا المعلومات في تحسن مستوى الخدمات المقدمة & $v$ \\
\hline$\cdot, 194$ & & 0 & $\% \wedge \uparrow, r$. & יוד & ו & القرارات في الوقدام الكناسبا المعلومات في توفير المعلومات اللازمة لاتخاذ & $\wedge$ \\
\hline$\cdot, \wedge i \vee$ & •, rrr & v & $\% \wedge \varepsilon, \uparrow$. & •, VMr & \&,rr & يسكالهم استخدام تكنولوجيا المعلومات في توفير الموارد المادية وتقليل & 9 \\
\hline$\cdot, . \infty \Delta$ & $1,9 \leqslant 1-$ & $\wedge$ & $\% \wedge \cdot, \wedge$. & $\cdot, \mathrm{V} \leqslant \Lambda$ & $\{, \cdot \varepsilon$ & داخل العمل. استخدام تكنولوجيا المعلومات في خفض معدلات النزاع والصراع & 1. \\
\hline & & & $\% \wedge \varepsilon, Y Y$ &., $01 \mathrm{~V}$ & $\{, r)$ & الإجمالي & \\
\hline
\end{tabular}

جدول 1 . تحليل وصفي للبعد الثالث: التعرف على العلاقة بين تكنولوجيا المعلومات وتتمية الموارد البشرية 
كان المتوسط الحسابي العام لواقع استخدام

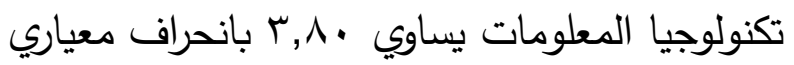

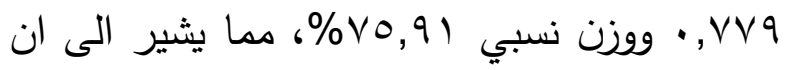

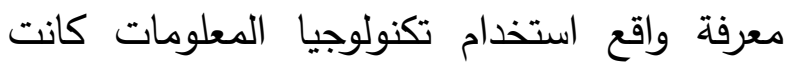
اعلى من المتوسط. ويظهر من نتائج اختبار ت أن أن أن
البعد الرابع: التعرف على واقع استخدام تكنولوجيا المعلومات بكلية الآداب والعلوم الإنسانية قام الباحثون بقياس واقع استخدام تكنولوجيا المعلومات وتأثيرها في تنمية الموارد البشرية.

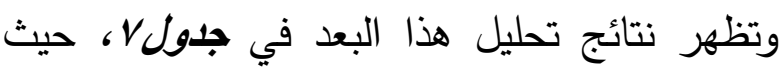

\begin{tabular}{|c|c|c|c|c|c|c|}
\hline 美䨗 & 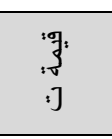 & 余哥 & 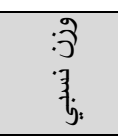 & $\frac{\bar{T}}{\cdot \frac{3}{g}} \frac{\xi}{9}$ & $\begin{array}{ll}3 \\
\frac{3}{3} \\
\end{array}$ & فقرات البعد الرابع \\
\hline$\cdot, 10$ & $1, \leqslant 0 \leqslant-$ & v & $\% \vee r, r \cdot$ & $\cdot, \wedge 14$ & $r, 74$ & يشمل استخدام وسائل تكنولوجيا المعلومات في كافة المستويات الإدارية بالكلية. \\
\hline$\cdot$ •, & $\cdot, \vee 9$ & r & $\% \vee \vee, \wedge$. & $1, \cdots 1$ & r,^9 & توفر الكلية أجهزة حاسب بمواصفات مناسبة تمكن الموارد البشرية من أداء أعمالهم. \\
\hline$\cdot$ •, ६१५ & $\cdot, \uparrow \wedge 9$ & r & $\% \vee \vee, \uparrow$. & $\cdot, 9 \vee 9$ & r,M & توفر الكلية شبكات اتصال سريعة وأمنة بالتنسيق من الجهات ذات الاختصاص بالجامعة. \\
\hline$\cdot, r 79$ & $1,11 \varepsilon$ & 1 & $\% \vee \wedge, \varepsilon$. & $\cdot, 911$ & r,q & توفر الكلية كافة ملحقات الحاسب التي يستخدمها الموارد البشرية في مجال أعمالهم. \\
\hline$\cdot, \cdot v$ & $1, \wedge \varepsilon-$ & $\wedge$ & $\% \vee 1, \varepsilon$. & $1, \cdot 14$ & r,ov & توجد قواعد بيانات كافية لحفظ البيانات والمعلومات. \\
\hline$\cdot, \mathrm{V} O \mathrm{~V}$ & $\cdot, r 11$ & ० & $\% \vee \neg, \wedge$. & $1, \cdot \varepsilon v$ & $\ulcorner, \wedge \varepsilon$ & تستجيب الكلية بثكل سريع لأي متطلبات تقنية تخدم مصلحة العمل. \\
\hline$\cdot, T \leqslant \vee$ & $\cdot, \leq 7-$ & 1 & $\% \vee \varepsilon, \wedge$. & $1, \cdot 71$ & $r, \mathrm{r} \varepsilon$ & تهتم الكلية بتحديث مواصفات الأجهزة التقنية حسب متطلبات العمل وتطوره. \\
\hline$\cdot$, OYA & r & $\varepsilon$ & $\% \vee V, r \cdot$ & $\cdot, \wedge \wedge 1$ & r,人 & تهتم الكلية وبالتسيق مع الجهات ذات الاختصاص بتطوير الأنظمة حسب حاجة العمل. \\
\hline & & & $\% \vee 0,91$ & $\cdot, \vee \vee \vee q$ & $r, \wedge$. & 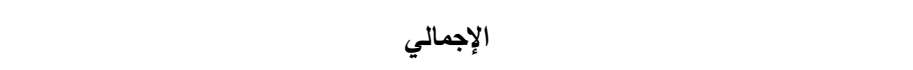 \\
\hline
\end{tabular}

جدول v. تحليل وصفي اللبعد الرابع: التعرف على واقع استذام تكولوجيا المعلومات بكلية الآداب والعلوم الإنسانية

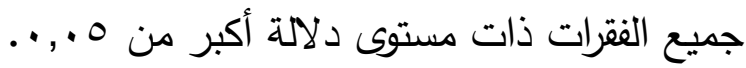

البعد الخامس: الكثف عن تأثير استخدام البشرية اعلى من معرفتهم بواقع استخدام تكنولوجيا

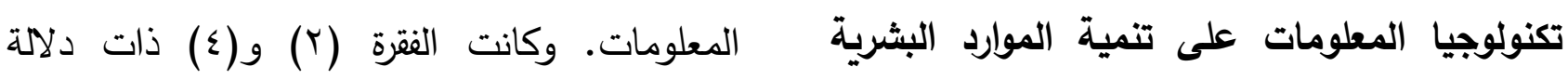
إحصائية اقل من 0 ., •، ومتوسط حسابي اعلى من المتوسط الحسابي العام للبعد، بينما كانت الفقرة (9) ذات دلالة إحصائية اقل من إب ,., ومتوسط حسابي اقل من المتوسط الحسابي العام. كما هو موضح في بكلية الآداب والعلوم الإنسانية

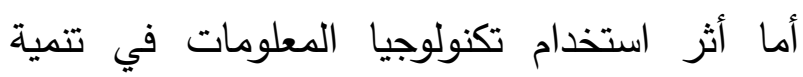
الموارد البشرية فكان يتمتع بمتوسط حسابي بلغت قيمته r +,ع بانحراف معياري ـ00,، ووزن نسبي •r, •^^\%، مما يدل على ان معرفة المبحوثين بأثر استخدام تكنولوجيا المعلومات في تتمية الموارد 


\begin{tabular}{|c|c|c|c|c|c|c|}
\hline 巻方 & : & 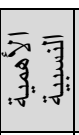 & 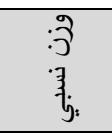 & $\frac{\bar{d}}{\bar{g}} \frac{\xi}{9:}$ & 乎争 $\frac{1}{3}$ & فقرات البعد الخامس \\
\hline$\cdot$, or & $\cdot$, Trt- & 1 & $\% \vee q, \varepsilon$. & $\cdot, \uparrow \leq$ & ५, १४ & يساهم استخدام تكنولوجيا المعلومات في زيادة معرفة الموارد البشرية بمهام العمل. \\
\hline$\cdot, \ldots r$ & $r, 1 \cdot r$ & 1 & $\% \wedge 0,7$. & $\cdot, \mathrm{V} / \mathrm{l}$ & $\varepsilon, Y \wedge$ & يساهم استخدام تكنولوجيا المعلومات في سرعة إنجاز العمل. \\
\hline$\cdot, 7 \wedge 0$ & $\cdot, \Sigma \cdot \vee$ & $\varepsilon$ & $\% \wedge,, \ldots$ & $\cdot, \times 19$ & $\varepsilon, .0$ & يساهم استخدام تكنولوجيا المعلومات في انخفاض نسبة الأخطاء في العمل. \\
\hline$\cdot, \cdot Y \wedge$ & r, r rq & r & $\% \wedge \varepsilon, \ldots$ & $\cdot, \mathrm{V} \cdot \mathrm{r}$ & $\varepsilon, r$ & يساهم استخدام تكنولوجيا المعلومات في زيادة الانتاجية لدى الموارد البشرية. \\
\hline$\cdot, r \cdot r$ & l, rیr- & v & $\% \vee \wedge, \varepsilon$. & $\cdot, T \vee \wedge$ & r,q & يساهم استخدام تكنولوجيا المعلومات في تحقيق الثفافية وإتاحة المعلومات. \\
\hline$\cdot, .0 \mathrm{r}$ & $1,9 \vee V$ & r & $\% \wedge r, r \cdot$ & $\cdot, \pi Y \leq$ & $\varepsilon, 17$ & يساهم استخدام تكنولوجيا المعلومات في تسهيل عملية الرقابة والمتابعة. \\
\hline$\cdot, 9 Y_{0}$ & $\cdot, \cdot 9 \varepsilon$ & $\circ$ & $\% \wedge \cdot, \uparrow$. & $\cdot,\rceil \leq$ & $\varepsilon, \cdot r$ & يساهم استخدام تكنولوجيا المعلومات في تدريب الموارد البشرية على مهام جديدة. \\
\hline$\cdot, 1 \leqslant V$ & $1, \leqslant 70-$ & $\wedge$ & $\% \vee \vee, \wedge$. & $\cdot, \mathrm{V} 0 \mathrm{~T}$ & r,^৭ & البشرية. استخدام تكنولوجيا المعلومات في تحفيز روح الإبداع والتطوير الذاتي بين الموارد \\
\hline$\cdot, \cdots r$ & 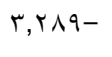 & 9 & $\% \vee r, \ldots$ & $\cdot, 9 \vee 1$ & r, 10 & يساهم استخدام تكنولوجيا المعلومات في مشاركة الموارد البشرية في اتخاذ القرارات. \\
\hline & & & $\% \wedge \cdot, r \cdot$ & $\cdot, 00 \leqslant$ & $\varepsilon, \cdot r$ & \\
\hline
\end{tabular}

جدول ^. تحليل وصفي للبعد الخامس: الكثف عن تأثير استخدام تكنولوجيا المعلومات على تتمية الموارد البشرية بكلية الآداب والعلوم الإنسانية

و 0ـ,ـ. وكان على قمة المقترحات والتوصيات

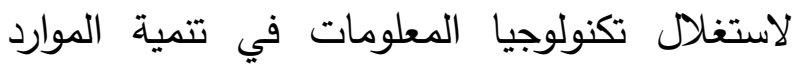

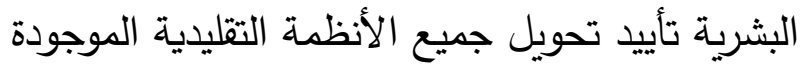

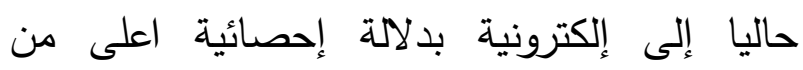

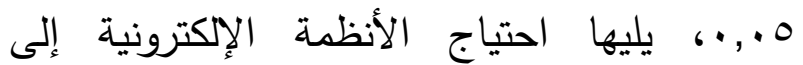

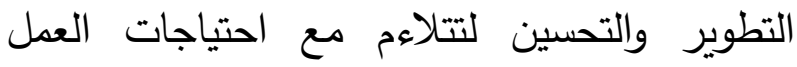
واحتياج الأنظمة الإكترونية إلى تطوير البنية

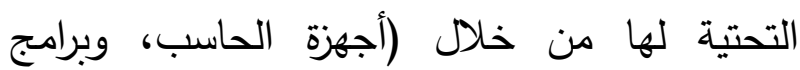
التشغيل، وشبكات الاتصال).
البعد السادس: تقديم مقترحات وتوصيات لاستغلال

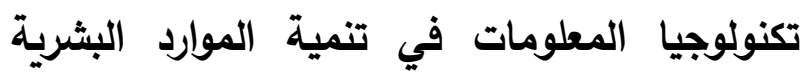
بكلية الآداب وإلعلوم الإنسانية يتبين ان المتوسط الحسابي العام لهذا البعد يساوي

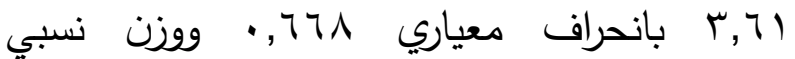

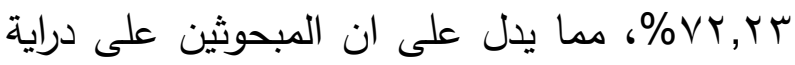
عالية بالمقترحات والتوصيات لاستغلال تكنولوجيا

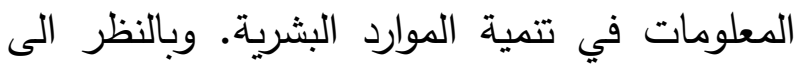

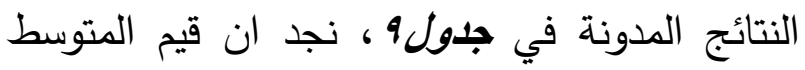

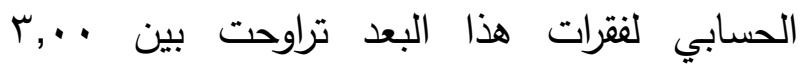




\begin{tabular}{|c|c|c|c|c|c|c|}
\hline 巻 & :日, & 牙哥 & : $:$ 寻 & $\frac{\bar{y}}{9} \frac{\xi}{9}$ & 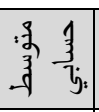 & فقرات البعد السادس \\
\hline$\cdot, \cdots 1>$ & $\varepsilon, \wedge 9 \uparrow-$ & 11 & $\%\urcorner \cdot, \cdots$ & $1, \cdot V r$ & $r, \cdots$ & توفر الكلية دورات تدربيية لتعليم الموارد البشرية كيفية استخدام تكنولوجيا \\
\hline$\cdot, \cdots 1>$ & $\varepsilon, Y Y T-$ & 1. & $\%$ \%,, . & $1, \cdot \leq 9$ & $r, \cdot 9$ & تهتم الكلية بنشر الوعي بخصوص الأنظمة الجديدة. \\
\hline$\cdot, \cdot 1 \wedge$ & $r, \Sigma T$ & 7 & $\% \vee \vee, 7$. & $\cdot, 90$ & 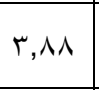 & تلففر الكلية برامج الأمان وحماية المعلومات من خلال وحدة الدعم \\
\hline$\cdot, 1 \cdot v$ & 1,Tr- & 9 & $\% \curlyvee \wedge, \varepsilon$. & $1, \cdots v$ & r, & 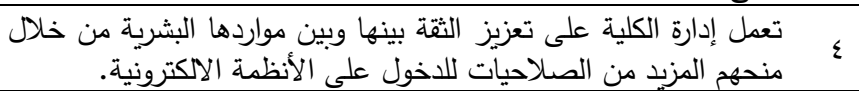 \\
\hline$\cdot, \varepsilon \cdot V$ & $\cdot, \wedge r \leq$ & $\wedge$ & $\% \vee \leq, \cdots$ & $\cdot, 9 \cdot 1$ & $r, \vee \cdot$ & 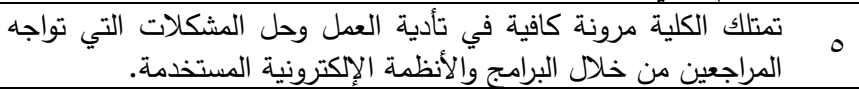 \\
\hline$\cdot, \cdot T r$ & 1,190 & V & $\% \vee \neg, \wedge$. & $1, \cdot r \leq$ & $\curlyvee, \wedge \varepsilon$ & تقوم الكلية بزيادة أجهزة الحاسوب حسب حاجة الأقسام والوحدات. \\
\hline$\cdot, \cdots 1>$ & $\varepsilon$, OY & $\varepsilon$ & $\% \wedge \cdot, 7$. & $\cdot, \vee \vee \uparrow$ & $\varepsilon, \cdot r$ & 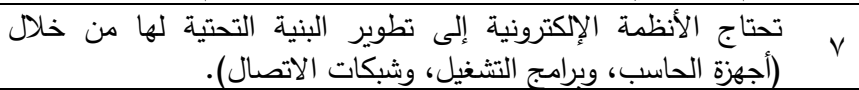 \\
\hline$\cdot, \cdots 1>$ & $\varepsilon, T Y \uparrow$ & r & $\% \wedge 1, \ldots$ & $\cdot, \wedge r \uparrow$ & $\varepsilon, .0$ & العمل. الأنظمة الإلكترونية إلى التطوير والتحسين لتتلاءم مع احتياجات \\
\hline$\cdot, \cdots>$ & $0, V \backslash \mathrm{Y}$ & r & $\% \wedge 1, \varepsilon$. & $\cdot, 7 \wedge 9$ & $\varepsilon, \cdot V$ & عملية الدخول للأنظمة الإلكترونية سهلة وسلسة. \\
\hline$\cdot, \cdots r$ & $r, 100$ & 0 & $\% \vee \vee, \wedge$. & $\cdot, \vee \vee \neg 9$ & 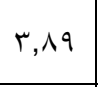 & تتصدها. تقده واجهات الأنظمة الإلكترونية بوضوح جميع الخدمات التي \\
\hline$\cdot, \cdots>$ & $1 \cdot, \leqslant 9$ & 1 & $\% \wedge 9, \cdots$ & $\cdot, 710$ & $\varepsilon, \leq 0$ & أؤيد تحويل جميع الأنظمة التقليدية الموجودة حاليا إلى إلكترونية. \\
\hline & & & \%VY,YT & $\cdot, 77 \wedge$ & r,ד & \\
\hline
\end{tabular}

جدول 9.

r. تتوفر بنية تحتية لدى كلية الآداب والعلوم الانسانية المعنية بالدراسة تعتبر كافية عمليا

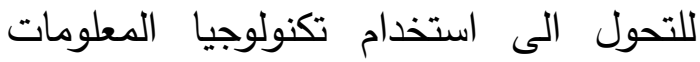
لتتمية الموارد البشرية، ويعلل الباحثون ذلك لكالك

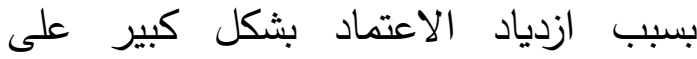

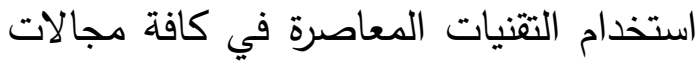

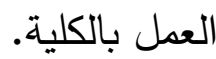
ع. يساهم استخدام تكنولوجيا المعلومات في لألي سرعة إنجاز العمل في كلية الآداب والعلوم الانسانية.

\section{نتائج وتوصيات الدراسة:}

يستعرض الباحثون في هذا الجزء الاخير من

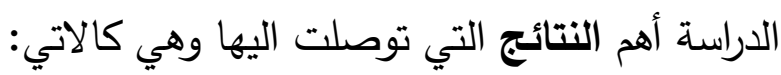
1. هناك وضوح لدى عينة الدراسة لأهمية استخدام تكنولوجيا المعلومات في اداره تتمية الموارد البشرية بكلية الآداب والعلوم الإنسانية،

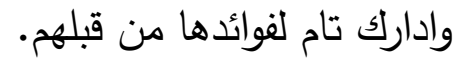
r. تدعم كلية الآداب والعلوم الانسانية عملية التحول الى استخدام تكنولوجيا المعلومات في الديه

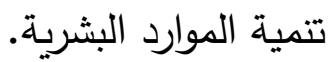


الموظف زعلى الادارة الاكترونية في المنظمات التركيز على هذا المجال بشكل الالئل واسع مما هو موجود حالياً. ه. إتاحة التدريب اللازم للإداريين لتعلم تكنولوجيا. المعلومات وتطوير أدائهم. 7. انشاء قاعده بيانات واحده تصب فئوير فيها جميع بيانات ومعاملات الاقسام العلمية والوحدات

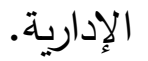

V. تطوير الموارد البشرية وزيادة الدورات التدريبية الدورية.

1. تفعيل عقد دورات علمية مكثفة على جميع الأنظمة إلكترونية الحديثة لكي تواكب مع دعبه التطورات السريعة في الإنجاز • 9. العمل على استخدام اخر ما تم التوصل اليه في وسائل التكنولوجيا بواقعية محسوسة بعيداً

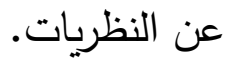

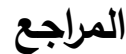

اولاً: المراجع العربية

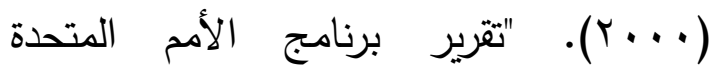

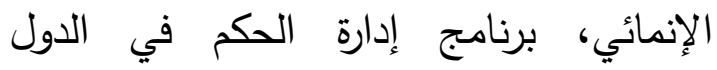

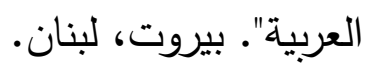

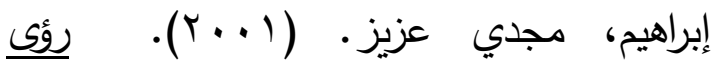
مستقبلية في تحديث منظومة التعليم. مكتبة الانجلو المصرية. القاهرة. مصر.

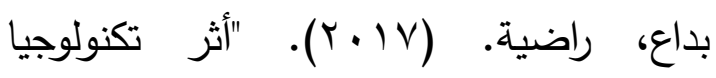
المعلومات والاتصال على الأداء الوظيفي في الدي المؤسسات الصغيرة والمتوسطة: حالة مؤسسة
ه. يساهم استخدام تكنولوجيا المعلومات في تسهيل عميات الاتصال بين الأقسام والإدارات المختلفة بكلية الآداب والعلوم لإنين

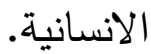
7. تتقق عينة الدراسة على ان استغلا تكنولوجيا

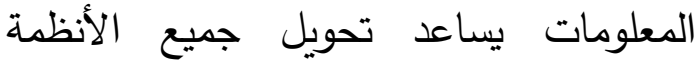
التقليدية الموجودة حاليا بكلية الآداب والعلوم الإنطاع الإنسانية إلى إلكترونية.

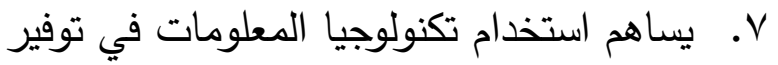

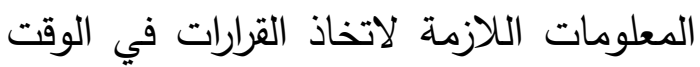

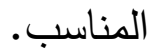
كما رأى الباحثون إن من التوصيات والمقترحات المناسبة لاستغلال تكنولوجيا المعلومات في تنمية البنات الموارد البشرية في المنظمات بناءً على نتائج هذها لانهات الدراسة كالآتي: - الآتربه ا ـ قيام الادارة الالكترونية في المنظمات بالتوجه الرسمي والعملي نحو استخدام تكنولوجيا المعلومات في تتمية الموارد البشرية.

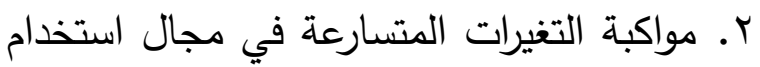
تكنولوجيا المعلومات في تتمية الموارد البشرية في المنظمات. r. الاستفادة من الخذمات الادارية والتعليمية

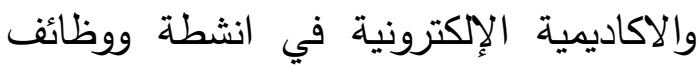
ادارة الموارد البشرية كالتدريب والتعليم والتعلم

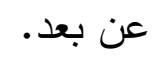
ع. التعلم والتدريب عن بعد هو أحد سمات

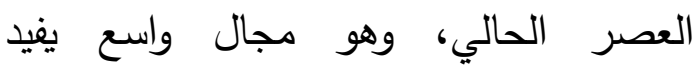


ماجستير غير منشورة. كلية الدراسات العليا، جامعة السودان للعلوم والتكنولوجيا.

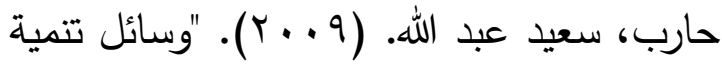
الموارد البشرية." وزارة الأوقاف و والثؤون الإسلامية (الوعي الإسلامي): $.79-71$

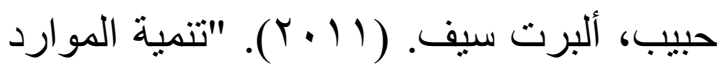
البشرية." المنظمة العربية للتنمية الإدارية وديوان الخدمة المدنية الأردني و والجهاز المركزي للتنظيم والإدارة المصري (مؤتمر: إدارة وتتمية الموارد البشرية في القطاع العام: الو اقع و التطلعات و التحديات): دون مجلد (دون عدد): זس - זד.

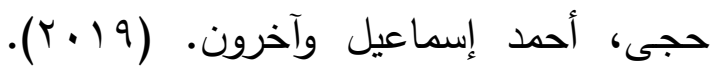
"تتمية الموارد البشرية بالجامعات في ضوء إلعاعيل

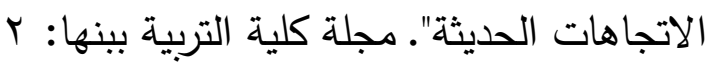

$$
\text { ( ) }
$$

حمادات، محمد حسن محد. (Y.V) (Y.V). وظائف وقضايا معاصرة في الإدارة التربوية. ط ا ا. دار الحامد للنشر والتوزيع. عمان.

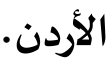
خريس، نهاد حسين محد. (11) (Y). "استخدام تكنولوجيا المعلومات وأثرها في الأداء في أجهزة الخدمة المدنية في الأردن". رسالة ماجستير غير منشورة. جامعة الشرق الأوسط،

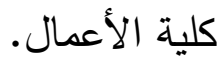

رغوة الجنوب - تقرت". رسالة ماجستير غير منشورة. كلية العلوم الاقتصادية والتجارية وعلوم التسيير، جامعة قاصدي مرباح - ورقلة،

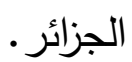
بدريسي، جميلة. (999 (1). "تكنولوجيات المعلومات وأثرها على الثغل" رسالة ماجستير منشورة. معهة العلوم الاقتصادية، جامعة

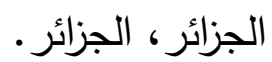
بومايله، سعاد وبوباكور، فارس. (ع . . ب). "

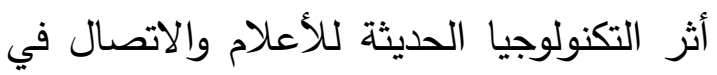
المؤسسة الاقتصادية". مجلة الاقتصاد: دون

$$
\text { مجلد (r). }
$$

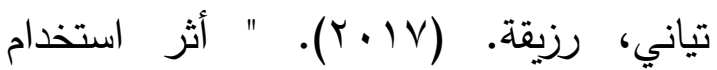
تكنولوجيا المعلومات والاتصال على الأداء الوظيفي: دراسة حالة مؤسسة نفطال، الجزائر". مركز البحث وتطوير الموارد البشرية رماح ومختبر التنمية التنظيمية وإدارة الموارد البشرية جامعة البليدة بالجزائر (أبحاث المؤتمر الدولي

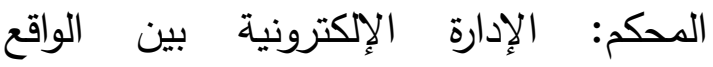

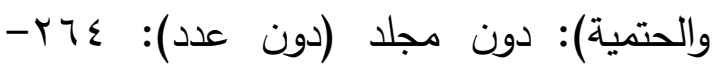
. YV جرجيس، جاسم محمد. (1) (1). المعلومات في الوطن العربي. ط ا. ـ دار الفكر المعاصر للطباعة والنشر والتوزيع.

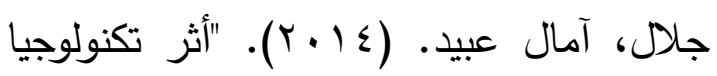

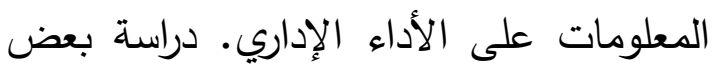
شركات المقاولات والبناء السوداني". رسالة 


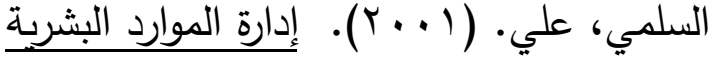

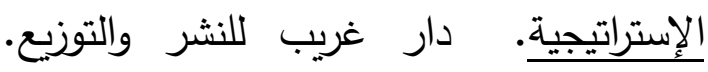

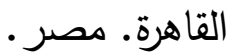

شاهين، محمد عبدالفتاح. (ع . . ب). "التطور المهني لأعضاء الهيئات التدريسية كمدخل لتحقيق جودة النوعية في التعليم الجامعي". مؤتمر النوعية في التعليم الجامعي الفلسطيني (برنامج التربية ودائرة ضبط النوعية).

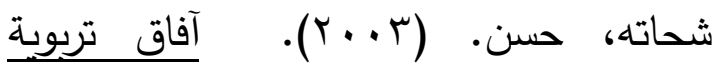
متجددة: نحو تطوير التعليم في الوطن العربي بين الواقع والمستقبل. الدار المصرية اللبنانية.

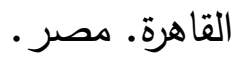

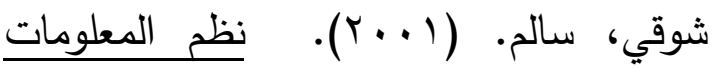

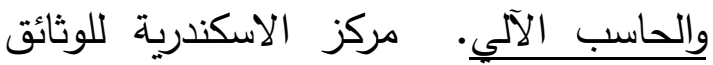
الثقافية والمكتبات. الإسكندرية. مصر . الثيبي، باسمة محمد صادق وعبد الحميد،

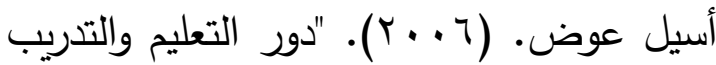
في تطوير الموارد البشرية مع إشارة إلى تجربة كوريا الجنوبية". وزارة التخطيط والتعاون الإنمائي (دائرة التنمية البشرية). طويهري فاطمة. (10 ب). "أثر استخدام تكنولوجيا المعلومات والاتصال على أداء الموارد البشرية في المؤسسة الجزائرية -دراسة حالة شركة انتاج الكهرباء بتيارت-". رسالة ماجستير غير منشورة. كلية العلوم الاقتصادية التجارية وعلوم التيسير ، جامعة وهران r.
الدهان، جمال علي والسيسي، جمال أحمد.

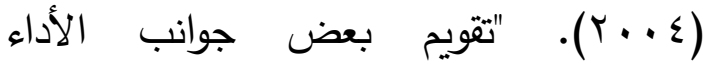

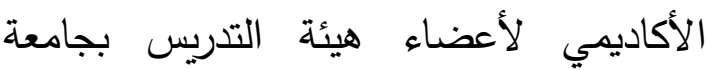

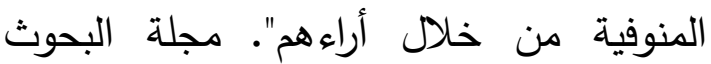
النفسية والتربوية بكلية التربية بجامعة المنوفية: .$(\Gamma) 19$

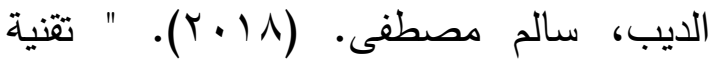
المعلومات ودورها في تتمية الموارد البشرية بجامعة المرقب". مجلة التربوي بجامعة المرقب- كلية التربية بالخمس- ليبيا: دون

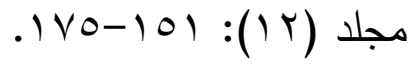

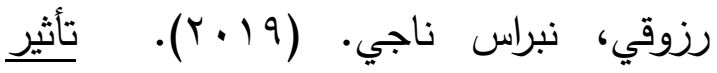
استراتيجية تقويم الأداء في الفاعلية التتظيمية. ط ا. . دار التعليم الجامعي للنشر والتوزيع. الإسكندرية. مصر • الإن الزعيبر، إبراهيم عبد الله عبدالرحمن.

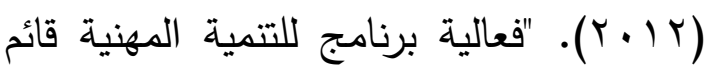
على تطبيقات الايزو بالمؤسسات التعليمية في تحسين جودة الحياة الوظيفية لدى أعضاء هيئة التدريس بجامعة المجمعة بالمملكة العربية السعودية". مجلة كلية التربية بالزقازيق

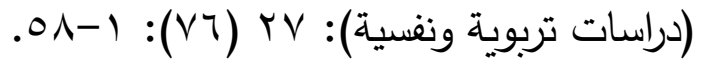

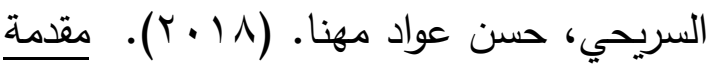

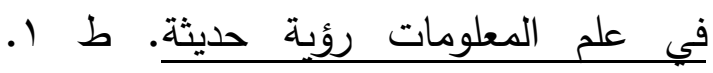
الثقري للنشر وتثنية المعلومات. الرياض.

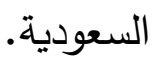




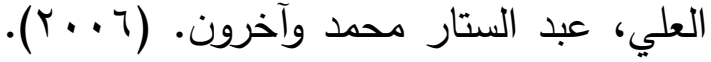

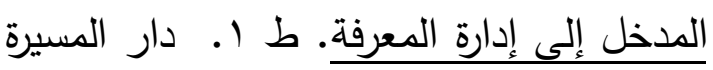

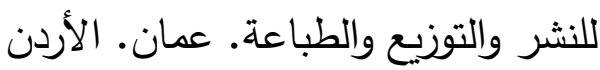

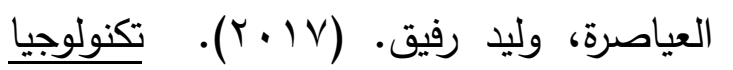

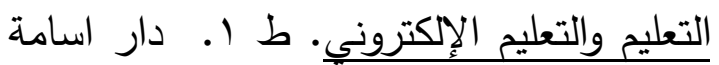
للنشر والتوزيع. عمان. الأردن.

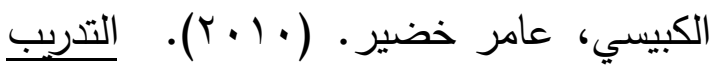
الإداري والمهني رؤية معاصرة للقرن الحادي

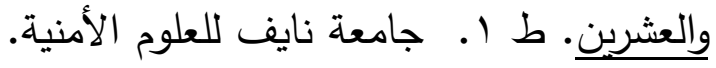

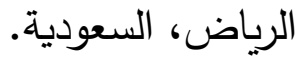

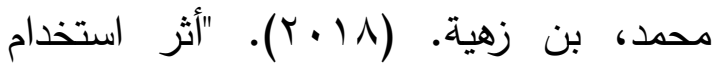
تكنولوجيا المعلومات في تنمية رأس المال البشري: دراسة حالة مؤسسة كوندور - ببرج

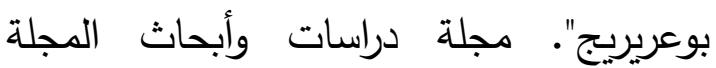
العربية في العلوم الإنسانية والاجتماعية:

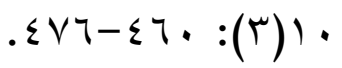

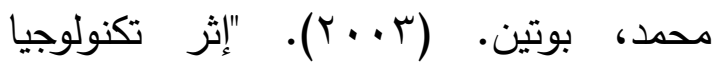
المعلومات على عملية اتخاذ القرارات والأداء - بل باءل واقع المؤسسة الجزائرية-". الملتقى العلمي العي الدولي الأول "أهمية الثفافية ونجاعة الأداء للاندماج الفعلي في الاقتصاد العالمي.

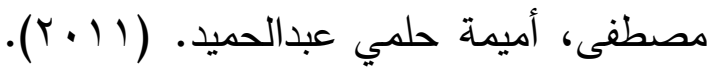
"تحسين الإنتاجية العلمية لأعضاء هيئة العئة التدريس بالجامعات المصرية باستخدام مدخل إدارة المعرفة". مجلة كلية التربية بجامعة لاندان طنطا: 1 ( (ะ).

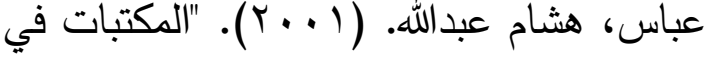
عصر الانترنت تحديات ومواجهة". مجلة

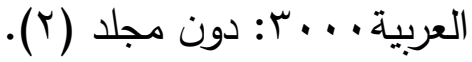

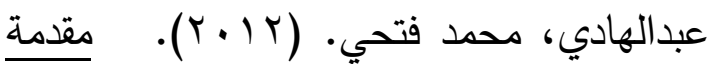

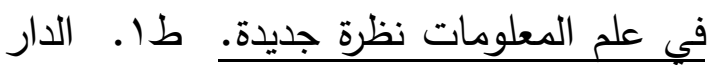
المصرية اللبنانية. القاهرة. مصر .

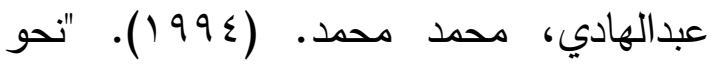
توظيف تكنولوجيا المعلومات لتطوير التعليم بمصر". المكتبة الأكاديمية بالقاهرة: (أبحاث

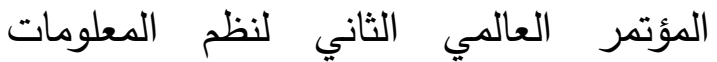
وتكنولوجيا المعلومات وتكنولوجيا الحاسبات):

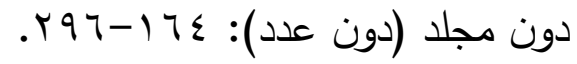

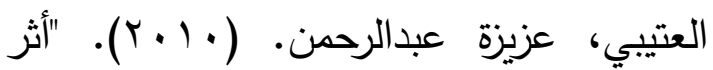
استخدام تكنلوجيا المعلومات على أداء الموارد البشرية دراسة ميدانية على الأكاديمية الدولية الأسترالية". الأكاديمية العربية البريطانية للتعليم

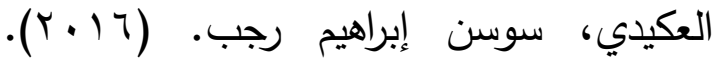
"عناصر تتمية الموارد البشرية: دراسة تشخيصية لآراء عينة من العاملين في شركة كرونجي للمشروبات الغازية والعصائر والمياه الصحية والألبان المحدودة في محافظة كركوك". مجلة الكلية الإسلامية الجامعة: $.7 r \varepsilon-7.9:(\varepsilon \cdot))$

علم الدين، محمود. (1991). تكنولوجيا

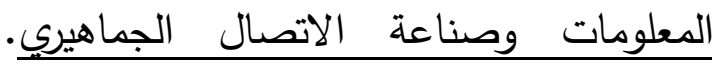
العربي للنشر والتوزيع. مصر . 


$$
\text { عثمان موسى عقيلي ومحمد عبداله العمري وعادل محمد الغامدي }
$$

Communication Technology Usage by Individuals, Businesses, and Government on Human Development: An International Analysis". IEEE Access :(7): 225-243.

- L. Gasco, Jose' and Others. (2004). "The use of information technology in training human resources an e-learning case study". Journal of European Industrial Training: 28(5).

- Lawal, Abdulrahaman W. (2014). "Technical and vocational education, a tool for national development in Nigeria". International Letters of Social and Humanistic Sciences: (14): 53-59.

- Mamoudou, Seyni. (2014). "Impact of Information Technology in Human Resources Management". Global Journal of Business Management and Information Technology: 4(1): 33-41.

- Sadiq, Usman and Others. (2012). "Impact of Information Systems on the Performance of Human Resources Department". Journal of Business Studies Quarterly: 3(4): 77-91.

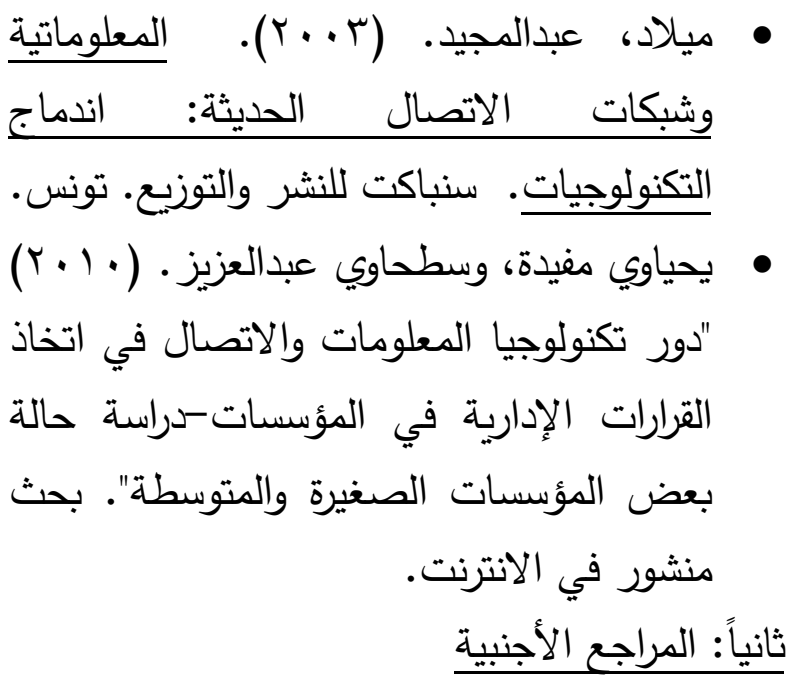

- Briscoe, Dennis. and Others. (2012). International Human Resource Management: Principles and Practices for Multinational. $4^{\mathrm{TH}}$ Edition. Published by Routledge: Taylor \& Francis Group. New York.

- Grant, Robert and Vogt, Emily M. (2015). "Human Resources Management: Self-Efficacy as a Determinant of Information Technology Effectiveness". International Journal of Management \& Organizational Studies: 4(4): 153-162.

- Hokka, Paivi, and Etelapelto, Anneli. (2014). "Seeking New Perspectives on the Development of Teacher Education A Study of the Finnish Context". Journal of Teacher Education: 65 (1): 39-52.

- Hoz-Rosales, Bladimir De La and others. (2019). "Effects of Information and 

أثر تكنولوجيا المعلومات على تتمية أداء الموارد البشرية: دراسة تطبيقية على كلية الآداب والعلوم الإنسانية

https://it.kau.edu.sa/Default-223-AR

• موقع عمادة التعلم الإلكتروني والتعليم عن بعد بجامعة الملك عبدالعزيز:

https://elearning.kau.edu.sa/Default-214-AR • موقع حياتك

https://hyatoky.com/

\section{ثالثاً: المواقع الإكترونية:}

• موقع كلية الآداب والعلوم الإنسانية بجامعة الملك

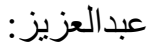

https://art.kau.edu.sa/Default-125-AR

• موقع عمادة تقنية المعلومات بامعة الملك

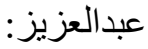




\title{
The Impact of Information Technology on Human Resource Development: An Applied Study at Faculty of Arts and Humanities
}

\author{
Dr. Othman Mousa Ageeli, Mohammed Abdullah AL-Amri, Adel Mohammed ALghamdi \\ Ministry of Education, King Abdulaziz University \\ Faculty of Arts and Humanities \\ Department of Information Science
}

\begin{abstract}
. the study aimed at identifying the impact of information technology on human resource development from the viewpoint of employees of the Faculty of Arts and Humanities. The study used the descriptive survey method through the use of the case study technique. The current study surveyed the opinions of the employees of the Faculty of Arts and Humanities. The researchers prepared a questionnaire that was applied electronically, and the study sample consisted of (74) individuals from the Faculty of Arts and Human Sciences at King Abdulaziz University. The questionnaire included five main areas. The study reached many results, the most important of which are: There is clarity among a sample of the importance of using information technology in managing human resource development in the Department of Arts and Humanities, as well as fully aware of its benefits from them. The results of the study also showed that the College of Arts and Humanities is conducting a process of transformation to the use of information technology in the development of human resources, which helps to convert all the traditional systems in the College of Arts and Humanities into electronic. In addition, the use of information technology contributes to facilitating communication operations between the various departments and departments of the College of Arts and Humanities. As in a study that uses information technology, it contributes to providing the information necessary to make decisions in a timely manner. The study suggested a set of recommendations as the following: The necessity for electronic management in organizations to formally and practically orientate towards using information technology in developing human resources. Keeping pace with the rapid transfers in the field of using information technology in developing human resources in organizations. Taking advantage of electronic administrative, educational and academic services in human resource management activities and functions such as training, education and distance learning.
\end{abstract}

